\title{
Polymerizations with elemental sulfur: A novel route to high sulfur content polymers for sustainability, energy and defense
}

Jared J. Griebel, ${ }^{a}$ Richard S. Glass, ${ }^{a}$ Kookheon Char,${ }^{b^{*}}$ and Jeffrey Pyun ${ }^{\mathrm{a}, b^{*}}$

${ }^{a}$ Department of Chemistry and Biochemistry, University of Arizona, 1306 E. University Blvd., Tucson, AZ 85721, USA, ${ }^{b}$ Program for Chemical Convergence for Energy and Environment, The National Creative Research Initiative Center for Intelligent Hybrids, School of Chemical and Biological Engineering, Seoul National University, Seoul 151-744, Korea.

*corresponding authors

Email:.jpyun@email.arizona.edu; khchar@snu.ac.kr

Tel. 520-626-1834; Fax. 520-621-8407

\section{Abstract}

Recent developments in the polymerizations of elemental sulfur $\left(\mathrm{S}_{8}\right)$ to prepare high sulfur content polymers are reviewed. While the homopolymerization of $\mathrm{S}_{8}$ via ring-opening processes to prepare high molar mass polymeric sulfur has long been known, this form of polymeric sulfur is chemically unstable and depolymerizes back to $\mathrm{S}_{8}$. In the current report, we discuss the background into the production of sulfur via petroleum refining and the challenges associated with utilizing $\mathrm{S}_{8}$ as a chemical reagent for materials synthesis. To circumvent these long standing challenges in working with sulfur, the use of $\mathrm{S}_{8}$ as a reaction medium and comonomer in a process termed, inverse vulcanization, was developed to prepare chemically stable and processable sulfur copolymers. Furthermore, access to polymeric materials with a very high content of sulfur-sulfur (S-S) bonds enabled for the first time the creation of materials with useful (electro)chemical and optical properties which are reviewed for use in Li-S batteries, IR imaging technology and self-healing materials.

Keywords: elemental sulfur, inverse vulcanization, Li-S batteries, IR optics, sulfur polymerization, dynamic covalent polymers, self-healing materials, high refractive index polymers, polymer batteries 


\section{Contents}

1. Introduction

2. Elemental Sulfur Production and Consumption

3. High Sulfur-Content Materials

3.1 Polymeric Sulfur

3.2 Polysulfides

3.2.1 Condensation Generated Copolymers

3.2.2 Free-Radically Generated Copolymers

3.2.3 Ionically Generated Copolymers

3.3 Sulfur and Sulfur Composite Colloids

3.4 Novel Sulfur Allotropes and Macrocycles

4. Challenges in Sulfur Chemistry and Processing

5. Sulfur as an Unconventional Solvent and Reaction Medium

5.1 In-situ Colloid Synthesis

5.2 Inverse Vulcanization Methodology

6. Useful Properties and Modern Applications of High Sulfur Content Polymeric Materials

6.1 Lithium-Sulfur Batteries

6.2 High Refractive Index Polymeric Optics

6.3 Stimuli-Responsive Polymeric Systems

6.4 Photocatalysis and Semi-Conducting Particles

7. Conclusions and Outlook

Addendum

Acknowledgements

References 


\section{Introduction}

Elemental sulfur has been recognized as a valuable chemical agent since antiquity: employed as far back as 1600 B.C.E. by the Egyptians to bleach cotton fabric. The Greeks and Romans utilized the elemental as an antimicrobial and topical pharmaceutical; while the Chinese were the first credited with use of sulfur in explosives for military and civilian applications. The mid- $19^{\text {th }}$ century saw the first application of sulfur in polymer chemistry as the accidentally discovered vulcanizing agent of natural rubber. Industrially, sulfur is currently employed in a plethora of areas including: petroleum refining, mining, pulp and paper processing, rubber production, and construction; where it is consumed in commodities from sulfuric acid and fertilizers to antimicrobial agents and chemical dyes [1-3]. Additionally, polymeric sulfur and sulfur-containing polymers have garnered scientific attention for nearly a century. However, limitations in chemistry involving elemental sulfur have plagued large volume consumption for the production of sulfur based polymeric materials. Ultimately the facile generation of unique polymers and composites directly from elemental sulfur offers an appealing new direction in chemistry, materials science, and chemical engineering to create innovative materials from an unconventional chemical feedstock. The incorporation of a high content of S-S bonds into polymers offers a route to materials with a number of useful properties since these moieties are redox active, highly polarizable, and exhibit dynamic covalent character.

Herein, we review modern advances in the polymer chemistry of sulfur along with the resulting properties and applications of high sulfur content polymeric materials. We first provide a brief history on industrial sulfur production and consumption routes followed by a cursory review of historical polymer syntheses whose genesis involves elemental sulfur, as a basis to the field of sulfur-containing polymeric materials and methods of utilizing sulfur as a monomeric 
component. Recent developments using a method termed, inverse vulcanization, are also discussed, where the novel concept of utilizing liquid sulfur as a reaction medium and comonomer to directly synthesize high sulfur content polymeric materials is reviewed. Finally, we discuss and provide context for the application of these materials in next generation batteries, infrared thermal imaging, and dynamic covalent materials, all of which have strong relevance to the emerging needs in sustainability, energy, and defense.

\section{Elemental sulfur production and consumption}

Elemental sulfur, mostly in the form of sulfur containing minerals, has a high natural abundance in the Earth's crust, making it the $16^{\text {th }}$ most abundant element in the lithosphere. Up until the late $19^{\text {th }}$ century the largest extractable source of sulfur was volcanic soil on the island of Sicily [3]. As industrialization began in earnest during the mid-19 $9^{\text {th }}$ century the demand for sulfur (mainly in the form of $\mathrm{H}_{2} \mathrm{SO}_{4}$ ) drastically increased, requiring a production route that was commensurately large in scale and considerably lower in cost than the Sicilian source. At the turn of the $20^{\text {th }}$ century the Frasch process enabled the extraction of large volumes of molten sulfur from salt dome deposits in North America [4]. By liquefying sulfur within the deposits and pumping the molten material to the surface the process enabled abstraction of deposits that were geologically inaccessible by traditional mining methods (Fig. 1) [5]. Extraction via the Frasch process would dominate global production until 1971 when environmental concerns necessitated removal of sulfur from crude petroleum feed stocks, resulting in the generation of exceedingly large volumes of by-product sulfur [3].

\section{Insert Figure 1 and Figure 1 caption}


In modern petroleum refining processes, the production of elemental sulfur $\left(\mathrm{S}_{8}\right)$ is achieved through removal of the highly toxic hydrogen sulfide $\left(\mathrm{H}_{2} \mathrm{~S}\right)$ gas from crude feedstocks by a stripping process utilizing amine-based reactants. The hydrocarbons are separated from the amine scrubber and the $\mathrm{H}_{2} \mathrm{~S}$ recovered through a thermal expulsion process. Complementary to the stripping process, removal of covalently bound sulfur (i.e., thiophenes, thiols) is achieved through the hydrodesulfurization process. Catalytic hydrogenolysis cleaves the sulfur-carbon bonds within the feedstock to yield desirable hydrocarbons and $\mathrm{H}_{2} \mathrm{~S}$ gas. Subsequent oxidation of $\mathrm{H}_{2} \mathrm{~S}$ gas from both hydrodesulfurization and the amine-stripping proceeds through the Claus process [6]. Initially a portion of the $\mathrm{H}_{2} \mathrm{~S}$ is fully converted into sulfur dioxide $\left(\mathrm{SO}_{2}\right)$, elemental sulfur, and water under substoichiometric combustion conditions at temperatures above $850{ }^{\circ} \mathrm{C}$. $\mathrm{SO}_{2}$ is then catalytically reacted with additional $\mathrm{H}_{2} \mathrm{~S}$ generating only elemental sulfur and water vapor, where $\mathrm{S}_{8}$ is condensed and removed in molten form from the reactor for utilization or storage.

\section{Insert Figure 2 and Figure 2 caption}

The removal of sulfur from petroleum feedstocks ultimately mitigates environmental issues associated with $\mathrm{SO}_{2}$ emissions resulting from fossil fuel combustion and minimizes the poisoning of catalysts utilized during downstream chemical processes. As emissions regulations have increased in stringency, coupled with cheaper, higher sulfur-content petroleum feed stocks, the amount of by-product sulfur recovered globally has risen to $\sim 70$ billion kilograms annually. Thus, refining of petroleum via hydrodesulfurization is currently the single largest source of sulfur production globally (nearly ten times the peak production from the Frasch process) [7]. Unfortunately, as the global demand for energy fueled by petroleum continues, the "excess sulfur

problem" will only be exacerbated as oil producing countries have turned to new reserves of 
continually "dirtier" feed stocks (e.g., Athabasca oil sands, Saudi Arabian and Venezuelan oil) that possess increased amounts of $\mathrm{H}_{2} \mathrm{~S}$ or other sulfur containing substances [8]. While a majority of this $\mathrm{S}_{8}$ is currently utilized ( $\sim 90 \%$ is consumed, mainly for sulfuric acid) the enormous unused supply currently offers little economic utility [3]. Therefore, the by-product sulfur is commonly stored in large megaton, above-ground facilities of $\mathrm{S}_{8}$ in powder, or brick form (Fig. 2) until the price of downstream commodities (e.g., sulfuric acid or fertilizer) warrants chemical conversion of sulfur. While elemental sulfur is largely considered to be environmentally innocuous, the effect of long-term storage of megaton quantities completely exposed to the environment has not been fully interrogated [9].

Attempts by the petroleum and chemical industries to consume sulfur through utilization in construction materials (e.g. waterless concrete and asphalt extender for road pavement) have been largely unsuccessful, due to high production costs, limitations in operating temperature, and moisture uptake sensitivity [10-16]. Thus, to date high volume consumption routes other than for sulfuric acid are virtually non-existent. Achieving the goal of consuming the immense amount of by-product sulfur will require the development of novel high value, high volume products and facile synthetic methods to prepare worthwhile materials.

\section{High sulfur-content materials}

\subsection{Polymeric sulfur}

In the $20^{\text {th }}$ century, a number of research endeavors were conducted with the aim of utilizing $\mathrm{S}_{8}$ for the preparation of polymeric materials. Notably, the most intensive research was devoted to the classical ring-opening polymerization (ROP) of neat, orthorhombic $\alpha-\mathrm{S}_{8}$ when the monomer is heated above its floor temperature $\left(\mathrm{T}_{\mathrm{f}}=159^{\circ} \mathrm{C}\right)$. Under standard conditions the most 
stable form of sulfur is the crystalline orthorhombic $\alpha-\mathrm{S}_{8}$, which is converted to the monoclinic $\beta$-S $\mathrm{S}_{8}$ form at $95^{\circ} \mathrm{C}$. The monoclinic $\beta-\mathrm{S}_{8}$ form exhibits the dominant melt transition at $119^{\circ} \mathrm{C}$ and upon continued heating the molten sulfur undergoes equilibrium polymerization (Fig. 3) [17-22]. The heating rate dictates the temperature of ROP, with extrapolation to a zero rate yielding an onset temperature of $159^{\circ} \mathrm{C}$ [23]. The polymerization of the $\alpha-\mathrm{S}_{8}$ is endothermic and endotropic and therefore only favorable above a certain temperature $\left(T_{f}\right)$ when the free-energy becomes negative.

Additionally, evidence suggests that other cyclic monomers $\left(S_{n}, n \neq 8\right)$ contribute to the polymerization through homolytic ring-opening reactions, as the activation energies are lower than that of $\mathrm{S}_{8}\left(\mathrm{~S}_{6}: 29.6 \mathrm{kcal} / \mathrm{mol} ; \mathrm{S}_{7}: 30 \mathrm{kcal} / \mathrm{mol} ; \mathrm{S}_{8}: 35 \mathrm{kcal} / \mathrm{mol}\right)$ [24]. These species can be present in commercial sulfur at low concentration (i.e., 1-3 mol\%) as a result of the Claus process utilized in the hydrodesulfurization of petroleum. The equilibrium polymerization results in a mixture of $S_{8}, S_{n}(n \neq 8)$, and polymeric sulfur; with the content of polymeric sulfur increasing with temperature, reaching a maximum value of $40-\mathrm{wt} \%$, at $\sim 240{ }^{\circ} \mathrm{C}[25,26]$. Through empirical determination of sulfur radical concentration via electron paramagnetic resonance (EPR) spectroscopy the calculated average degree of polymerization, assuming a diradical and linear structure, approaches $2.14 \times 10^{5}$ (in $\mathrm{S}_{8}$ units) at $170{ }^{\circ} \mathrm{C}[27,28]$. The formation of the high molecular weight polymer when the reaction exceeds $T_{f}$, generates a discontinuity in physical properties (i.e., viscosity, specific heat, electrical conductivity, density, and magnetic susceptibility) which has been extensively studied [29-32].

\section{Insert Figure 3 and Figure 3 caption}


Although high molar mass polymers are readily formed via ROP of $\mathrm{S}_{8}$, polymeric sulfur is chemically unstable at temperatures above $\mathrm{T}_{\mathrm{f}}$ (i.e., under equilibrium polymerization conditions) since terminal sulfur radicals promote depolymerization back to cyclic monomeric sulfur. However, rapid quenching of the equilibrium melt polymerization of $\mathrm{S}_{8}$ has been demonstrated to preserve of the polymeric form of sulfur (plasticized with small molecules $\mathrm{S}_{8}$ and $S_{n} n \neq 8$ ) for an extended period of time when the temperature is kept below the glass transition temperature of the mixture $\left(\mathrm{T}_{\mathrm{g}},-30^{\circ} \mathrm{C}\right)$. At temperatures exceeding the $\mathrm{T}_{\mathrm{g}}$ the amorphous mixture becomes elastic and crystallizes rapidly; ultimately leading to the polymer undergoing break down into cyclic species over time, even at low temperatures, through a process that is not wholly understood. While the rate of depolymerization is temperature dependent and it is conventionally believed that the radical chain ends undergo intramolecular reaction (backbiting), resulting in extrusion of a cyclic species $\left(\mathrm{S}_{\mathrm{n}}\right)$, spectroscopic (or other) evidence of terminal sulfur radical species has not been detected in a sulfur melt below $158^{\circ} \mathrm{C}$ or in solid sulfur forms [28]. However, the formation of a sulfurane-like transition species (with tetravalent $\mathrm{S}$ atoms) has been proposed as an alternative means by which diradical terminated polymeric sulfur can break down even at low temperatures [33]. Stabilizing the polymer chain can be accomplished by capping the chain ends to yield a crystalline material. Tobolsky noted that this material was fairly stable up $90^{\circ} \mathrm{C}$ before S-S bond scission resulted in polymer degradation. Despite these chemical stability issues and poor solubility of polymeric sulfur, the polymer has found utility in the rubber industry as a vulcanizing agent (e.g., Crystex, Eastman Chemical) [34].

\subsection{Polysulfides}


To develop novel chemical synthetic methods to address the issues associated with polymeric sulfur (i.e., poor chemical stability and inferior thermomechanical properties) extensive research over the past century has focused on preparing high sulfur content polymers with enhanced properties. In this report, we focus on sulfur-containing polymeric materials derived directly from $\mathrm{S}_{8}$ and thus have a high sulfur catenation (i.e., high S-S bond rank) within the polymer structure. Sulfur rank is typically estimated from the molar feed ratios and/or molar composition of the sulfur containing comonomer (e.g., $\mathrm{S}_{8}$ ) in the desired material. Comprehensive reviews of sulfur-containing polymers can also be found in the references listed [35-37]. Polysulfides are a class of high sulfur content polymers which are structurally similar to polymeric sulfur, but with improved stability and processing capabilities. A variety of copolymerization strategies have been applied to the synthesis of polysulfides directly from elemental sulfur including condensation, free-radical, and ionic copolymerizations.

\subsubsection{Condensation generated copolymers}

Patrick and Mnookin reported on the first synthesis of high sulfur content polysulfides via a polycondensation reaction of $\alpha, \omega$-alkyl halides and inorganic polysulfides (e.g., $\mathrm{Na}_{2} \mathrm{~S}_{\mathrm{x}}, \mathrm{x}=$ 4-6) to generate high molecular weight rubbers with good solvent and wear resistance [38-40]. It proved necessary to employ an emulsion condensation polymerization between the aqueous polysulfide solutions and organic alkyl halides to aid in the processing of the resulting polymer. Several alkyl halide comonomers were applicable to the condensation reaction and sulfur content in the polymer was easily varied during the emulsion polymerization step by controlling the sulfur rank of the inorganic polysulfides (Fig. 4a) [41, 42]. In turn, the sulfur rank within the inorganic polysulfide was dictated by the molar ratio of sodium sulfide and sulfur, although the distribution of rank was greatly affected by $\mathrm{pH}$, temperature, and concentration. These materials 
have seen wide spread use as sealants and binders, being trademarked under the name Thiokol rubber (Morton Thiokol Inc.)

\section{Insert Figure 4 and Figure 4 caption}

Expanding upon these seminal findings, the synthesis of polysulfides with high sulfur content were also investigated using alternative condensation synthetic methods. Bordoloi et al. demonstrated the base catalyzed reactions between sulfur and dithiols to generate polymer through a thiol-ene type reaction which accounted for the deviation observed in molecular weight versus the theoretical values. It was observed that as the molecular weight of the polymer increased, the sulfur rank plateaued to a value of 2.5 (Fig. 4b) [43, 44]. Thermal or alkali metal initiated reaction between sulfur and either 1,3 dichlorobenzene or 1,4 dichlorobenzene has been investigated to generate crosslinked or linear polysulfides, respectively (Fig. 4c) [45, 46]. The linear, high molecular weight materials are important high-performance thermoplastics that possess excellent thermal stability and solvent resistance. However, the generation of reaction side products (e.g., $\mathrm{Li}_{2} \mathrm{~S}_{\mathrm{y}}, \mathrm{LiCl}$ ) was problematic since the removal of these byproducts increased the costs of the overall process. Boscato et al. [47, 48]and Catala et al. [49-51] demonstrated a two-step copolymerization involving alkali metal initiated oligomerization of vinylic comonomers followed by reaction with sulfur (Fig. 4d). Kinetic studies revealed that the sulfur content and polymer structure was achieved by control of $\mathrm{S}_{8}$ in the comonomer feed. Additionally, the carbanion was found to react at different rates with vinylic monomers (Fig. 4d), and rate of $\mathrm{S}_{8}$ consumption was observed to dominate in the initial stages over vinylic polymerization [51]. More recently Bowden et al. developed a new class of sulfur containing polymers based upon poly(aminosulfides) [52-54]. 


\subsubsection{Free-radically generated copolymers}

The free-radical copolymerization between sulfur and a variety of unsaturated molecules has been extensively investigated as a means of generating high sulfur content polysulfides. Examples include vinylics (styrene [55-59], methyl methacrylate [60], methyl acrylate [60], vinyl acetate [61], tetrafluoroethylene [62-64], 2-chloroprene [65-70], butadiene [71]); cyclic olefins (cyclododeca-1,5,9-triene [56], cyclohepta-1,3,5-triene [72], cycloocta-1,3-diene [56], cyclohexene [73], 1-methylcyclohexene [73], norbornene [74], dicyclopentadiene [56, 75-78], tricyclopentadiene [56, 77]); and terpenoids (limonene [56], 2,6-dimethylocta-2,4,6-triene [56], 7-methyl-3-methyleneocta-1,6-diene [56], 3,7-dimethylocta-1,6-diene [73], 2,6-dimethylhepta1,5-diene [73]) (Fig. 5). In solution-based copolymerizations conducted at temperatures commonly used for free radical polymerizations of vinylic comonomers (i.e., between $60-90{ }^{\circ} \mathrm{C}$ ) $\mathrm{S}_{8}$ acts as an inhibitor due to the significant chain transfer rate between the carbon radical and sulfur $[58,61]$. The high rate of chain transfer to sulfur, coupled with a low rate of attack on vinylic bonds by sulfur radicals ultimately led to a majority of the materials having low sulfur content $(<10-\mathrm{wt} \%)[58,60,61]$. The products of solution-based copolymerization reactions have been characterizable using conventional methods, such as, gel-permeation chromatography (GPC), nuclear magnetic resonance (NMR) spectroscopy, or viscometry measurements as the polymers are generally low molecular weight and low in sulfur content.

\section{Insert Figure 5 and Figure 5 caption}

In order to obtain polymeric materials with higher molecular weights and increased sulfur content, bulk copolymerization methodologies have also been explored and generally afforded improved materials due to the higher reactivity ratio of the monomers when compared to 
solution-based experiments. Curell et al. investigated bulk copolymerization reactions between molten sulfur and several olefinic comonomers at various temperatures [55]. The resulting copolymers were found to be of moderate molecular weight $\left(\mathrm{M}_{\mathrm{n}} \leq 7000\right)$, but possessed a high weight percentage of unreacted sulfur, which over time crystallized, resulting in constantly changing mechanical properties. It was noted, however, when utilizing a monofunctional comonomer (e.g., styrene) that prolonged reaction times at high temperatures $\left(\mathrm{T} \geq 140{ }^{\circ} \mathrm{C}\right)$ resulted in a significant decrease in molecular weight due to depolymerization from dangling radical chain ends. Blight et al. [55-57] and Bordoloi et al. [78] demonstrated that the reaction of higher functionality monomers (i.e., dicyclopentadiene) led to stable copolymeric materials which were soluble in $\mathrm{CS}_{2}$. NMR spectroscopy revealed that only the norbornenyl unsaturation was consumed at $140{ }^{\circ} \mathrm{C}$ to yield a linear polymer microstructure with a lower amount of unreacted sulfur content than observed with monofunctional olefins. By heating the bulk copolymerization above $150{ }^{\circ} \mathrm{C}$ a fraction of the reaction mixture became insoluble in $\mathrm{CS}_{2}$ due to crosslinking. However, at temperatures in excess of $140{ }^{\circ} \mathrm{C}$, the generation of $\mathrm{H}_{2} \mathrm{~S}$ was also observed along with polymer degradation $[55,57,73]$. Ultimately, this general route to sulfur copolymers (i.e., free radical methods) was historically complicated by incomplete sulfur consumption, depolymerization, and $\mathrm{H}_{2} \mathrm{~S}$ generation. However, this work also established a strong foundation for thiol-ene based reactions of $\mathrm{S}_{8}$ with vinylic monomers that would later be exploited in the inverse vulcanization process.

\subsubsection{Ionically generated copolymers}

Frequently the side-products of free-radical copolymerization between sulfur and olefins (e.g., norbornene and dicyclopentadiene) were small sulfur-containing molecules, such as, triand pentathia-cyclic derivatives. These molecules and other cyclic sulfides (e.g., thiiranes) were 
observed to readily copolymerize with elemental sulfur under anionic conditions to generate linear polysulfides (Fig. 6a) [35, 75]. The seminal discovery on the anionic copolymerization of $\mathrm{S}_{8}$ with thiiranes was achieved by Penczek et al. [79-84] and Duda et al. [85-87]. The sulfur content in these copolymers could be tailored by controlling the comonomer feed ratios and reaction temperature; although the sulfur catenation in the polysulfides was found to be thermodynamically limited to $\mathrm{x} \sim 9$ before the homopolymerization began to compete with the copolymerization [87]. Evidence for true copolymeric synthesis was established via ${ }^{1} \mathrm{H},{ }^{13} \mathrm{C}$ NMR, and Raman spectroscopy [81-83, 87]. It was also observed that the reactivity of the thiolate anion decreased with increasing the number of $\mathrm{S}$ atoms in the propagating chain as a result of negative charge stabilization, presumably via delocalization along the S-S framework. UV/VIS measurements verified these findings which showed a red shift in the optical absorption with increasing sulfur rank $[81,87]$. Copolymers with lower sulfur rank $(\mathrm{x}<5)$ were found to be soluble in traditional organic solvents (e.g., toluene, chloroform, or dimethylsulfoxide); while copolymers of high sulfur rank $(x \geq 5)$ were only soluble in $\mathrm{CS}_{2}$. The resulting copolymers were amorphous yellow materials that were found to be either rubbery or glassy [84]. Mechanical analysis of a particular copolymer $(\mathrm{x}=5)$ revealed the material to be highly elastic (yield strength $\delta=0.4 \mathrm{MPa}$ and \% elongation at break $\left.\varepsilon_{\mathrm{f}}=900 \%\right)[84]$.

\section{Insert Figure 6 and Figure 6 caption}

In contrast to the thiirane copolymerization, the anionic copolymerization between trithioles (e.g., norbornenyl and dicyclopentadienyl) and sulfur was found to be the only thermodynamically allowed route of polymerization between the $\mathrm{T}_{\mathrm{c}}$ of trithiole $\left(101{ }^{\circ} \mathrm{C}\right.$ for norbornenyl derivative) and $\mathrm{T}_{\mathrm{f}}$ of sulfur $\left(159^{\circ} \mathrm{C}\right)$. These copolymers were found to be possess 
moderate sulfur rank $(x=3-6)$ and moderate molar mass $\left(M_{n}\right.$ was below $\left.10^{4} \mathrm{~g} / \mathrm{mol}\right)$. Interestingly, by comparison the thermally initiated copolymerization of sulfur and trithioles as reported by Bordoloi et al. yielded a copolymer with comparable sulfur rank $(x=5.6)$ but with a much lower molecular weight $\left(\mathrm{M}_{\mathrm{n}}=700 \mathrm{~g} / \mathrm{mol}\right)$ [78].

Sulfur can also undergo copolymerization via cationic conditions, as the S-S bond was likewise demonstrated to be susceptible to attack by electrophiles. Schmidt et al. demonstrated cationic bulk copolymerizations by ring-opening of cyclic sulfur-containing comonomers with a Lewis acid (i.e., $\mathrm{BF}_{3}$ ) to yield linear polysulfides (Fig. 6b) [88-90]. The semi-crystalline polymer was reportedly colorless and partially decomposes upon melting [88]. While solubility and material properties were not discussed in detail it is assumed that due to similarities in molecular composition, the copolymer behaved similarly to those prepared by anionic copolymerizations techniques.

\subsection{Sulfur and sulfur-composite colloids}

The preparation of sulfur sols comprised of elemental, or zero-valent sulfur through precipitative methods has been investigated since the discovery by von Weimarn of sulfur colloids at the beginning of the $20^{\text {th }}$ century. Sulfur sols are composed of colloids containing either liquid sulfur or high sulfur-content compounds (e.g., polythionates) that were historically prepared using either "hydrophobic" or "hydrophilic methods [91]. The hydrophobic and hydrophilic methods differ in the sulfurous starting material utilized to generate the colloids (i.e., elemental sulfur or sodium thiosulfate, respectively). Steudel recently provided a broad overview on the methods typically utilized in synthesis of aqueous sulfur sols and the reader is directed to 
this elegant review for further details [91]. Hydrophobic sols, also known as Weimarn sols, were the first sulfur colloids generated by precipitation methods. Sol generation relied upon formation of a saturated solution of elemental sulfur in polar organic solvents which are miscible with water (e.g., acetone and ethanol). Dilution of the saturated sulfur solutions into an excess of water precipitated the sulfur into meta-stable colloids at very low concentrations $(\mathrm{c}<0.1$ $\mathrm{mg} / \mathrm{mL}$ ). The colloids, were reported to be comprised of liquid rather than of crystalline solid colloidal cores, and were initially a diameter of $\sim 800 \mathrm{~nm}$ as observed by optical microscopy. However, because the colloids were only metastable at $20{ }^{\circ} \mathrm{C}$, after a few days the liquid sulfur form reverted back to the thermodynamically stable $\alpha$-sulfur which then crystallized to form aggregates of up to $50 \mu \mathrm{m}$. Weimarn sols were further stabilized through physical adsorption of surfactants to the colloid surface and provided a route to higher concentration sols due to improved stability of the colloids against aggregation.

Hydrophilic sulfur sols, most important of which are Raffo or La Mer sols, are colloids stabilized by the amphiphilic nature of the sulfur molecules formed during the precipitation process. The acid decomposition of sodium thiosulfate was demonstrated to generate sodium polythionates and cyclic sulfur species $\left(S_{n}, n>5\right)$. The hydrophobic sulfur portion of the polythionates and the cyclic sulfur species coalesce into the core of the colloids while the hydrophilic sulfonate end-groups provide stabilization to the colloids (Fig. 7). Initially the colloids were reported to be in a meta-stable liquid state but after aging there is a disproportionation of the higher order polythionates to generate crystalline $\alpha$-sulfur. The colloids did not aggregate as was the case with the Weimarn sols due to the electrostatic repulsion from the charged head groups. The particle diameter of the Raffo sol was smaller than that of the Weimarn sols (100-500 nm, as determined by light scattering techniques), likely due to the 
higher stabilization in the case of the Raffo sols. Additionally, Raffo sols can be prepared in much high concentrations (up to $600 \mathrm{mg} / \mathrm{mL}$ ) due to enhanced electrostatic colloidal stabilization, making these colloids applicable as antimicrobial agents.

\section{Insert Figure 7 and Figure 7 caption}

The antimicrobial properties of elemental sulfur has long been recognized by ancient Roman civilizations but the use of sulfur colloids as an antimicrobial agent was first investigated by Lawson in 1934 [92]. Several early studies on the antimicrobial and fungicidal properties of colloidal sulfur demonstrated that the particle size was directly connected with the inhibitory properties [93-95]. The surface groups (i.e., thionates or sulfides) of the particles were hypothesized as the active agents as certain chemicals acted upon the potency of the colloids [95, 96]. However, reductive degradation of the particle into $\mathrm{H}_{2} \mathrm{~S}$ has also been reported as a route for antimicrobial activity [95]. Schneider et al. demonstrated that sulfur colloids $(150 \mathrm{~nm})$ were active against several microbial agents but did not present toxicity again human cells allowing for potentially high doses of colloids for in vivo treatments [97]. Recently Choudhury et al. extensively studied a variety of aspects on the efficacy of sulfur colloids as antimicrobial agents (bacterial and fungal) including the crystal phase (orthorhombic versus monoclinic), particle size, and morphology [98-105]. The particle size of these sulfur-based colloids was a key factor in the prevention of microbial growth; with sulfur nanoparticles being more effective against traditionally sulfur-resistant microbes. Additionally, $\alpha$-sulfur (orthorhombic) nanoparticles were found to be the most effective allotrope at perturbing growth (Fig. 8) [102]. The facile synthesis, tailorability, and low toxicity of sulfur nanoparticles provided a crucial route to potential control over microbial agents that have become immune to traditional treatments, posing a serious health and economic threat to modern society. 


\section{Insert Figure 8 and Figure 8 caption}

Wang and coworkers also investigated the synthesis of sulfur composites in colloidal form for utilization as the active cathode material in lithium-sulfur (Li-S) batteries [106, 107]. In this report, a sulfur containing nanocomposite was synthesized via pyrolysis of polyacrylonitrile (PAN) in the presence of elemental sulfur under inert atmosphere. Due to the high temperatures utilized during pyrolysis, a reaction between the sulfur and the PAN generated a complex composite which contained a mixture of sulfur nanoparticles and polysulfane chains bonded directly to the carbon matrix (Fig. 9) [108-111].

\section{Insert Figure 9 and Figure 9 caption}

\subsection{Novel sulfur allotropes and macrocycles}

Steudel and coworkers extensively investigated the synthesis, generation, and characterization of novel, discrete sulfur allotropes and high sulfur-content molecules over the past four decades [26, 112-118]. Of particular relevance to this review is the utilization of the activated sulfur agents to prepare for the first time a new class of well-defined, high sulfurcontent compounds and complexes (Fig. 10). The seminal work of Steudel at al. demonstrated the preparation of high sulfur rank cyclic polysulfide using organometallic metallocene precursors $[114,119,120]$.

\section{Insert Figure 10 and Figure 10 caption}

As can be seen in Fig. 10a, molecules up to the cyclo-tridecasulfur $\left(\mathrm{S}_{13}\right)$, which possess

an odd number of sulfurs, can be generated by the reaction of bis $\left(\eta^{5}\right.$-cyclopentadienyl)titanium pentasulfide $\left(\mathrm{Cp}_{2} \mathrm{TiS}_{5}\right)$ with a dichlorosulfane $\left(\mathrm{S}_{\mathrm{x}} \mathrm{Cl}_{2}\right)$ containing the desired number of 
remaining sulfur atoms necessary to complete the ring. Additionally, cyclo-hexasulfur $\left(\mathrm{S}_{6}\right)$ and cyclo-dodecasulfur $\left(\mathrm{S}_{12}\right)$ were prepared by the use of one or two equivalents of sulfur dichloride, respectively. However, the synthesis of larger rings of cyclo-decasulfur $\left(\mathrm{S}_{10}\right)$, cyclopentadecasulfur $\left(\mathrm{S}_{15}\right)$, and cyclo-eicosasulfur $\left(\mathrm{S}_{20}\right)$ required the use of sulfuryl dichloride, as this provided a necessary intermediate to promote efficient cyclization (e.g., cyclic $S_{20}$ ) [120]. Interestingly, the synthesis of cyclo-tetradecasulfur $\left(\mathrm{S}_{14}\right)$ required the reaction of a hexasulfido complex (Fig. 10b) which was reacted with a dichloro-octasulfane $\left(\mathrm{S}_{8} \mathrm{Cl}_{2}\right)$ to generate the 14membered ring. This was required presumably due to the instability of dichloro-nonasulfane $\left(\mathrm{S}_{9} \mathrm{Cl}_{2}\right)$ which would be necessary to react with the $\mathrm{Cp}_{2} \mathrm{TiS}_{5}$ complex to yield the 14-membered S-S ring. To our knowledge, homocyclic polysulfides with between 16 and 19 sulfur atoms have not been prepared by the utilization of activated sulfur agents. However, the preparation of these species was presumably feasible given the development of suitable conditions for the use of sulfuryl dichloride and the appropriate metallocene $\mathrm{Cp}_{2} \operatorname{TiS}_{\mathrm{x}}(\mathrm{x}=3,5,7,8)$ complex $[121,122]$.

The prior literature on the synthesis of sulfur-rich macrocycles in Fig. 10b offered a strong precedence for the synthesis of high sulfur-content linear copolymers by ring opening polymerizations with $\mathrm{S}_{8}$ comonomers. Ding et al. demonstrated thermally initiated copolymerization of cyclic arylene disulfides oligomers with sulfur to generate high sulfurcontent copolymers with high molecular weights (Fig. 11) [123-127].

\section{Insert Figure 11 and Figure 11 caption}

In these systems, cyclic aromatic disulfide monomers possessing the geminal dimethyl group were observed to afford soluble copolymers capable of characterization by GPC and ${ }^{1} \mathrm{H}$ NMR. For this monomer it was observed that solution copolymerizations yielded copolymers of 
the highest molecular weights $\left(\mathrm{M}_{\mathrm{n}}=50,000 ; \mathrm{PDI}=2.16\right)$ at $200^{\circ} \mathrm{C}$ and maximum sulfur ranks of $x=3-4$. The addition of larger equivalents of sulfur (based upon $S_{8}$ ) with respect to the cyclic oligomers only resulted in excess unreacted sulfur after the copolymerization. However, melt copolymerizations of cyclic arylene sulfides and $\mathrm{S}_{8}$ conducted at either $150{ }^{\circ} \mathrm{C}$ or $200{ }^{\circ} \mathrm{C}$ afforded copolymers of higher molar mass $(\mathrm{Mn}=84,000 ; \mathrm{PDI}=1.94)$ and higher sulfur rank

( $x=8$ via ${ }^{1} \mathrm{H}$ NMR) as determined from the soluble portion of the copolymerization reaction. When four or less molar equivalents of sulfur (based upon $\mathrm{S}_{8}$ ) were copolymerized with one equivalent of the cyclic disulfide oligomers the products were completely soluble in chloroform; however, with five or more equivalents of sulfur (based upon $\mathrm{S}_{8}$ ) added to the bulk copolymerizations the products no longer fully dissolved in chloroform due to the sulfur catenation. Melt copolymerization of the second monomer (i.e., thioether linkage, Fig. 11) reportedly yielded materials which are wholly insoluble at room temperature in common organic solvents. Characterization, conducted via differential scanning calorimetry (DSC), dynamic mechanical thermal analysis (DMTA), and thermal gravimetric analysis (TGA), revealed that as the sulfur content within the copolymer increased, both the glass transition temperature and the onset temperature for degradation decreased [125]. These systems demonstrated the viability of bulk copolymerization using $\mathrm{S}_{8}$ and obtaining high sulfur content copolymer possessing tunable thermomechanical properties.

\section{Challenges in sulfur chemistry and processing}

Several challenges are encountered when attempting to use elemental sulfur (Fig. 12-1) in synthetic chemistry, or via processing of the bulk form of sulfur in powder or melt forms. Although sulfur melts at relatively low temperature $\left(\sim 119^{\circ} \mathrm{C}\right)$ to form a low viscosity liquid (Fig. 12-2), molten sulfur is immiscible with the vast majority of conventional organic reagents which 
affords biphasic mixtures (Fig. 12-3). However, a limited range of chemical substances were found to be miscible with molten $\mathrm{S}_{8}$ (which is cyclic and nonpolar) which include planar aromatic compounds, certain amines, carbon disulfide $\left(\mathrm{CS}_{2}\right)$ and more recently, ionic liquids [32, 128]. Based on this literature precedence several general trends have been observed in exploring reactions with molten sulfur: 1) aromatic or conjugated linear molecules were regularly miscible over a wide range of concentrations; 2) the presence of polar groups, even on aromatic molecules, generally precluded mixing at all but very low concentrations $(\sim 1 \%)$; and 3$)$ molten sulfur was found to be chalcogenophilic, but oxophobic and did not readily dissolve molecules containing oxygen, although identical molecules containing sulfur were miscible [31]. While these above trends were generally consistent, certain compounds such as, low molar mass polyethylene glycol oligomers (i.e., "Carbowaxes") were also found to be miscible with liquid sulfur. Miscibility of $\mathrm{S}_{8}$ in certain cases was facilitated by heating mixtures above the melting of sulfur which can afford single phase "solutions" (Fig. 12-4), however, rapid precipitation of the $\mathrm{S}_{8}$ is observed after cooling of the mixture (Fig. 12-5).

\section{Insert Figure 12 and Figure 12 caption}

Melt, or solution processing of elemental sulfur into useful forms, such as, free-standing objects or thin films on substrates was also highly complicated due to the crystallinity and intractability of $\mathrm{S}_{8}$. Although molten sulfur can be easily poured into molds, when cooled to room temperature, these materials exhibit poor mechanical properties (Fig. 12-6) [129]. Solution processing of sulfur into thin films (e.g., spin-coating concentrated solutions) onto surfaces is also challenging since $\mathrm{S}_{8}$ does not wet many conventional substrates (e.g., glass, $\mathrm{Si}$ wafers, $\mathrm{Al}$, carbon) (Fig. 12-7). 
Ultimately the limited miscibility of molten sulfur with conventional organic reagents presented a significant challenge in developing synthetic methods to modify, or utilize $\mathrm{S}_{8}$ to prepare useful materials. These synthetic challenges, coupled with the aforementioned processing issues with $\mathrm{S}_{8}$ were likely deterrents for exploratory studies to prepare high sulfur content substances directly from $\mathrm{S}_{8}$. And while historically elemental sulfur has been utilized in the production of several classes of copolymers there are still challenges associated with preparing novel materials which are homogenous, stable, and have controllable properties; all while utilizing facile chemistry and process techniques.

\section{Sulfur as an unconventional solvent and reaction medium}

\subsection{In-situ colloid synthesis}

In an effort to directly utilize elemental sulfur as an alternative feed stock for materials synthesis, Pyun et al. demonstrated that molten sulfur could be utilized as a reaction medium for the direct synthesis of gold nanoparticles from an organometallic precursor (Fig. 13) [130]. The triphenylphosphine ligand on the $\mathrm{Au}(\mathrm{I})$ complex was found to be critical for dissolution in molten sulfur and to ultimately stabilize the formed colloidal $\mathrm{Au}$. The gold nanoparticles ( $\mathrm{D} \approx 20$ $\mathrm{nm}$ ) were characterized by transmission electron microscopy (TEM) after sublimation of the excess sulfur. However, in order to directly observe the particles within the reaction medium, crosslinking of the sulfur matrix was carried out with subsequent addition of divinylbenzene (DVB, a mixture of the 1,3 and 1,4 isomers). The dark brown, glassy composite could then be microtomed and the particles analyzed by TEM. In a similar fashion, molten sulfur was once again utilized as a reactant and solvent in the generation of lead sulfide particles. The in-situ 
generation of hydrogen sulfide from the reaction of sulfur and oleylamine, facilitated the reduction of the lead precursor to nanoparticles $(\sim 7.5-10 \mathrm{~nm})$ and generated a low molecular weight copolymer in a single step. Substrate-supported thin films or free-standing particle/polymer composite films were easily generated via solution processing techniques [131]. Additionally, Block et al. recently investigated the synthesis of a variety of allylic terminated polysulfides ( $\left.\mathrm{R}-\mathrm{S}_{\mathrm{n}}-\mathrm{R}, \mathrm{n}=3-22\right)$ utilizing elemental sulfur as the reactant and solvent [132].

\section{Insert Figure 13 and Figure 13 caption}

\subsection{Inverse Vulcanization of elemental sulfur}

A major challenge associated with the bulk ROP of $\mathrm{S}_{8}$ via free radical process was the high temperature required to promote homolytic generation of sulfur radical species (i.e., $\sim 185$ ${ }^{\circ} \mathrm{C}$ ) which limited the choice of possible vinylic comonomers that did not volatilize under these conditions. Comonomers, such as, DVB (b.p. $=195^{\circ} \mathrm{C}$ ) were sufficiently nonvolatile to use for bulk copolymerizations with $\mathrm{S}_{8}$ at $185^{\circ} \mathrm{C}$; however, large scale bulk copolymerization reactions proved to be difficult to control and reproduce. To circumvent these issues, Griebel and Pyun et al. developed a process termed, inverse vulcanization, that employed 1,3-diisopropenylbenzene (DIB, b.p. $=231^{\circ} \mathrm{C}$ ) in the bulk copolymerization with $\mathrm{S}_{8}$. This methodology provided a route to high sulfur-content, statistical copolymers poly(sulfur-random-(1,3-diisopropenylbenzene) (poly(S-r-DIB) using solvent free methods and inexpensive starting materials.

\section{Insert Figure 14 and Figure 14 caption}


The inverse vulcanization process enabled facile control over copolymer composition and modulation of thermomechanical properties by simple variation of comonomer feed ratios (Fig. 14a) [133]. In a series of poly(S-r-DIB) copolymers, semi-crystalline materials were observed at lower compositions of DIB (0-15 wt $\%)$, while wholly amorphous copolymers were obtained at higher DIB compositions (20-65 wt\%) (Fig.14b). Concurrently, the glass transition ( $\left.\mathrm{T}_{\mathrm{g}}\right)$ temperature of the copolymers increased as the content of DIB was increased within the materials [133]. Dynamic rheological characterization of these materials confirmed the formation of thermoplastic copolymers that were NOT crosslinked, as noted by the observation of a zero shear viscosity $[133,134]$. In these copolymers, the average sulfur rank were estimated from the molar feed ratios of $\mathrm{S}_{8}$ to DIB (assuming full monomer conversions) and was easier to determine in comparison to other types of polysulfides, since S-S bonds were the primary units in the copolymer backbone.

Variation in comonomer feed ratios of $\mathrm{S}_{8}$ and DIB in the inverse vulcanization process also afforded different copolymer microstructures, as a higher DIB content increased the degree of branching (Fig. 15). As discussed previously, the homo-ROP of $\mathrm{S}_{8}$ afforded the linear polymeric sulfur that depolymerized back to cyclic monomers. However, by copolymerizing $\mathrm{S}_{8}$ with DIB via free radical processes, the introduction of branching sites into the copolymer was achieved, which was proposed as a means to suppress the depolymerization processes through the formation of polysulfide loops and thiol terminal groups. Hence, for sulfur copolymers with $10-\mathrm{wt} \%$ DIB (poly $\left(\mathrm{S}-r-\mathrm{DIB}_{10-\mathrm{wt} \%}\right)$, it was proposed the formation of thermoplastic branched copolymers compromised of longer polysulfide loops and thiol terminated chains were formed. Concurrently, higher DIB content copolymers (20-50 wt\% DIB) afforded (hyper)branched copolymers. 


\section{Insert Figure 15 and Figure 15 caption}

One of the unusual features of the inverse vulcanization process between $\mathrm{S}_{8}$ and DIB was that each of these individual monomers possess a floor and ceiling temperature $\left(T_{f}\right.$, and $\left.T_{c}\right)$, respectively. DIB (and other $\alpha$-methylstyrenics) possess a relatively low ceiling temperature $\left(\mathrm{T}_{\mathrm{c}}\right)$ which thermodynamically prevented the formation of polymer above $66^{\circ} \mathrm{C}$ (Fig. 16a) [133, 135]. Likewise elemental sulfur has a floor temperature $\left(T_{f}\right)$, which required a temperature greater than $159{ }^{\circ} \mathrm{C}$ for the formation of polymer to be thermodynamically favorable (Fig. 16b). However, these comonomers readily copolymerized in bulk at elevated temperatures, where it is anticipated that growing copolymer chains terminated by DIB radicals favored cross-propagation to $\mathrm{S}_{8}$ due to the low $\mathrm{T}_{\mathrm{c}}$ observed in DIB free radical homopolymerizations [133].

\section{Insert Figure 16 and Figure 16 caption}

To mechanistically probe the benefits of copolymerizing $\mathrm{S}_{8}$ with DIB in the inverse vulcanization process, copolymerizations of $\mathrm{S}_{8}$ with monofunctional comonomers (e.g., $\alpha$ methylstyrene) were also investigated. In these model reactions, it was anticipated that the copolymerization of $\mathrm{S}_{8}$ and $\alpha$-methylstyrene would afford chemically unstable linear copolymers that would readily depolymerize, as observed in the homo-ROP of $\mathrm{S}_{8}$ (Fig. 17a). Phenomenologically, this was observed to be the case, where crude mixtures from the copolymerization of $\mathrm{S}_{8}$ and $\alpha$-methylstyrene were observed to possess significant amounts of residual $\mathrm{S}_{8}$ which readily crystallized from the reaction medium. Size exclusion chromatography (SEC) of this crude reaction mixture further confirmed that depolymerization processes were

dominant in the $\mathrm{S}_{8}$ and $\alpha$-methylstyrene copolymerization as noted by the presence of only small molecular weight species (Fig. 17b). In contrast, as discussed previously for the $\mathrm{S}_{8} / \mathrm{DIB}$ 
comonomer pair, DIB resulted in branching and quenched the polysulfide radical chain ends which was proposed to form macromolecular polysulfide loops that suppress depolymerization processes (Fig. 17c). Analysis via SEC at different time points in the inverse vulcanization of $\mathrm{S}_{8}$ and DIB (for $50-\mathrm{wt} \%$ DIB comonomer feeds) revealed the formation of a low molar mass polymer of broad molecular weight distribution (Fig. 17d).

\section{Insert Figure 17 and Figure 17 caption}

Poly(S-r-DIB) copolymers were found to be readily melt, or solution processed into a wide range of arbitrary forms for a variety of applications. An attractive feature of the inverse vulcanization process is the ability to prepare high sulfur content liquid pre-polymer resins that could be poured into various molds and then cured into the final desired form (Fig. 18). Poly(dimethylsiloxane) (PDMS) based molds were readily fabricated from a variety of master templates. To generate a sulfur based replica, liquid pre-polymer mixtures produced via the inverse vulcanization processes were prepared at the desired reaction scale and kept to low monomer conversion to enable pouring into the target mold (Fig. 18a,b). The low viscosity prepolymer was then thermally cured at $185{ }^{\circ} \mathrm{C}$ while in the PDMS mold to yield the final replica object (Fig. 18c). Several objects with a variety of different complexities have been generated by this facile process requiring only the appropriate PDMS mold and optimizing the curing time to lock in the final form of the sulfur copolymer. Simpler objects with only a single molded face, such as the lens and University of Arizona logo (Fig. 18-1 and Fig. 18-2), were generated in twodimensional flat molds; while more complicated objects, such as the connectable block and tire (Fig. 18-3 and Fig. 18-4), were generated in three-dimensional molds. The mold utilized for creation of the object in Fig. 18-5 was prepared by PDMS replication of an electron beam 
generated micropattern. The poly(S-r-DIB) copolymer replica can once again be prepared from this complex structure and exquisitely illustrated the high fidelity of pattern transfer and the precision afforded from molding of the low-viscosity pre-polymer. While these objects are novel, the molding of a high precision copolymer lens provided a means of characterizing the copolymers further and ultimately the molding process clearly demonstrated the improved properties afforded by the inverse vulcanization methodology.

\section{Insert Figure 18 and Figure 18 caption}

The inverse vulcanization methodology in principal can be extended to any di-, or multivinylic, or alkynyl comonomer that can undergo thiol-ene/thiol-yne reactions and is miscible in liquid sulfur $[133,134,136]$. Furthermore, Dirlam et al., recently demonstrated that functional groups can be introduced into the inverse vulcanization process by copolymerization approaches with functional styrenics. In this system, a monofuntional styrenic compound carrying a pendant 3,4-propyleneoxydithiophene (Sty-ProDOT) was synthesized and copolymerized with $\mathrm{S}_{8}$ and DIB to prepare a chemically stable and soluble linear copolymer. The terpolymer was then solution deposited onto indium tin oxide (ITO) substrates and electropolymerized to prepare interpenetrating networks of poly(S-r-DIB) and poly(ProDOT) (Fig. 19) [137]. Both cyclic voltammetry and electrochemical impedance spectroscopy of electropolymerized films confirmed the formation of polythiophene inclusions in the sulfur matrix and a dramatic increase in electrical conductance. This demonstration clearly highlighted the utility of tandem inverse vulcanization methodology to afford materials that possessed the desirable attributes of poly(S-r-DIB) but with more functionality incorporated into the copolymer and provided a novel route to materials with unique properties. 


\section{Insert Figure 19 and Figure 19 caption}

\section{Useful properties and modern applications of high sulfur content polymeric materials}

Recent demand for materials in energy storage, energy conversion, IR optics, and advanced stimuli responsive applications has spurred exploration into polymeric materials and nanocomposites with high sulfur content (Fig. 20). The incorporation of S-S bonds into polymeric materials was advantageous since such moieties are electrochemically active toward lithium, impart high refractive index, and exhibit dynamic covalent character. In the following sections, we provide background into the three main areas of application that our group has found utility for sulfur based polymers: Li-S batteries, IR imaging, and dynamic covalent polymers. We further discuss material opportunities where these sulfur based copolymers have found advantage, along with a short review of related material systems that have been explored.

\section{Insert Figure 20 and Figure 20 caption}

\subsection{Lithium-Sulfur Batteries}

Investigation of sulfur for electrochemical storage applications has been conducted for the past half century, relying mainly on high temperature device architectures (e.g., Na-S and $\mathrm{Li}-\mathrm{S}$ batteries) to enable efficient power generation [138]. Early efforts into lithium-sulfur (Li-S) batteries were focused mainly on primary cells; however recent renewed research effort has concentrated on improved capacity and higher cycle lifetimes in secondary batteries [139-141]. Interest in Li-S secondary batteries has ballooned in the last decade, owing to the fact that such cells have a theoretical capacity of $1672 \mathrm{mAh} \cdot \mathrm{g}^{-1}$ and a theoretical specific energy density of $2567 \mathrm{Wh} \cdot \mathrm{kg}^{-1}$. Practical capacities typically range from $800-1200 \mathrm{mAh} \cdot \mathrm{g}^{-1}$, which are approximately 4-6 times higher than that achieved in current Li-ion technology. The high 
capacity, coupled with the low cost and low density of sulfur, provides a distinct advantage to Li$\mathrm{S}$ batteries over traditional Li-ion technology. However, several critical limitations have prevented commercialization of Li-S batteries, particularly the insulating nature of elemental sulfur, large capacity fading, and severely limited cycle lifetimes [142, 143].

A traditional $\mathrm{Li}-\mathrm{S}$ cell consists of a sulfur composite cathode, an organic electrolyte, and a lithium metal anode. At the time of assembly the battery resides in the charged state and both sulfur and lithium are present in their neutral form. Upon discharge; the lithium metal is oxidized at the negative electrode (anode) to produce lithium ions and electrons. The lithium ions diffuse to the positive electrode through the liquid electrolyte while the electrons travel through an external electrical circuit, thereby generating an electrical current (Fig. 21a). At the positive electrode (cathode), sulfur associates with lithium ions and electrons and is reduced in a series of complex reactions to ultimately produce lithium sulfide $\left(\mathrm{Li}_{2} \mathrm{~S}\right)$. Upon recharge the back reactions occur and the lithium ions and electrons are stripped from the positive electrode to once again reform sulfur at the cathode and lithium metal at the anode (Fig. 21b).

\section{Insert Figure 21 and Figure 21 caption}

Under ideal cycling conditions, discharging results in elemental sulfur reduction and ring opening with the incorporation of lithium ions, to generate high order polysulfides $\mathrm{Li}_{2} \mathrm{~S}_{\mathrm{x}}(6<\mathrm{x} \leq$ 8). As discharge continues, additional lithium ions are incorporated and lower order polysulfides $\mathrm{Li}_{2} \mathrm{~S}_{\mathrm{x}}(2<\mathrm{x} \leq 6)$ are formed. The final product of full discharge is conventionally described as $\mathrm{Li}_{2} \mathrm{~S}$, although mixtures of lower polysulfides have been observed [144]. The reduction of $\mathrm{S}_{8}$ to $\mathrm{Li}_{2} \mathrm{~S}_{4}(2.3 \mathrm{~V})$ results in the first of two voltage plateaus observed in the voltage profile, with the second plateau resulting from $\mathrm{Li}_{2} \mathrm{~S}_{4}$ conversion to $\mathrm{Li}_{2} \mathrm{~S}$ (2.1 V) (Fig. 21c). Under ideal charging 
conditions the $\mathrm{Li}_{2} \mathrm{~S}$ is converted back to the intermediate lithium polysulfide species, and ultimately $\mathrm{S}_{8}$ is reformed at the end of the charging cycle. However, there is still some debate as to whether or not within the traditional voltage window of operation for a Li-S cell $(2.6-1.7 \mathrm{~V})$ if $\mathrm{Li}_{2} \mathrm{~S}$ can be fully formed upon discharge and if the cyclo-octasulfur $\left(\mathrm{S}_{8}\right)$ is fully regenerated upon recharging of the cell. Regardless, the most relevant species to long-term functioning of a Li-S cell are the highly soluble, intermediate polysulfides $\operatorname{Li}_{2} \mathrm{~S}_{\mathrm{x}}(6<\mathrm{x} \leq 8)$ species.

The primary challenges in Li-S cells that require addressing are the rapid capacity loss and short cycle lifetimes of these devices. These challenges have primarily been attributed to two dominate factors: dissolution of the active sulfur material from the cathode (i.e., "shuttling mechanism") and mechanical deterioration of the composite cathode structure [145]. Shuttling of the active material is a parasitic side reaction resulting from the substantial solubility of higher order polysulfides $\mathrm{Li}_{2} \mathrm{~S}_{\mathrm{x}}(6<\mathrm{x} \leq 8)$ in the ether-based electrolytes. The soluble polysulfides are able to diffuse from the cathode, across the separator, and react with the lithium anode resulting in a permanent loss of the active material. Mikhaylik et al. perturbed the parasitic side reaction between the soluble polysulfides and the lithium anode by the addition of $\mathrm{LiNO}_{3}$ to the etherbased electrolyte [146-148]. However, the repeated dissolution and deposition of reactive species at the cathode can lead to passivation, causing an increase in the internal resistance. Mechanical deterioration of the composite cathode structure results from the stresses placed upon the structure due to the $80 \%$ volume expansion that occurs when sulfur is converted to $\mathrm{Li}_{2} \mathrm{~S}$ during discharge. Continued stress from the volume change inevitably leads to structural breakdown and electrical isolation from the current collector, leading to further loss of active material. Ultimately the loss of active material by both routes leads to quick capacity fade and outright failure after only a short lifetime. 
The preparation of novel nanocomposite materials that encapsulate $\mathrm{S}_{8}$ active phase has been extensively investigated as a route to enhanced cathode materials in Li-S batteries (Fig. 22). This approach primarily enabled sequestration of the active sulfur phase within an electrically or ionically conductive shell to concurrently suppress dissolution of the polysulfide discharge products and increase the mechanical integrity within the cathode. The fabrication of these nanocomposites has focused primarily on the utilization of two methods: 1) infusion of either liquid or gaseous sulfur into a variety of nanomaterials, and 2) synthesis of sulfur nanoparticles which were subsequently enwrapped to generate the composite. While several in depth reviews on the subject of novel active materials for Li-S batteries have recently been published, a brief discussion of the field herein is necessary to provide understanding for the necessity of high sulfur-content polymers as an alternative means of improving Li-S battery performance [141, 149-157].

\section{Insert Figure 22 and Figure 22 caption}

The preparation of enhanced Li-S cathode materials via the synthesis of sulfur nanocomposites by infusion methods (e.g., with molten or vaporized sulfur) has been extensively studied as a route to both suppress polysulfide dissolution during cycling and improve the electrical conductivity of the active cathode material. The hybridization of sulfur with a conductive filler, such as, carbon black, was initially investigated since the microporosity of particulate carbon black enabled (pore diameter $\leq 2 \mathrm{~nm}$ ) sequestration of polysulfides [158-164]. Later efforts to control (micro)porosity in conductive carbon additives to enhance compatibility with impregnated sulfur were also reported as a means of improving Li-S battery performance [165-167]. In $2009 \mathrm{Ji}$ et al. reported on the preparation of carbon sulfur nanocomposites using a hierarchical mesoporous carbon agent (pore diameter 2-50 nm) followed by infusion of molten 
sulfur [168]. This seminal work demonstrated a means of improving capacity retention by presumably confining the active sulfur phase/discharge products into nanoscopic domains, thereby perturbing polysulfide dissolution. Numerous groups have since reported on using ordered carbonaceous fillers, or additives to improve capacity retention and promote longer lifetimes [169-176]. Additionally, several other examples of mesoporous materials have been utilized for polysulfide sequestration. The mechanism of sulfur entrapment is the same as microporous carbons but with the ability to incorporate higher sulfur loadings and allow easier infiltration of liquid electrolyte [177-185].

High aspect ratio 1-D nanomaterials (i.e., hollow nanotubes and solid nanofibers) have also been hybridized with sulfur to prepare enhanced Li-S cathode materials as a route to improve the mechanical integrity and electrical transport within the cathode composite. For various nanotubes, a large axial diffusion length coupled with a minimal radial diffusion distance was found to favorably affect polysulfide dissolution while affording high sulfur utilization within the composite as the electrolyte and lithium ions were permeable to the walls of the nanotubes [186-195]. Cui et al. generated composites from hollow nanotubes and elemental sulfur, which yielded high initial capacity coupled with longer lifetimes as a result of the nanotube morphology ( $>900 \mathrm{mAh} \cdot \mathrm{g}^{-1}$ at 300 cycles) [196-198]. However, when more extreme temperatures are utilized for the sulfur infiltration step, a detrimental effect on the Li-S battery performance was observed [187]. Nanotube composites have also been demonstrated to form polymer binder-free Li-S cathodes, by direct growth of nanotubes onto the current collector [194, 199] or through the formation of free-standing cathodes via processing of the nanotubes [186, 200, 201]. Similar results with nanofiber-sulfur nanocomposites have also been reported; while composites of polymeric nanotubes and nanofibers also garnered improved cycling performance 
in Li-S batteries [202-210]. Xiao et al. demonstrated the use of poly(aniline) nanotubes as a reactive reservoir for sulfur, showing that partial vulcanization occurred during infusion and afforded improved capacity retention of $>400 \mathrm{mAh} \cdot \mathrm{g}^{-1}$ after 500 cycles at $1 \mathrm{C}\left(1 \mathrm{C}=1672 \mathrm{mAh} \cdot \mathrm{g}^{-}\right.$ $\left.{ }^{1}\right)[211,212]$.

The fabrication of Li-S cathode materials from nanocomposites using mesoporous hollow carbon spheres have also been explored, where the large interior void space of these hollow colloids (200-500 nm), enabled facile infiltration of sulfur and suppressed polysulfide dissolution upon battery cycling [213-220]. Jayprakash et al. reported the first example of hollow carbonsulfur core-shell colloid composites and demonstrated high capacity retention $\left(\sim 950 \mathrm{mAh} \cdot \mathrm{g}^{-1}\right.$ after 100 cycles at $0.5 \mathrm{C}$ ) [213]. More recently the fabrication of Li-S batteries with improved lifetimes ( $>900 \mathrm{mAh} \cdot \mathrm{g}^{-1}$ after 1000 cycles at $\left.1 \mathrm{C}\right)$ was achieved by Peng et al. by generation of hollow graphene nanoshells on a solid template [219].

Core-shell colloids for Li-S cathode materials have also been prepared using various heterophasic polymerization methods (e.g., suspension, dispersion polymerizations). Using these approaches, colloidal sulfur dispersions were prepared using standard methods (e.g., the methods of LaMer) [221], followed by overcoating of the sulfur colloidal core with some conductive shell, typically a polymeric material, such as, poly(pyrrole) [222-225], poly(thiophene) [226, 227], or poly(3,4-(ethylenedioxy)thiophene) (PEDOT) [228, 229]. Recently, Li et al. demonstrated a core-shell colloidal nanocomposite composed of an interior sulfur shell and an exterior shell of either poly(vinylpyrrolidone), or PEDOT, which when used as the active material in Li-S cathodes afforded batteries with high cycle stability (1000 cycles at $0.5 \mathrm{C})$ or high rate capabilities (849 and $610 \mathrm{mAh} \cdot \mathrm{g}^{-1}$ at, $2 \mathrm{C}$ and $4 \mathrm{C}$, respectively) [230]. The large interior void space provided volume for expansion that takes place during conversion from sulfur to 
$\mathrm{Li}_{2} \mathrm{~S}$, obviating the mechanical stress on the cathode. In a similar fashion researchers have also investigated the formation of yolk-shell morphologies. Zhou et al. demonstrated a yolk-shell composite composed of a sulfur yolk and a polyaniline shell which demonstrated improved capacity retention $\left(765 \mathrm{mAh} \cdot \mathrm{g}^{-1}\right.$ after 200 cycles at $\left.0.2 \mathrm{C}\right)$ [231]. Likewise Seh et al. demonstrated a yolk-shell composite with a titanium dioxide shell, which possessed extremely high cycling stability (67\% retention in capacity at 1000 cycles) [232].

The use of graphene and graphene oxide $(\mathrm{GO})$ as conductive agents in preparing sulfur nanocomposites for $\mathrm{Li}-\mathrm{S}$ cathode materials have also received considerable attention as a route to improved battery performance. Nanocomposite formation has been achieved via infusion techniques [233-242] and through precipitation of sulfur colloids onto dispersed graphene, or GO sheets [243-250]. Song et al. demonstrated drastically improved performance with a GOsulfur based nanocomposite encapsulated with an ionic surfactant (i.e., cetyltrimethlyammonium bromide) [251]. Li-S batteries fabricated using these materials exhibited extended cycle lifetimes (1500 cycles); however, deconvolution of the effect which the composite structure has upon the battery performance is difficult since a non-traditional discharge/charge protocol, electrolyte, and binder were also utilized in the battery [251]. Qiu et al. demonstrated enhanced Li-S battery performance in graphene-sulfur composites via nitrogen doping of the graphene to generate electrostatic interactions with the polysulfide discharge products $\left(\sim 350 \mathrm{mAh} \cdot \mathrm{g}^{-1}\right.$ at $2 \mathrm{C}$ after 2000 cycles). Polymer binder-free electrodes containing graphene or GO-sulfur composites have also been investigated for improved Li-S batteries [252, 253].

While it is clear there has been significant improvement to Li-S batteries in terms of capacity retention and cycle lifetimes through the utilization of sulfur based nanocomposites; translation of these approaches to industrial scale production would appear to offer numerous 
challenges. Additionally, the reduced loading of active sulfur material in these various nanocomposites also lowers the ultimate energy density of the Li-S batteries below that of Li-ion technology, negating the higher charge capacity advantage attributed to Li-S batteries systems.

An alternative approach to preparing improved cathode materials for Li-S and other related systems has been the development of new electrochemically active polymers to afford improved performance. In the past two decades a number of different functionalities have been applied to this purpose; however, the low weight fraction of redox active bonds within the polymeric structure leads to low capacities and low energy densities [254-278]. Additionally, a number of the initial studies on secondary batteries containing redox active polymer systems showed poor cycling stability. Lutkenhaus and coworkers have recently demonstrated very high cycle number and fast C-rate capability based on electroactive polymers [279-282]. Liu et al. and Jeon et al. recently demonstrated electroactive polymer cathodes with high cycle numbers and having capacities similar to that of $\mathrm{Li}$-ion batteries $\left(\approx 200 \mathrm{mAh} \cdot \mathrm{g}^{-1}\right)[283,284]$.

The development of high capacity polymeric electrodes for Li-batteries has more recently been focused on incorporating a higher weight fraction of redox active bonds into the macromolecules. Trofimov et al. demonstrated polyeneoligosulfides with up to 77 -wt $\%$ sulfur content, which showed an increased capacity of $>700 \mathrm{mAh} \cdot \mathrm{g}^{-1}$ for the initial discharge [285287]. Unfortunately these novel polymers exhibited significant short term capacity fading (extended cycle experiments were not conducted). With the notion of improving Li-S battery performance through the use of a high sulfur-content copolymer, Pyun et al. investigated poly(sulfur-random-1,3-diisopropenylbenzene) (poly(S-r-DIB)) copolymers as the active material in Li-S batteries. In these systems, high sulfur content copolymers based on poly(S-r$\left.\mathrm{DIB}_{10}\right)(90-\mathrm{wt} \%$ sulfur and $10-\mathrm{wt} \% \mathrm{DIB})$ were synthesized and readily utilized to prepare 
copolymer-based cathodes for Li-S batteries that exhibited large initial charge capacities (1100 $\left.\mathrm{mAh} \cdot \mathrm{g}^{-1}\right)$ along with high cycle stability $\left(823 \mathrm{mAh} \cdot \mathrm{g}^{-1}\right.$ after 100 cycles at $\left.0.1 \mathrm{C}\right)$ [133]. Cyclic voltammetry of these sulfur copolymers and $\mathrm{S}_{8}$ found that the two materials were nearly electrochemical equivalent under the conditions encountered when used as the active material in cathodes for Li-S batteries. However, copolymer-based cathodes fabricated from poly(S-r$\left.\mathrm{DIB}_{10}\right)$ afforded batteries with significantly improved performance relative to $\mathrm{S}_{8}$-based cathodes at 100 cycles (Fig. 23; sulfur (539 $\mathrm{mAh} \cdot \mathrm{g}^{-1}$, red squares) and poly(S-r-DIB 10$)\left(823 \mathrm{mAh} \cdot \mathrm{g}^{-1}\right.$, blue triangles)). Fabrication methods with copolymer active materials were further optimized in Li-S batteries using poly $(\mathrm{S}-r$-DIB 10$)$ and afforded a higher initial capacity $\left(1225 \mathrm{mAh} \cdot \mathrm{g}^{-1}\right)$, along with enhanced cycle lifetimes and very good capacity retention $\left(635 \mathrm{mAh} \cdot \mathrm{g}^{-1}\right.$ after 500 cycles at $0.1 \mathrm{C}$, Fig. 23 black circles) [144]. The performance of these Li-S batteries after extended cycling was among the highest reported specific capacities using a polymer-based electrode material.

A singular advantage that poly(S-r-DIB) cathode systems exhibit in improving Li-S batteries performance is the low cost of the materials and facile process of preparing the sulfur copolymer. Griebel and Pyun et al. demonstrated facile scale up for the preparation of these materials using a single-step, low temperature (i.e., $130{ }^{\circ} \mathrm{C}$ ) inverse vulcanization process to successfully generate one kilogram of the poly $(\mathrm{S}-r$-DIB 10$)$ copolymer [288]. Thermal analysis (e.g., DSC and TGA) revealed the copolymer products prepared from this scaled up process were essentially identical to materials prepared from smaller scale reactions as noted by the decomposition temperatures and $\mathrm{T}_{\mathrm{g}}$. Furthermore, these materials also exhibited excellent capacity and cycle stability when used as the active material in cathode for Li-S batteries (initial capacity of $1033 \mathrm{mAh} \cdot \mathrm{g}^{-1}$ and $631 \mathrm{mAh} \cdot \mathrm{g}^{-1}$ after 500 cycles at $0.1 \mathrm{C}$, Fig. 23 green diamonds).

\section{Insert Figure 23 and Figure 23 caption}


An attractive feature of the inverse vulcanization process is the ability to readily prepare poly(S-r-DIB) copolymers of varying composition to enable facile structure property correlations of sulfur content on Li-S battery performance. Hence, a survey of several poly(S-r-DIB) copolymer compositions were prepared with DIB compositions ranging from $1-50-w t \%$ DIB (i.e., 50-99 wt $\%$ sulfur) and screened to determine optimal compositions for ideal Li-S battery performance (Fig. 24) [144]. In this study, copolymers of very low DIB content (i.e. 1-wt\%; Fig. 24-open purple circles) exhibited rapid charge capacity fading in a manner comparable to Li-S batteries fabricated from $\mathrm{S}_{8}$ based cathodes (Fig. 24-filled black diamonds). Conversely, poly(S$r$-DIB) copolymers with a higher DIB content (25-50 wt\% DIB) also exhibited rapid capacity fading within 75 charge-discharge cycles (Fig. 24-filled left-pointing navy blue triangles for 20wt $\%$ DIB; open right-pointing maroon triangles for 30-wt $\%$ DIB; filled red hexagons for 50-wt $\%$ DIB). The highest retention of charge capacity were observed for DIB copolymer compositions from $5-15 \mathrm{wt} \%$ of the organic comonomer, where compositions of $90-\mathrm{wt} \%$ sulfur $/ 10-\mathrm{wt} \%$ DIB (i.e., poly $\left(\mathrm{S}-r-\mathrm{DIB}_{10 \mathrm{wt} \%}\right)$ were deemed optimal from the standpoint of high sulfur loading, cost and processing characteristics (Fig. 24-open red triangles) [144]. From this study, DIB incorporation into sulfur copolymer cathodes was proposed to generate intimate blends of organosulfur species (from DIB) with polysulfide discharge products and served to "plasticize" the cathode during charge-discharge cycling. At optimal copolymer compositions (i.e., 10-wt $\%$ DIB) the organosulfur discharge product of the copolymer suppressed irreversible large deposits of $\mathrm{Li}_{2} \mathrm{~S}_{\mathrm{x}}(\mathrm{x} \sim 1-3)$ on the composite structure, thereby mitigating mechanical wear of the cathode.

\section{Insert Figure 24 and Figure 24 caption}


Sun et al. utilized 1,3 diethynylbenzene (DEB) as the comonomer in the bulk copolymerization with $\mathrm{S}_{8}$ to afford a semi-interpenetrating network that was used as the active material in cathodes for Li-S batteries (Fig. 25) [289]. The copolymer could also be generated in the presence of carbon black, which the authors argue is entrained within the network once the copolymer forms and can further improve battery performance. While the sulfur content is lower than for the poly(S-r-DIB $\left.{ }_{10}\right)$ copolymer, both poly(S-r-DEB) batteries showed very good cycling stability out to 500 cycles at $1 \mathrm{C}$, with the copolymer containing carbon black demonstrating a high capacity of $504 \mathrm{mAh} \cdot \mathrm{g}^{-1}$ at 500 cycles.

\section{Insert Figure 25 and Figure 25 caption}

Wei et al. recently utilized a modified inverse vulcanization methodology to generate a soluble inverse vulcanized hyperbranched polymer (SIVHP) (Fig. 26) [290]. Postfunctionalization of the poly(S-r-DIB) copolymer by a thiol-ene reaction, followed by a Menschutkin click reaction afforded a water-soluble copolymer. These copolymers were then processed with graphene oxide inclusions to prepare polymeric nanocomposite active materials for Li-S batteries. The SIVHP nanocomposites were found to be superior in performance to a control sulfur/graphene composite, showing an initial capacity $>1200 \mathrm{mAh} \cdot \mathrm{g}^{-1}$ and remaining higher in capacity at 400 cycles. Additionally, the SIVHP nanocomposite was able to perform more effectively under varying rate conditions, being able to cycle at $5 \mathrm{C}\left(8360 \mathrm{~mA} \cdot \mathrm{g}^{-1}\right)$. It is foreseen that additional copolymer active materials, with facile methods of generation, will afford even greater improvements beyond those recently demonstrated with utilization of the inverse vulcanization methodology.

Insert Figure 26 and Figure 26 caption 


\subsection{High refractive index polymeric optics}

Infrared (IR) optical technology has numerous potential applications in the civil, medical, and military sectors. As all objects emit IR radiation (i.e., black body radiation) the detection of that radiation and generation of a digital thermogram with an imaging device (Fig. 27a) provides a means of observing IR emitting objects entirely without illumination (Fig. 27b). Traditional materials utilized as the optical components in IR imaging devides are base upon inorganic semiconductors (e.g., Ge, Si) and chalcogenide glasses (Fig. 27c). Such materials have been widely used for device components functioning in the mid $(3-8 \mu \mathrm{m})$ and far-IR $(8-15 \mu \mathrm{m})$ regions due to their high refractive indices $(n \sim 2.0-4.0)$ and low optical losses from 1-15 $\mu \mathrm{m}$. However, such materials are also expensive, difficult to fabricate, and toxic in comparison to organic polymers. Unfortunately, the development of polymeric materials for mid-IR optical applications has not been achieved due to challenges in designing systems with sufficiently high refractive index $(n)$ and good transparency in the IR spectral regime. Covalent bonds, such as, those between carbon and hydrogen atoms $(\mathrm{C}-\mathrm{H})$ strongly absorb in the 3-5 $\mu \mathrm{m}$ IR window, which precludes the vast majority of synthetic polymeric materials for use as an IR transmitting material. Therefore to date, high refractive index polymers have been primarily used for optical and imaging applications within the visible spectrum.

\section{Insert Figure 27 and Figure 27 caption}

High refractive index (high- $n$ ) polymers have recently been investigated due to the advantages the materials have over inorganic glasses, such as, increased impact resistance, reduced densities (i.e., lighter weight) and facile solution/melt processability. High- $n$ polymeric 
materials, whether thermoplastic or thermosetting in nature, are easily processed into lenses, prisms, and waveguides through traditional methods [291]. The majority of work in the area has been motivated by fabrication of components for device applications requiring high $n$ and high transparency in the visible spectrum. As such, the field has focused on developing novel polymeric materials for advanced optoelectronic devices such as antireflective coatings, adhesives and encapsulants for LEDs, and microlens arrays for charge coupled devices (CCD) or complementary metal oxide semiconductor (CMOS) image sensors [292]. Ueda and coworkers recently provided a broad overview of the high- $n$ polymer field and current advances to novel chemistry affording high- $n$ polymers [291, 292]. However, a brief summary herein will provide a quick perspective on purely organic materials with the highest refractive indices $(n>1.65)$.

Traditional organic polymers (i.e., poly(styrene) or poly(methyl methacrylate)) typically possess refractive indices in the range of $n=1.3-1.6$ in the visible spectrum and therefore are not amenable to the optical applications mentioned above. In order to access high- $n$ polymers, researchers have relied heavily on the use of the Lorentz-Lorenz equation as a guide to proper selection of functionality within the polymer structure [291-294]. Previous approaches to prepare high $n$ polymers incorporated functional groups with high molar refractivity and low molar volumes, such as, aromatic moieties (e.g., phenyl and naphthyl), heavy halides (e.g., bromine and iodine), and chalcogenides (e.g., sulfur and selenium). High- $n$ polymers have also been generated with nitrogen and phosphorus containing functionalities.

The introduction of sulfur containing functional groups (e.g., thioethers, thianthrenes, trithiocarbonates, or thiophene) into polymers has been extensively investigated as a means of imparting high molar refractivity. Ueda and coworkers have prepared several examples of copolymers, with varying sulfur content and facile control over the polymer structure and 
properties via the modularity afforded by polyimide chemistry (Fig. 28a) [291, 295-307]. These materials possessed high refractive indices ranging from 1.695 to 1.7692 (measured and operating at $589 \mathrm{~nm}$ ); coupled with excellent thermomechanical properties. The same researchers also investigated other high sulfur-content copolymers such as poly(thioether sulfone) (Fig. 28b) [308]; and poly(thianthrene phenylene sulfides) (Fig. 28c) [309]. The generation of the poly (thianthrene phenylene sulfides) copolymers was found be to a highly versatile and modular system for the preparation of high $n$ polymers. This class of materials possessed the highest refractive index for optically transparent polymers reported in literature $(n=1.8020$, measured and operating at $633 \mathrm{~nm}$ ). Nakano et al. demonstrated the preparation of poly(trithiocarbonate) copolymers by a coordination anionic copolymerization of propylene sulfide and carbon disulfide (Fig. 28d) [310]. The resulting copolymer had a high refractive index ( $n=1.78$, measured and operating at $589 \mathrm{~nm}$ ), but also a low $\mathrm{T}_{\mathrm{g}}\left(\mathrm{i} . \mathrm{e} ., 25^{\circ} \mathrm{C}\right.$ ) due to the high sulfur content and aliphatic backbone.

The incorporation of heteroatoms aside from sulfur has also been investigated to increase the refractive indices of polymeric materials. The inclusion of heterocyclic moieties containing $\mathrm{C}=\mathrm{N}-\mathrm{C}-$ bonds have more recently been investigated as an alternative approach to prepare high- $n$ polymers. Li et al. prepared a series of poly(phenylquinoxalines) in a modular fashion to enable optimization of the refractive index by control over copolymer structure (Fig. 28e) [311, 312]. These materials possessed refractive indices ranging from 1.6996 to 1.7953 (measured and operating at $633 \mathrm{~nm}$ ). Ueda and coworkers reported on the generation of processable, high- $n$ polymers by preparation of triazine-containing poly(phenylene sulfides) (Fig. 28f) [313, 314]. These materials have vastly improved solubility compared to traditional poly(phenylene sulfide) and possess refractive indices ranging from 1.6990 to 1.7720 (measured and operating at 633 
$\mathrm{nm})$. Allcock et al. have extensively studied the improvement of refractive indices in poly(phosphazene) polymers through variation in the side groups; showing a range of high refractive indices (1.620-1.753) (measured and operating at $550 \mathrm{~nm}$ ) (Fig. 28g) [315, 316]. Carbazole or fluorene moieties were also found to increase the refractive indices when incorporated into the backbone of poly(thioether) polymers [317], but the optical properties were even further improved upon functionalization of the ring in the polymeric structure with high molar refractivity elements (e.g., bromine and iodine) (Fig. 28h). Minns et al. prepared several functionalized carbazole rings as side-groups on a poly(methyl methacrylate) backbone to generate materials with good thermomechanical properties and high refractive indices $\left(\mathrm{n}=1.68_{-}\right.$ 1.77, measured at $589 \mathrm{~nm}$ ) [318]. Unfortunately for halide containing polymers there is concern about stability under high intensity illuminated conditions. And, although not as widely utilized in the optics field, it should also be mentioned that extensive work has been conducted on conjugated and more rigid functionality systems for preparing high- $n$ polymers [319, 320]. However, the strongly absorbing groups and bonds in all of these materials unfortunately relegates their use to visible wavelength optical devices.

\section{Insert Figure 28 and Figure 28 caption}

In addition to visible wavelength devices there are also technological opportunities to develop high refractive polymeric materials for applications functioning in the near and midinfrared (near and mid-IR) wavelengths. Such materials would complement traditional inorganic glasses; which possess very high refractive indices but are difficult to process, contain toxic materials, and are generally expensive. To date, investigation into polymeric materials

functioning at such wavelengths has not been undertaken due to the high content of IR absorbing functional groups (i.e., $\mathrm{C}-\mathrm{H}, \mathrm{C}-\mathrm{O}, \mathrm{C}=\mathrm{O},-\mathrm{OH}, \mathrm{N}=\mathrm{O}$ ) within the polymeric structures presented 
above. The IR spectral window from 3-5 microns is of particular interest for IR thermal imaging which also overlaps with the IR absorbance from $\mathrm{C}-\mathrm{H}$ bonds. Hence for the preparation of highly transparent IR transmitting polymers, the omission of widely used $\mathrm{C}-\mathrm{H}, \mathrm{C}-\mathrm{O}, \mathrm{C}-\mathrm{N}$ bonds would be required, which greatly narrows the scope of possible candidate materials.

Griebel and Pyun et al. demonstrated the use of poly(sulfur-random-1,3diisopropenylbenzene) copolymers with a high content of S-S bonds for IR imaging, since these bonds were largely inactive in the near and mid IR spectrum of interest [321]. The poly(S-r-DIB) copolymers were easily processed into several forms (i.e., thin-films and free-standing lens) and the optical properties were investigated at several wavelengths across the UV-visible-near IR optical regimes (Fig. 29). Ellipsometry measurements confirmed that control over refractive index in the material was readily accomplished by variation of the copolymer composition. Refractive index values remained above $n=1.7$ with minimal losses out to $1.550 \mu \mathrm{m}$ for poly(S$r$-DIB) compositions ranging from $50-80 \mathrm{wt} \% \mathrm{~S}_{8}$ (Fig. 29a). An attractive feature of these copolymers was the high transparency throughout large portions of the visible (500-700 nm, Fig. 29b); near-IR (1550 nm, Fig. 29c); and mid-IR (3-5 $\mu$ m, Fig. 29d) spectrum. Poly(S-r-DIB) copolymers were the first example of high refractive index polymers which possessed high optical transparency in all three regions of the electromagnetic spectrum. By comparison a traditional thermoplastic, such as, poly(methyl methacrylate) was found to be highly opaque in the mid-IR region of interest for IR thermal imaging (Fig. 29e). The easy of processing, control over refractive index, and high transparency in the mid-IR clearly demonstrated the ability to use poly(S-r-DIB) copolymers as processable, high $n$ materials for IR imaging in the near and midIR.

\section{Insert Figure 29 and Figure 29 caption}




\subsection{Stimuli-responsive polymeric systems}

Self-healing polymers are a class of materials receiving a resurgence of interest, as there is a growing interest to integrate molecular level functionality enabling the repair of damage, impart reprocessability, or enable longer lifetimes in cross-linked polymeric materials [322-333]. Stimuli-responsive polymers are materials in which there is an inherent dynamic bond incorporated into the polymer architecture (either within a side chain or the polymer backbone) that is structurally dynamic and upon exposure to stimuli (e.g. heat or light) allows for reorganization of the polymeric architecture, translating a molecular-level interaction into a macroscopic scale response. Stimuli-responsive polymers encompass two regularly recognized types of dynamic bonds: dynamic covalent bonds and non-covalent supramolecular interactions. Dynamic covalently bonded materials combine the stability of covalent bonds with the reversibility of non-covalent interactions. Likewise, reversible, non-covalent interactions in supramolecular materials afford high molecular weights and combine the properties of a typical covalent polymer with those of low molecular weight molecules. Dynamic covalent chemistries employed for self-healing materials have included disulfide exchange (Fig. 30a) [53, 334-336], radical mediated addition-fragmentation chain transfer reactions (Fig. 30b) [337-345], alkoxyamine exchange reactions (Fig. 30c) [346-349], thermoreversible Diels-Alder reactions (Fig. 30d) [350-353], and transesterification reactions (Fig. 30e) [354-357]. Supramolecular materials with self-healing capabilities have been prepared through incorporation of hydrogen bonding motifs (Fig. 30f) [358-360], $\pi-\pi$ stacking functionalities (Fig. 30g) [361-364], and metal-ion ligand interactions (Fig. 30h) [323, 326, 332, 362, 364-381].

While a variety of functionalities have been utilized to synthesize dynamic covalent polymers the investigation of polymers where the dynamic bonds constituent a majority of the 
structure $(\geq 50$-wt $\%)$ have not been intensively studied. Furthermore, the preparation of these types of dynamic covalent materials requires the explicit installation of functional moieties that enable reversible bond scission that are orthogonal to the polymerization process. Previous work by Tobolsky and coworkers on sulfur-containing poly(urethanes) provided the basis for controlling dynamic properties within the copolymer by control over the sulfur catenation [382386]. A notable and recent exception was developed by Rowan et al. on the preparation of dynamic covalent polymers based on polysulfide network that also exhibited shape memory properties [336]. Building upon this, Griebel and Pyun et al. reported on the preparation of dynamic covalent copolymers via the inverse vulcanization of $\mathrm{S}_{8}$ and DIB [134]. An attractive feature of the poly(S-r-DIB) copolymers is the ability to control sulfur rank and the S-S bond scission dynamics by simple variation in the comonomer feed ratios (Fig. 31a). The variation in sulfur rank and control over dynamic properties of the copolymer was interrogated with rheological self-healing experiments at different strain loads (Fig. 31b). Under low strain rates the materials possessed high molecular weights and a commensurately high modulus due to the intact covalent S-S bonds (Fig. 31b-1). However, upon application of a high strain, which caused S-S bond scission, the molecular weight and modulus dropped substantially (Fig. 31b-2). Once the high strain is removed the initial shear modulus was fully recovered and the material regains is pristine-state properties as the dynamic covalent bonds are reformed (Fig. 31b-3). The response of the copolymers to the high strain conditions was found to be composition dependent and the damage-heal cycling was fully reversibly for several cycles (Fig. 31b-4 and 5).

\section{Insert Figure 30 and Figure 30 caption}




\section{Insert Figure 31 and Figure 31 caption}

\subsection{Photocatalysis and semiconducting particles}

The facile and low cost generation of energy (e.g., electricity or hydrogen fuel) from renewable resources is an area receiving intense investigation in an attempt to curb the issues associated with the burning of fossil fuels for current energy production. The photocatalytic splitting of water offers a clean and environmentally friendly process to create renewable hydrogen for transportation or grid-scale energy production. A significant challenge in the production of clean hydrogen is the development of cheap and efficient visible-light-driven catalysts with photochemical and photoelectrochemical (PEC) activity for the hydrogen evolution reaction (HER) [387-391]. Recent efforts have focused on using $\mathrm{S}_{8}$ and $\mathrm{S}_{8}$ derived materials as agents to assist in either catalytic, or "sacrificial" water splitting reactions for HER, particularly in "electrodeless" methods using solar assisted processes. Poly(sulfur-random-1,3diisopropenylbenzene) copolymer has been utilized to prepare both photocatalytic nanowires for HER reactions and the synthesis of photoactive quaternary $\mathrm{Cu}_{2} \mathrm{ZnSnS}_{4}$ colloids for photovoltaic devices. Zhuo et al. recently demonstrated the use of the inverse vulcanization technique to prepare poly(S-r-DIB) copolymers within anodic aluminum oxide (AAO) templates to form free standing 1-D polymeric materials after etching of the AAO phase. These 1-D polymeric materials (along with copolymers modified by deposition of semiconductor NPs) were then cast onto an ITO electrode and demonstrated to generate a photocurrent upon UV and visible irradiation (Fig. 32) [390]. It was demonstrated that these 1-D templated copolymers were superior in photocurrent generation than bulk elemental sulfur. Additionally, the photocurrent generation was observed to depend on copolymer composition and morphology with optimal performance observed using $100 \mathrm{~nm}$ wide nanowires of poly(S-r-DIB$\left.{ }_{30}\right)$. In an additional 
seminal publication utilizing poly(S-r-DIB) copolymer, Zou et al. synthesized quaternary photoactive semi-conducting colloids $\left(\mathrm{Cu}_{2} \mathrm{ZnSnS}_{4}\right)$ by high temperature reactions between the copolymer and metal precursors (Fig. 33) [391]. It was found that because of the high reactivity of the sulfur in the poly $\left(\mathrm{S}-r-\mathrm{DIB}_{30}\right)$ copolymer that the wurtzite crystal phase of the colloids was accessible. These novel uses of the inverse vulcanization methodology and poly(S-r-DIB) copolymers continue to expand the area of sulfur research; which is ultimately necessary for further increasing the consumption of sulfur by novel materials and applications.

\section{Insert Figure 32 and Figure 32 caption}

\section{Insert Figure 33 and Figure 33 caption}

\section{Conclusions and Outlook}

In this review we have discussed the traditional production and consumption methods that contribute to an ever expanding global issue of elemental sulfur utilization and storage. We then reviewed the field of polymers and polymer synthesis which utilize elemental sulfur to generate high sulfur-content polymers; followed by a discussion of recent research that highlights additional high sulfur-content precursors to generate colloidal sulfur and novel sulfur allotropes. The reader is then provided with a brief synopsis on the limitations of sulfur utilization in chemistry, focusing on the challenges associated with the dissolution and processing of elemental sulfur. Overcoming these challenges enabled the utilization of elemental sulfur as a novel solvent and finally led to the development of the inverse vulcanization 
methodology. A thorough discussion on the high sulfur content copolymers afforded by the inverse vulcanization process highlights the novelty of the materials and sets the stage for the unique fields of research to which the material can be applied. Ultimately a discussion of new areas in which the sulfur copolymer have been utilized will provide guidance for the reader in their own investigations of sulfur chemistry and novel applications with which to begin sulfur consumption.

\section{Addendum}

Since this manuscript was under review, a number of new studies on sulfur utilization for the synthesis and application of high sulfur content polymers have reported which point to the emerging potential of this field.[392-407]

\section{Acknowledgements}

We acknowledge the NSF (CHE-1305773), the University of Arizona Renewable Energy Network, the Ventana/GIGA Summer Assistantship Award, Tech Launch Arizona, the WCU

Program through the NRF of Korea funded by the Ministry of Education, Science and Technology (R31-10013) for support of this work. KC acknowledges the support from NRF for the National Creative Research Initiative Center for Intelligent Hybrids (2010-0018290).

\section{References}

[1] Deshpande AS, Khomane RB, Vaidya BK, Joshi RM, Harle AS, Kulkarni BD. Sulfur nanoparticles synthesis and characterization from $\mathrm{H}_{2} \mathrm{~S}$ gas, using novel biodegradable iron chelates in w/o microemulsion. Nanoscale Res Lett 2008;3:221-9.

[2] Chaudhuri RG, Paria S. Synthesis of sulfur nanoparticles in aqueous surfactant solutions. J Colloid Interface Sci 2010;343:439-46.

[3] Ober JA. Materials flow of Sulfur. US Geological Survey Open File Report 02-298, 2003;1-56. 
[4] Frasch H. Mining sulphur. US 416429, 1891.

[5] Brown TL, LeMay HE, Bursten BE. Chemistry: The Central Science. 8th ed. Upper Saddle River, New Jersey: Prentice Hall, Inc, 2000. p. 950-950.

[6] Claus CF. Obtaining sulphur from hydrogen sulphide. US 349981A, 1886.

[7] Apodoca LA. Sulfur. US Geological Survey, mineral commodity summaries 2014. p. 1567.

[8] Apodoca LA. Sulfur. United States Geological Survey 2011. p. 74.1-.15.

[9] Anonymous, EPA. Reregistration eligibility document facts: Sulfur. Case 0031, Washington D.C: Environmental Protection Agency. 1991. p. 1-4.

[10] Deme I. Sulfur as an asphalt diluent and a mix filler. Adv Chem Ser 1978;165:172-89.

[11] Gillott JE, Jordaan IJ, Loov RE, Shrive NG, Ward MA. Characteristics of some sulfurbonded civil engineering materials. Adv Chem Ser 1978;165:98-112.

[12] Gregor R, Hackl A. A new approach to sulfur concrete. Adv Chem Ser 1978;165:54-78.

[13] Kennepohl GJ, Miller LJ. Sulfur-asphalt binder technology for pavements. Adv Chem Ser 1978;165:113-34.

[14] McBee WC, Sullivan TA. Sulfur utilization in asphalt paving materials. Adv Chem Ser 1978;165:135-60.

[15] Meyer B, Mulliken B. Wood-sulfur composites. Adv Chem Ser 1978;165:255-71.

[16] Paulson JE, Simic M, Campbell RW, Ankers JW. Sulfur composites as protective coatings and construction materials. Adv Chem Ser 1978;165:215-26.

[17] Chiu J. Visual observation in differential thermal analysis. Anal Chem 1963;35:933-4.

[18] Miller GW. Thermal analysis of polymers. VIII. Dilatometric and thermal optical behavior of sufur. J Appl Polym Sci 1971;15:1985-94.

[19] Currell BR, Williams AJ. Thermal analysis of elemental sulfur. Thermochim Acta 1974;9:255-9.

[20] Gee G. The molecular complexity of sulphur in the liquid and vapour. T Faraday Soc $1952 ; 48: 515-26$.

[21] Fairbrother F, Gee G, Merrall GT. The polymerization of sulfur. J Polym Sci 1955;16:459-69.

[22] Tobolsky AV. Equilibrium polymerization in the presence of an ionic intiator. J Polym Sci $1957 ; 25: 220-1$. 
[23] Klement JW. Study of the lambda transition in liquid sulfur with a differential scanning calorimeter. J Polym Sci Part B Polym Phys 1974;12:815-18.

[24] Steudel R, Passlackstephan S, Holdt G. Thermal polymerization and depolymerization reactions of 10 sulfur allotropes studied by HPLC and DSC. Z Anorg Allg Chem $1984 ; 517: 7-42$.

[25] Schenk PW. Zur kenntnis der schwefelmodifikationen Z Anorg Allg Chem 1955;280:123.

[26] Steudel R. Liquid sulfur. Top Curr Chem 2003;230:81-116.

[27] Steudel R, Strauss R, Koch L. Quantitative HPLC analysis and thermodynamic of sulfur melts. Angew Chem Int Ed 1985;24:59-60.

[28] Kennedy SJ, Wheeler JC, Osuch C, Wasserman E. Free-radical concentration in doped sulfur. Theory and experiment. J Phys Chem 1983;87:3961-6.

[29] Tobolsky AV, Macknight WJ. Polymeric sulfur and related polymers. New York: WileyInterscience, 1965. p. 16-18.

[30] Meyer B. Solid allotropes of sulfur. Chem Rev 1964;64:429-51.

[31] Meyer B. Elemental sulfur. New York: Wiley-Interscience, 1965. p. 109-124.

[32] Meyer B. Elemental sulfur. Chem Rev 1976;76:367-88.

[33] Laitinen RS, Pakkanen TA, Steudel R. Ab initio study of hypervalent sulfur hydride as model intermediates in the interconversion reactions of compounds containing sulfursulfur bonds. J Am Chem Soc 1987;109:710-4.

[34] Tobolsky AV. Polymeric sulfur and related poly.mers J Polym Sci Part C Polym Symp 1966;12:71-8.

[35] Duda A, Penczek S. Sulfur-containing polymers. In: Kroschwitz JI, editor. Encyclopedia of Polymer Science and Engineering. Vol. 16, 2nd Ed. New York: John Wiley \& Sons Inc, 1989. p. 246-368.

[36] Spassky N, Sepulchre M, Sigwalt P. Polymers containing sulfur in the main chain. In: Kricheldorf HR, editor. Handbook of Polymer Synthesis Part B. New York: Marcel Dekker, Inc.; 1992. p. 991-1076.

[37] Kausar A, Zulfiqar S, Sarwar MI. Recent developments in sulfur-containing polymers. Polym Rev 2014;54:185-267.

[38] Patrick JC, Mnookin NM. Plastic compositions. US 1890231, 1932. 
[39] Patrick JC. The formation of high polymers by condensation between metallic polysulphides and dihalogenated hydrocarbons and ethers. T Faraday Soc 1936;32:347-57.

[40] Patrick JC, Ferguson HR. Polysulfide polymer. US 2466963, Thiokol Corp, 1949.

[41] Bertozzi ER. Chemistry and technology of elastomeric polysulfide polymers. Rubber Chem Technol 1968;41:114-60.

[42] Berenbaum MB, Panek IR. Polysulfide polymers. In: Gaylord NG, editor. Polyethers, Part 3: Polyalkylene sulfides and other polythioethers. New York: Wiley-Interscience, 1962. p. 43-114.

[43] Bordoloi BK, Pearce EM. Kinetics of the base-catalyzed reactions of cyclo-octameric and catenapolymeric sulfur with dithiol. J Appl Polym Sci 1979;23:2757-61.

[44] Bordoloi BK, Pearce EM. Oliogomeric alkenyl polysulfide: Synthesis and characterization by NMR analysis. J Polym Sci Part A Polym Chem 1978;16:3293-300.

[45] Schmidt M. Sulfur-containing polymers. Inorg Macromol Rev 1970;1:101.

[46] Boscato JF, Catala JM, Clouet F, Brossas J. Synthesis of polyphenylene polysulfur. Polym Bull 1981;4:357-9.

[47] Boscato JF, Catala JM, Franta E, Brossas J. Investigations on the reaction of sulfur with carbanionic oligomers. Makromol Chem 1979;180:1571-4.

[48] Boscato JF, Catala JM, Franta E, Brossas J. Action of elementary sulfur onto carbanions: A new route to dialkylpolysulfides. Tetrahedron Lett 1980;21:1519-20.

[49] Catala JM, Boscato JF, Brossas J. Electron-transfer and nucleophilic-addition reactions of omega, omega'-dicarbanionic oligomers with elemental sulfur. J Organomet Chem 1984;276:155-60.

[50] Catala JM, Pujol JM, Brossas J. Synthesis and crosslinking of polymeric polysulfides. FR 2577932A1, Saint-Gobain Vitrage Fr, 1986.

[51] Catala JM, Pujol JM, Brossas J. New synthesis of polysulfide polymers: Kinetic study. Makromol Chem 1987;188:2517-22.

[52] Yoo J, D'Mello SR, Graf T, Salem AK, Bowden NB. Synthesis of the first poly(diaminosulfide)s and an investigation of their applications as drug delivery vehicles. Macromolecules 2012;45:688-97. 
[53] Graf TA, Yoo J, Brummett AB, Lin R, Wohgenannt M, Quinn D, Bowden NB. New polymers possessing a disulfide bond in a unique environment. Macromolecules 2012;45:8193-200.

[54] Yoo J, Kuruvilla DJ, D'Mello SR, Salem AK, Bowden NB. New class of biodegradable polymers formed from reactions of an inorganic functional group. Macromolecules 2012;45:2292-300.

[55] Currell BR, Williams AJ, Mooney AJ, Nash BJ. Plasticization of sulfur. Adv Chem Ser 1975;140:1-17.

[56] Blight L, Currell BR, Nash BJ, Scott RAM, Stillo C. Preparation and properties of modified sulfur systems. Adv Chem Ser 1978;165:13-30.

[57] Blight LB, Currell BR, Nash BJ, Scott RTM, Stillo C. Chemistry of the modification of sulfur by the use of dicyclopentadiene and of styrene. Br Polym J 1980;12:5-11.

[58] Bartlett PD, Trifan DS. Some experiments on sulfur as inhibitor for the polymerization of styrene. J Polym Sci 1956;20:457-76.

[59] Ahmed A, Blanchard LP. Copolymerization of elemental sulfur with styrene. J Appl Polym Sci 1984;29:1225-39.

[60] Kice JL. Inhibition of polymerization. II. Methyl acrylate. J Polym Sci 1956;19:123-40.

[61] Bartlett PD, Kwart H. Some inhibitors and retarders in the polymerization of liquid vinyl acetate. II. 1,3,5-Trinitrobenzene and sulfur. J Am Chem Soc 1952;74:3969-73.

[62] Krespan CG, Brasen WR. Fluorinated cyclic polysulfides and their polymers. J Org Chem 1962;27:3995-4000.

[63] Krespan CG. Fluorinated polysulfides. In: Tobolsky AV, editor. The Chemistry of Sulfides. New York: Wiley-Intersciences, 1968. p. 211-9.

[64] Krespan CG, Brasen WR, Cripps HN. Fluorinated sulfide polymers. Adv Chem Ser 1972;110:179-89.

[65] Carothers WH, Collins AM, Kirby JE. Polymerizing 2-halo-1,3-butadiene. US 1950438, EI du Pont de Nemours \& Co, 1934.

[66] Schmitt SW, Anolick C. New sulfur modified polychloroprene. Rubber Chem Technol 1978;51:888-96.

[67] Mochel WE. Structure of neoprene. V. Viscosity conversion relationships in sulfurmodified polychloroprenes. J Polym Sci 1952;8:583-92. 
[68] Klebanskii AL, Zukerman NJ, Fomina LP. Uber den deactionsmechanismus des schwefels in der polymerization der chloroprens und des thiurams in der destruktion und strukturienung der chloroprenpolymere. J Polym Sci 1958;30:363-74.

[69] Miyata Y, Sawada M. Copolymerization of chloroprene with elemental sulfur- $\mathrm{H}^{1}$ NMR study on the stereochemistry of the chloroprene unit adjacent to the sulfur unit. Polymer 1988;29:1683-8.

[70] Miyata Y, Sawada M. Copolymerization of chloroprene with elemental sulfur- $\mathrm{H}^{1}$ NMR study on the sequence length of polysulfide linkages in the copolymer. Polymer 1988;29:1495-500.

[71] Kirpichnikov PA. The syntheses and chemical reactions of some reactive oligomers. Polym Sci USSR 1979;21:2714-26 (Vysokomol Soedin Ser A 21:2457-69).

[72] Fritz H, Weis CD. 2,3,4-trithiabicyclo[4,3,1]deca-6,8-diene. Sulfuration of cycloheptatriene. Tetrahedron Lett 1974;1659-60.

[73] Farmer EH, Shipley FW. The reaction of sulphur and sulphur compounds with olefinic substances. I. The reaction of sulphur with mono-olefins and with $\Delta^{1: 5}$-diolefins. J Chem Soc 1947;1519-32.

[74] Shields TC, Kurtz AN. Active sulfuration of norbornenes. J Am Chem Soc 1969;91:54156.

[75] Emsley J, Griffiths DW. Polymerization, depolymerization and desulfurization of 1,2,3Trithiolan. Phosphorus Sulfur Silicon Relat Elem 1980;9:227-30.

[76] Emsley J, Griffiths DW, Jayne GJJ. Synthesis and spectra of polycyclic 1,2,3-trithiolans. J Chem Soc Perk T 1 1979 :228-32.

[77] Bordoloi BK, Pearce EM, Blight L, Currell BR, Merrall R, Scott RAM, Stillo C. Copolymerization of liquid sulfur with certain olefinic systems and structure-property studies on the polymeric materials. J Polym Sci Part A Polym Chem 1980;18:383-406.

[78] Bordoloi BK, Pearce EM. Plastic sulfur stabilization by copolymerization of sulfur with dicyclopentadiene. Adv Chem Ser 1978;165:31-53.

[79] Baran T, Duda A, Penczek S. Anionic-polymerization of norbornene trisulfide (exo-3,4,5trithia-tricyclo [5.2.1.0 $\left.{ }^{2.6}\right]$ decane). J Polym Sci Part A Polym Chem 1984;22:1085-95. 
[80] Baran T, Duda A, Penczek S. Anionic-polymerization of (exo-2,4,5trithiatetracyclo $\left[5 \cdot 5 \cdot 1 \cdot \mathrm{O}^{2,6} \cdot \mathrm{O}^{8,12}\right]$ tridec-10-ene (dicyclopentadiene trisulfide). Makromol Chem 1984;185:2337-46.

[81] Duda A, Penczek S. Anionic copolymerization of elemental sulfur with propylene sulfide. Macromolecules 1982;15:36-40.

[82] Duda A, Penczek S. Anionic copolymerization of elemental sulfur with 2,2dimethylthiirane. Makromol Chem 1980;181:995-1001.

[83] Duda A, Szymanski R, Penczek S. Anionic copolymerization of elemental sulfur with propylene sulfide. Equilibrium sulfur concentration. J Macromol Sci Chem 1983;A20:967-78.

[84] Penczek S, Slazak R. Copolymers of elementary sulfur. PL 78934A5, Centrum Badan Molekularnych i Makromolekularnych, 1975.

[85] Penczek S, Duda A. Anionic copolymerization of elemental sulfur. Pure Appl Chem 1981;53:1679-87.

[86] Penczek S, Slazak R, Duda A. Anionic copolymerization of elemental sulfur. Nature 1978;273:738-9.

[87] Penczek S. Anionic Copolymerization of Elemental Sulfur. PhD Thesis. Lodz Poland: Polish Academy of Sciences, 1984.

[88] Schmidt M, Weissflog E. Copolymerization of tetrameric thioformaldehyde with oligomeric thioformaldehydes, subsituted analogs, or sulfur. Angew Chem Int Ed 1978;17:51-2.

[89] Weissflog E, Schmidt M. Synthesis and properties of some polymeric compounds, formed from six membered and eight membered rings. Z Anorg Allg Chem 1978;445:175-83.

[90] Anonymous. Polymerizable compositions containing sulfur and a thione. FR 1450603, Dunlop Co Ltd, 1966.

[91] Steudel R. Aqueous sulfur sols. Top Curr Chem 2003;230:153-66.

[92] Lawson GB. The inhibitory action of sulphur on the growth of tubercle bacilli. Am Rev Tuberc 1934;29:650-1.

[93] Weld JT, Gunther A. The antibacterial properties of sulfur. J Exp Med 1947;85:531-42.

[94] Woiwod AJ. The inhibition of bacterial growth by colloidal heavy-metal sulphides and by colloidal sulphur. J Gen Microbiol 1954;10:509-20. 
[95] Libenson L, Hadley FP, McIlroy AP, Wetzel VM, Mellon RR. Antibacterial effect of elemental sulfur. J Infect Dis 1953;93:28-35.

[96] Massey AB, Snider GE. Inhibitory action of colloidal sulphur in Corper's agar on the growth of four strains of Mycobacterium Tuberculosis Hominis. Am J Public Health Nations Health 1936;26:811-2.

[97] Schneider T, Baldauf A, Ba LA, Jamier V, Khairan K, Sarakbi MB, Reum N, Schneider M, Roeseler A, Becker K, Burkholz T, Winyard PG, Kelkel M, Diederich M, Jacob C. Selective antimicrobial activity associated with sulfur nanoparticles. J Biomed Nanotechnol 2011;7:395-405.

[98] Choudhury SR, Ghosh M, Mandal A, Chakravorty D, Pal M, Pradhan S, Goswami A. Surface-modified sulfur nanoparticles: an effective antifungal agent against Aspergillus niger and Fusarium oxysporum. Appl Microbiol Biotechnol 2011;90:733-43.

[99] Choudhury SR, Roy S, Goswami A, Basu S. Polyethylene glycol-stabilized sulphur nanoparticles: an effective antimicrobial agent against multidrug-resistant bacteria. J Antimicrob Chemother 2012;67:1134-7.

[100] Choudhury SR, Ghosh M, Goswami A. Inhibitory effects of sulfur nanoparticles on membrane lipids of Aspergillus niger: A novel route of Fungistasis. Curr Microbiol 2012;65:91-7.

[101] Choudhury SR, Mandal A, Ghosh M, Basu S, Chakravorty D, Goswami A. Investigation of antimicrobial physiology of orthorhombic and monoclinic nanoallotropes of sulfur at the interface of transcriptome and metabolome. Appl Microbiol Biotechnol 2013;97:596578.

[102] Choudhury SR, Goswami A. Supramolecular reactive sulphur nanoparticles: a novel and efficient antimicrobial agent. J Appl Microbiol 2013;114:1-10.

[103] Choudhury SR, Basu A, Nag T, Sengupta K, Bhowmik M, Goswami A. Expedition of in vitro dissolution and in vivo pharmacokinetic profiling of sulfur nanoparticles based antimicrobials. Environ Toxicol Pharmacol 2013;36:675-9.

[104] Choudhury SR, Mandal A, Chakravorty D, Gopal M, Goswami A. Evaluation of physicochemical properties, and antimicrobial efficacy of monoclinic sulfur-nanocolloid. J Nanopart Res 2013;15:1-11. 
[105] Choudhury SR, Dey KK, Bera S, Goswami A. Colloidal stability and coagulation kinetics study of different sized sulphur nanoparticles. J Exp Nanosci 2013;8:267-72.

[106] Wang JL, Yang J, Xie JY, Xu NX. A novel conductive polymer-sulfur composite cathode material for rechargeable lithium batteries. Adv Mater 2002;14:963-5.

[107] Wang JL, Yang J, Wan CR, Du K, Xie JY, Xu NX. Sulfur composite cathode materials for rechargeable lithium batteries. Adv Funct Mater 2003;13:487-92.

[108] Fanous J, Wegner M, Grimminger J, Andresen A, Buchmeiser MR. Structure-related electrochemistry of sulfur-poly(acrylonitrile) composite cathode materials for rechargeable lithium batteries. Chem Mater 2011;23:5024-8.

[109] Yu XG, Xie JY, Yang J, Huang HJ, Wang K, Wen ZS. Lithium storage in conductive sulfur-containing polymers. J Electroanal Chem 2004;573:121-8.

[110] Wang L, He X, Li J, Gao J, Guo J, Jiang C, Wan C. Analysis of the synthesis process of sulphur-poly(acrylonitrile)-based cathode materials for lithium batteries. J Mater Chem 2012;22:22077-81.

[111] Yin L, Wang J, Lin F, Yang J, Nuli Y. Polyacrylonitrile/graphene composite as a precursor to a sulfur-based cathode material for high-rate rechargeable Li-S batteries. Energy Environ Sci 2012;5:6966-72.

[112] Steudel R. The chemistry of organic polysulfanes $R-S_{n}-R(n>2)$. Chem Rev 2002;102:3905-45.

[113] Eckert B, Steudel R. Molecular spectra of sulfur molecules and solid sulfur allotropes. Top Curr Chem 2003;231:31-98.

[114] Steudel R, Eckert B. Solid sulfur allotropes. Top Curr Chem 2003;230:1-80.

[115] Steudel R. Inorganic polysulfanes $\mathrm{H}_{2} \mathrm{~S}_{\mathrm{n}}$ with $\mathrm{n}>1$. Top Curr Chem 2003;231:99-125.

[116] Steudel R. Homocyclic sulfur molecules. Top Curr Chem 1982;102:149-76.

[117] Steudel R. Inorganic polysulfides $\mathrm{S}_{\mathrm{n}}{ }^{2-}$ and radical anions $\mathrm{S}_{\mathrm{n}}{ }^{--}$. Top Curr Chem 2003;231:127-52.

[118] Steudel R. Sulfur-rich oxides $\mathrm{S}_{\mathrm{n}} \mathrm{O}$ and $\mathrm{S}_{\mathrm{n}} \mathrm{O}_{2}(\mathrm{n}>1)$. Top Curr Chem 2003;231:203-30.

[119] Steudel R, Schumann O, Buschmann J, Luger P. A new allotrope of elemental sulfur: Convenient preparation of cyclo-S ${ }_{14}$ from $\mathrm{S}_{8}$. Angew Chem Int Ed 1998;37:2377-8.

[120] Steudel R, Strauss R. Convenient preparation of cyclo-eicosasulphur $\left(\mathrm{S}_{20}\right)$ from bis $(\eta-$ cyclopentadienyl)(pentasulphido)titanium (IV). J Chem Soc Dalton Trans 1984;1775-7. 
[121] Steudel R, Kustos M, Munchow V, Westphal U. Novel titanocene thiolato complexes and their application in preparing new sulfur-containing heterocycles. Chem Ber Recl 1997; 130:757-64.

[122] Steudel R, Hassenberg K, Munchow V, Schumann O, Pickardt J. Preparation of organic polysulfanes $\mathrm{R}_{2} \mathrm{~S}_{\mathrm{n}}(\mathrm{n}=5,7,8,9)$ from sulfenyl chlorides, $\mathrm{RSCl}$, and transition metal polysulfido complexes. Eur J Inorg Chem 2000;921-8.

[123] Ding Y, Hay AS. Cyclic aromatic disulfide oligomers: Synthesis and characterization. Macromolecules 1996;29:6386-92.

[124] Ding Y, Hay AS. Novel synthesis of poly(p-phenylene sulfide) from cyclic disulfide oligomers. Macromolecules 1996;29:4811-2.

[125] Ding Y, Hay AS. Copolymerization of elemental sulfur with cyclic(arylene disulfide) oligomers. J Polym Sci Part A Polym Chem 1997;35:2961-8.

[126] Ding Y, Hay AS. Preparation of poly(thioarylene)s from cyclic disulfide oligomers. Macromolecules 1997;30:2527-31.

[127] Ding Y, Hay AS. Ring-opening polymerization study of cyclic (aromatic disulfide) oligomers derived from 4,4'-isopropylidene bisthiophenol. Polymer 1997;38:2239-44.

[128] Boros E, Earle MJ, Gilea MA, Metlen A, Mudring AV, Rieger F, Robertson AJ, Seddon KR, Tomaszowska AA, Trusov L, Vyle JS. On the dissolution of non-metallic solid elements (sulfur, selenium, tellurium and phosphorus) in ionic liquids. Chem Commun 2010;46:716-8.

[129] Donaldson A, Caplin AD. Refractive index of molten sulfur. Philos Mag B 1985;52:18597.

[130] Chung WJ, Simmonds AG, Griebel JJ, Kim ET, Suh HS, Shim IB, Glass RS, Loy DA, Theato P, Sung YE, Char K, Pyun J. Elemental sulfur as a reactive medium for gold nanoparticles and nanocomposite materials. Angew Chem Int Ed 2011;50:11409-12.

[131] Kim ET, Chung WJ, Lim J, Johe P, Glass RS, Pyun J, Char K. One-pot synthesis of PbS $\mathrm{NP} /$ sulfur-oleylamine copolymer nanocomposites via the copolymerization of elemental sulfur with oleylamine. Polym Chem 2014;5:3617-23.

[132] Wang K, Groom M, Sheridan R, Zhang S, Block E. Liquid sulfur as a reagent: synthesis of polysulfanes with 20 or more sulfur atoms with characterization by UPLC-( $\left.\mathrm{Ag}^{+}\right)$coordination ion spray-MS. J Sulfur Chem 2013;34:55-66. 
[133] Chung WJ, Griebel JJ, Kim ET, Yoon H, Simmonds AG, Ji HJ, Dirlam PT, Glass RS, Wie JJ, Nguyen NA, Guralnick BW, Park J, Somogyi A, Theato P, Mackay ME, Sung YE, Char K, Pyun J. The use of elemental sulfur as an alternative feedstock for polymeric materials. Nat Chem 2013;5:518-24.

[134] Griebel JJ, Nguyen NA, Astashkin AV, Glass RS, Mackay ME, Char K, Pyun J. Preparation of dynamic covalent polymers via inverse vulcanization of elemental sulfur. ACS Macro Lett 2014;3:1258-61.

[135] Odian G. Principles of polymerization. 4th ed. Hoboken NJ: John Wiley \& Sons Inc, 2004;282-289.

[136] Dirlam PT, Simmonds AG, Kleine TS, Nguyen NA, Anderson LE, Klever AO, Florian A, Costanzo PJ, Theato P, Mackay ME, Glass RS, Char K, Pyun J. Inverse vulcanization of elemental sulfur with 1,4-diphenylbutadiyne for cathode materials in Li-S batteries. RSC Adv 2015;5:24718-22.

[137] Dirlam PT, Simmonds AG, Shallcross RC, Arrington KJ, Chung WJ, Griebel JJ, Hill LJ, Glass RS, Char K, Pyun J. Improving the charge conductance of elemental sulfur via tandem inverse vulcanization and electropolymerization. ACS Macro Lett 2015;4:111-4.

[138] Moss V, Nole DA. The use of sulfur and sulfur-containing compounds in energy conversion devices. Top Sulfur Chem 1977;4:63-99.

[139] Rao MLB. Organic electrolyte cells. US 3413154A, PR Mallory and Co Inc, 1968.

[140] Cairns EJ, Shimotak H. High-temperature batteries. Science 1969;164:1347-55.

[141] Manthiram A, Fu Y, Chung SH, Zu C, Su YS. Rechargeable lithium-sulfur batteries. Chem Rev 2014;114:11751-87.

[142] Rauh RD, Abraham KM, Pearson GF, Surprenant JK, Brummer SB. A lithium/dissolved sulfur battery with an organic electrolyte. J Electrochem Soc 1979;126:523-7.

[143] Yamin H, Peled E. Electrochemistry of a nonaqueous lithium/sulfur cell. J Power Sources $1983 ; 9: 281-7$.

[144] Simmonds AG, Griebel JJ, Park J, Kim KR, Chung WJ, Oleshko VP, Kim J, Kim ET, Glass RS, Soles CL, Sung YE, Char K, Pyun J. Inverse vulcanization of elemental sulfur to prepare polymeric electrode materials for Li-S batteries. ACS Macro Lett 2014;3:22932. 
[145] Shim J, Striebel KA, Cairns EJ. The lithium/sulfur rechargeable cell - Effects of electrode composition and solvent on cell performance. J Electrochem Soc 2002;149:A1321-A5.

[146] Akridge JR, Mikhaylik YV, White N. Li/S fundamental chemistry and application to highperformance rechargeable batteries. Solid State Ionics 2004;175:243-5.

[147] Mikhaylik YV, Akridge JR. Polysulfide shuttle study in the Li/S battery system. J Electrochem Soc 2004;151:A1969-A76.

[148] Mikhaylik YV. Electrolytes for lithium sulfur batteries. US 20050147891-A1, Moltech Corp, Sion Power Corporation, 2005.

[149] Bresser D, Passerini S, Scrosati B. Recent progress and remaining challenges in sulfurbased lithium secondary batteries - a review. Chem Commun 2013;49:10545-62.

[150] Ji XL, Nazar LF. Advances in Li-S batteries. J Mater Chem 2010;20:9821-6.

[151] Evers S, Nazar LF. New approaches for high energy density lithium-sulfur battery cathodes. Acc Chem Res 2013;46:1135-43.

[152] Manthiram A, Fu Y, Su YS. Challenges and prospects of lithium-sulfur batteries. Acc Chem Res 2013;46:1125-34.

[153] Yin YX, Xin S, Guo YG, Wan LJ. Lithium-sulfur batteries: Electrochemistry, materials, and prospects. Angew Chem Int Ed 2013;52:13186-200.

[154] Lin Z, Liang C. Lithium-sulfur batteries: From liquid to solid cells. J Mater Chem A 2015;3:936-58.

[155] Xu G, Ding B, Pan J, Nie P, Shen L, Zhang X. High performance lithium-sulfur batteries: advances and challenges. J Mater Chem A 2014;2:12662-76.

[156] Song MK, Cairns EJ, Zhang Y. Lithium/sulfur batteries with high specific energy: old challenges and new opportunities. Nanoscale 2013;5:2186-204.

[157] Chen R, Zhao T, Wu F. From a historic review to horizons beyond: lithium-sulphur batteries run on the wheels. Chem Commun 2015;51:18-33.

[158] Wang JL, Yang J, Xie JY, Xu NX, Li Y. Sulfur-carbon nano-composite as cathode for rechargeable lithium battery based on gel electrolyte. Electrochem Commun 2002;4:499502.

[159] Wang JL, Liu L, Ling ZJ, Yang J, Wan CR, Jiang CY. Polymer lithium cells with sulfur composites as cathode materials. Electrochim Acta 2003;48:1861-7. 
[160] Zhang B, Lai C, Zhou Z, Gao XP. Preparation and electrochemical properties of sulfuracetylene black composites as cathode materials. Electrochim Acta 2009;54:3708-13.

[161] Su YS, Manthiram A. A facile in situ sulfur deposition route to obtain carbon-wrapped sulfur composite cathodes for lithium-sulfur batteries. Electrochim Acta 2012;77:272-8.

[162] Chung SH, Manthiram A. Low-cost, porous carbon current collector with high sulfur loading for lithium-sulfur batteries. Electrochem Commun 2014;38:91-5.

[163] Manthiram A, Su YS. Conductive polymer-coated and shaped sulfur-nanocomposite cathodes for rechargeable lithium-sulfur batteries and manufacture of cathodes thereof. US 20130164625-A1, The University of Texas System, 2013.

[164] Wang C, Chen JJ, Shi YN, Zheng MS, Dong QF Preparation and performance of a coreshell carbon/sulfur material for lithium/sulfur battery. Electrochim Acta 2010;55:7010-5.

[165] Ye H, Yin YX, Xin S, Guo YG. Tuning the porous structure of carbon hosts for loading sulfur toward long lifespan cathode materials for Li-S batteries. J Mater Chem A 2013;1:6602-8.

[166] Zhang B, Qin X, Li GR, Gao XP. Enhancement of long stability of sulfur cathode by encapsulating sulfur into micropores of carbon spheres. Energy Environ Sci 2010;3:15317.

[167] Xin S, Gu L, Zhao NH, Yin YX, Zhou LJ, Guo YG, Wan LJ. Smaller sulfur molecules promise better lithium-sulfur batteries. J Am Chem Soc 2012;134:18510-3.

[168] Ji X, Lee KT, Nazar LF. A highly ordered nanostructured carbon-sulphur cathode for lithium-sulphur batteries. Nat Mater 2009;8:500-6.

[169] Chen SR, Zhai YP, Xu GL, Jiang YX, Zhao DY, Li JT, Huang L, Sun SG. Ordered mesoporous carbon/sulfur nanocomposite of high performances as cathode for lithiumsulfur battery. Electrochim Acta 2011;56:9549-55.

[170] Wei S, Zhang H, Huang Y, Wang W, Xia Y, Yu Z. Pig bone derived hierarchical porous carbon and its enhanced cycling performance of lithium-sulfur batteries. Energy Environ Sci 2011;4:736-40.

[171] He G, Ji X, Nazar L. High "C" rate Li-S cathodes: sulfur imbibed bimodal porous carbons. Energy Environ Sci 2011;4:2878-83. 
[172] Schuster J, He G, Mandlmeier B, Yim T, Lee KT, Bein T, Nazar LF. Spherical ordered mesoporous carbon nanoparticles with high porosity for lithium-sulfur batteries. Angew Chem Int Ed 2012;51:3591-5.

[173] Ding B, Yuan C, Shen L, Xu G, Nie P, Zhang X. Encapsulating sulfur into hierarchically ordered porous carbon as a high-performance cathode for lithium-sulfur batteries. Chem Eur J 2013;19:1013-9.

[174] Xi K, Cao S, Peng X, Ducati C, Kumar RV, Cheetham AK. Carbon with hierarchical pores from carbonized metal-organic frameworks for lithium sulphur batteries. Chem Commun 2013;49:2192-4.

[175] Liang CD, Dudney NJ, Howe JY. Hierarchically structured sulfur/carbon nanocomposite material for high-energy lithium battery. Chem Mater 2009;21:4724-30.

[176] Li Z, Jiang Y, Yuan L, Yi Z, Wu C, Liu Y, Strasser P, Huang Y. A highly ordered meso@microporous carbon-supported sulfur@smaller sulfur core-shell structured cathode for Li-S batteries. ACS Nano 2014;8:9295-303.

[177] Li D, Han F, Wang S, Cheng F, Sun Q, Li WC. High sulfur loading cathodes fabricated using peapodlike, large pore volume mesoporous carbon for lithium-sulfur battery. ACS Appl Mater Interfaces 2013;5:2208-13.

[178] Tao X, Chen X, Xia Y, Huang H, Gan Y, Wu R, Chen F, Zhang W. Highly mesoporous carbon foams synthesized by a facile, cost-effective and template-free Pechini method for advanced lithium-sulfur batteries. J Mater Chem A 2013;1:3295-301.

[179] Strubel P, Thieme S, Biemelt T, Helmer A, Oschatz M, Brueckner J, Althues H, Kaskel S. $\mathrm{ZnO}$ hard templating for synthesis of hierarchical porous carbons with tailored porosity and high performance in lithium-sulfur battery. Adv Funct Mater 2015;25:287-97.

[180] Hart CJ, Cuisinier M, Liang X, Kundu D, Garsuch A. Rational design of sulphur host materials for Li-S batteries: correlating lithium polysulphide adsorptivity and selfdischarge capacity loss. Chem Commun 2014;51:2308-11.

[181] Demir-Cakan R, Morcrette M, Nouar F, Davoisne C, Devic T, Gonbeau D, Dominko R, Serre C, Ferey G, Tarascon JM. Cathode composites for Li-S Batteries via the use of oxygenated porous architectures. J Am Chem Soc 2011;133:16154-60.

[182] Ji X, Evers S, Black R, Nazar LF. Stabilizing lithium-sulphur cathodes using polysulphide reservoirs. Nat Commun 2011;2:325-31. 
[183] Evers S, Yim T, Nazar LF. Understanding the nature of absorption/adsorption in nanoporous polysulfide sorbents for the Li-S battery. J Phys Chem C 2012;116:19653-8.

[184] Pang Q, Kundu D, Cuisinier M, Nazar LF. Surface-enhanced redox chemistry of polysulphides on a metallic and polar host for lithium-sulphur batteries. Nat Commun 2014;5:4759-66.

[185] Li X, Cao Y, Qi W, Saraf LV, Xiao J, Nie Z, Mietek J, Zhang JG, Schwenzer B, Liu J. Optimization of mesoporous carbon structures for lithium-sulfur battery applications. J Mater Chem 2011;21:16603-10.

[186] Su YS, Fu YZ, Manthiram A. Self-weaving sulfur-carbon composite cathodes for high rate lithium-sulfur batteries. Phys Chem Chem Phys 2012;14:14495-9.

[187] Guo J, Xu Y, Wang C. Sulfur-impregnated disordered carbon nanotubes cathode for lithium-sulfur batteries. Nano Lett 2011;11:4288-94.

[188] Han SC, Song MS, Lee H, Kim HS, Ahn HJ, Lee JY. Effect of multiwalled carbon nanotubes on electrochemical properties of lithium sulfur rechargeable batteries. $\mathrm{J}$ Electrochem Soc 2003;150:A889-A93.

[189] Yuan L, Yuan H, Qiu X, Chen L, Zhu W. Improvement of cycle property of sulfur-coated multi-walled carbon nanotubes composite cathode for lithium/sulfur batteries. J Power Sources 2009;189:1141-6.

[190] Chen JJ, Jia X, She QJ, Wang C, Zhang Q, Zheng MS, Dong QF. The preparation of nano-sulfur/MWCNTs and its electrochemical performance. Electrochim Acta 2010;55:8062-6.

[191] Wei W, Wang J, Zhou L, Yang J, Schumann B, NuLi Y. CNT enhanced sulfur composite cathode material for high rate lithium battery. Electrochem Commun 2011;13:399-402.

[192] Kim DJ, Park JW, Kim JS, Cho KK, Kim KW, Ahn JH, Jo MK, Choi HJ, Bae DH, Ahn HJ. The electrochemical properties of lithium/sulfur cell using sulfur-carbon nanotubes composite. J Nanosci Nanotechnol 2011;11:484-8.

[193] Chen JJ, Zhang Q, Shi YN, Qin LL, Cao Y, Zheng MS, Dong QF. A hierarchical architecture S/MWCNT nanomicrosphere with large pores for lithium sulfur batteries. Phys Chem Chem Phys 2012;14:5376-82. 
[194] Dörfler S, Hagen M, Althues H, Tuebke J, Kaskel S, Hoffmann MJ. High capacity vertical aligned carbon nanotube/sulfur composite cathodes for lithium-sulfur batteries. Chem Commun 2012;48:4097-9.

[195] Zhao MQ, Peng HJ, Tian GL, Zhang Q, Huang JQ, Cheng XB, Tang C, Wei F. Hierarchical vine-tree-like carbon nanotube architectures: In-Situ CVD self-assembly and their use as robust scaffolds for lithium-sulfur batteries. Adv Mater 2014;26:7051-8.

[196] Zheng G, Yang Y, Cha JJ, Hong SS, Cui Y. Hollow carbon nanofiber-encapsulated sulfur cathodes for high specific capacity rechargeable lithium batteries. Nano Lett 2011;11:4462-7.

[197] Yao H, Zheng G, Li W, McDowell MT, Seh Z, Liu N, Lu Z, Cui Y. Crab shells as sustainable templates from nature for nanostructured battery electrodes. Nano Lett 2013;13:3385-90.

[198] Zheng G, Zhang Q, Cha JJ, Yang Y, Li W, Seh ZW, Cui Y. Amphiphilic surface modification of hollow carbon nanofibers for improved cycle life of lithium sulfur batteries. Nano Lett 2013;13:1265-70.

[199] Hagen M, Doerfler S, Althues H, Tuebke J, Hoffmann MJ, Kaskel S, Pinkwart K. Lithium-sulphur batteries - binder free carbon nanotubes electrode examined with various electrolytes. J Power Sources 2012;213:239-48.

[200] Zhou G, Wang DW, Li F, Hou PX, Yin L, Liu C, Lu GQ, Gentle IR, Cheng HM. A flexible nanostructured sulphur-carbon nanotube cathode with high rate performance for Li-S batteries. Energy Environ Sci 2012;5:8901-6.

[201] Jin K, Zhou X, Zhang L, Xin X, Wan G, Liu Z. Sulfur/carbon nanotube composite film as a flexible cathode for lithium-sulfur batteries. J Phys Chem C 2013;117:21112-9.

[202] Ji LW, Rao MM, Aloni S, Wang L, Cairns EJ, Zhang YG. Porous carbon nanofiber-sulfur composite electrodes for lithium/sulfur cells. Energy Environ Sci 2011;4:5053-9.

[203] Rao M, Song X, Liao H, Cairns EJ. Carbon nanofiber-sulfur composite cathode materials with different binders for secondary Li/S cells. Electrochim Acta 2012;65:228-33.

[204] Li Q, Zhang Z, Guo Z, Zhang K, Lai Y, Li J. Coaxial-cable structure composite cathode material with high sulfur loading for high performance lithium-sulfur batteries. J Power Sources 2015;274:338-44. 
[205] Zhang Z, Li Q, Zhang K, Lai Y, Li J. Micro-nano structure composite cathode material with high sulfur loading for advanced lithium-sulfur batteries. Electrochim Acta 2015;152:53-60.

[206] Li Q, Zhang Z, Guo Z, Lai Y, Zhang K, Li J. Improved cyclability of lithium-sulfur battery cathode using encapsulated sulfur in hollow carbon nanofiber@nitrogen-doped porous carbon core-shell composite. Carbon 2014;78:1-9.

[207] Liang X, Wen ZY, Liu Y, Wang XY, Zhang H, Wu MF, Huang LZ. Preparation and characterization of sulfur-polypyrrole composites with controlled morphology as high capacity cathode for lithium batteries. Solid State Ionics 2011;192:347-50.

[208] Liang X, Liu Y, Wen ZY, Huang LZ, Wang XY, Zhang H. A nano-structured and highly ordered polypyrrole-sulfur cathode for lithium-sulfur batteries. J Power Sources 2011;196:6951-5.

[209] Sun M, Zhang S, Jiang T, Zhang L, Yu J. Nano-wire networks of sulfur-polypyrrole composite cathode materials for rechargeable lithium batteries. Electrochem Commun 2008;10:1819-22.

[210] Rao M, Song X, Cairns EJ. Nano-carbon/sulfur composite cathode materials with carbon nanofiber as electrical conductor for advanced secondary lithium/sulfur cells. J Power Sources 2012;205:474-8.

[211] Xiao L, Cao Y, Xiao J, Schwenzer B, Engelhard MH, Saraf LV, Nie Z, Exarhos GJ, Liu J. A soft approach to encapsulate sulfur: Polyaniline nanotubes for lithium-sulfur batteries with long cycle life. Adv Mater 2012;24:1176-81.

[212] Xiao L, Cao Y, Xiao J, Schwenzer B, Engelhard MH, Saraf LV, Nie Z, Exarhos GJ, Liu J. Molecular structures of polymer/sulfur composites for lithium-sulfur batteries with long cycle life. J Mater Chem A 2013;1:9517-26.

[213] Jayaprakash N, Shen J, Moganty SS, Corona A, Archer LA. Porous hollow carbon@sulfur composites for high-power lithium-sulfur batteries. Angew Chem Int Ed 2011;50:5904-8

[214] Xin S, Yin YX, Wan LJ, Guo YG. Encapsulation of sulfur in a hollow porous carbon substrate for superior Li-S batteries with long lifespan. Part Part Syst Char 2013;30:321-5.

[215] Zhang C, Wu HB, Yuan C, Guo Z, Lou XW. Confining sulfur in double-shelled hollow carbon spheres for lithium-sulfur batteries. Angew Chem Int Ed 2012;51:9592-5. 
[216] Brun N, Sakaushi K, Yu L, Giebeler L, Eckert J, Titirici MM. Hydrothermal carbon-based nanostructured hollow spheres as electrode materials for high-power lithium-sulfur batteries. Phys Chem Chem Phys 2013;15:6080-7.

[217] Brun N, Sakaushi K, Eckert J, Titirici MM. Carbohydrate-derived nanoarchitectures: On a synergistic effect toward an improved performance in lithium sulfur batteries. ACS Sustain Chem Eng 2014;2:126-9.

[218] Zhang K, Zhao Q, Tao Z, Chen J. Composite of sulfur impregnated in porous hollow carbon spheres as the cathode of Li-S batteries with high performance. Nano Res 2013;6:38-46.

[219] Peng HJ, Liang J, Zhu L, Huang JQ, Cheng XB, Guo X, Ding W, Zhu W, Zhang Q. Catalytic self-limited assembly at hard templates: A mesoscale approach to graphene nanoshells for lithium-sulfur batteries. ACS Nano 2014;8:11280-9.

[220] Zhou W, Xiao X, Cai M, Yang L. Polydopamine-coated, nitrogen-doped, hollow carbon sulfur double-layered core-shell structure for improving lithium sulfur satteries. Nano Lett 2014;14:5250-6.

[221] Lamer VK, Barnes MD. Monodispersed hydrophobic colloidal dispersions and light scattering properties. 1. Preparation and light scattering properties of monodispersed colloidal sulfur. J Colloid Sci 1946;1:71-7.

[222] Wang J, Chen J, Konstantinov K, Zhao L, Ng SH, Wang GX, Guo ZP, Liu HK. Sulphurpolypyrrole composite positive electrode materials for rechargeable lithium batteries. Electrochim Acta 2006;51:4634-8.

[223] Fu Y, Manthiram A. Core-shell structured sulfur-polypyrrole composite cathodes for lithium-sulfur batteries. RSC Adv 2012;2:5927-9.

[224] Fu YZ, Manthiram A. Orthorhombic bipyramidal sulfur coated with polypyrrole nanolayers as a cathode material for lithium-sulfur batteries. J Phys Chem C 2012;116:8910-5.

[225] Wang C, Wan W, Chen JT, Zhou HH, Zhang XX, Yuan LX, Huang YH. Dual core-shell structured sulfur cathode composite synthesized by a one-pot route for lithium sulfur batteries. J Mater Chem A 2013;1:1716-23. 
[226] Wu F, Chen J, Chen R, Wu S, Li L, Chen S, Zhao T. Sulfur/polythiophene with a core/shell structure: synthesis and electrochemical properties of the cathode for rechargeable lithium batteries. J Phys Chem C 2011;115:6057-63.

[227] Wu F, Wu S, Chen R, Chen J, Chen S. Sulfur-polythiophene composite cathode materials for rechargeable lithium batteries. Electrochem Solid St 2010;13:A29-A31.

[228] Yang Y, Yu G, Cha JJ, Wu H, Vosgueritchian M, Yao Y, Bao Z, Cui Y. Improving the performance of lithium-sulfur batteries by conductive polymer coating. ACS Nano 2011;5:9187-93.

[229] Chen H, Dong W, Ge J, Wang C, Wu X, Lu W, Chen L. Ultrafine sulfur nanoparticles in conducting polymer shell as cathode materials for high performance lithium/sulfur batteries. Sci Rep 2013;3:1-6.

[230] Li W, Zheng G, Yang Y, Seh ZW, Liu N, Cui Y. High-performance hollow sulfur nanostructured battery cathode through a scalable, room temperature, one-step, bottom-up approach. Proc Natl Acad Sci USA 2013;110:7148-53.

[231] Zhou W, Yu Y, Chen H, DiSalvo FJ, Abruna HD. Yolk-shell structure of polyanilinecoated sulfur for lithium-sulfur batteries. J Am Chem Soc 2013;135:16736-43.

[232] Seh ZW, Li W, Cha JJ, Zheng G, Yang Y, McDowell MT, Hsu PC, Cui Y. Sulphur-TiO yolk-shell nanoarchitecture with internal void space for long-cycle lithium-sulphur batteries. Nat Commun 2013;4:1331-8.

[233] Wang JZ, Lu L, Choucair M, Stride JA, Xu X, Liu HK. Sulfur-graphene composite for rechargeable lithium batteries. J Power Sources 2011;196:7030-4.

[234] Cao YL, Li XL, Aksay IA, Lemmon J, Nie ZM, Yang ZG, Liu J. Sandwich-type functionalized graphene sheet-sulfur nanocomposite for rechargeable lithium batteries. Phys Chem Chem Phys 2011;13:7660-5.

[235] Zhang FF, Zhang XB, Dong YH, Wang LM. Facile and effective synthesis of reduced graphene oxide encapsulated sulfur via oil/water system for high performance lithium sulfur cells. J Mater Chem 2012;22:11452-4.

[236] Ji L, Rao M, Zheng H, Zhang L, Li Y, Duan W, Guo J, Cairns EJ, Zhang Y. Graphene oxide as a sulfur immobilizer in high performance lithium/sulfur cells. J Am Chem Soc 2011;133:18522-5. 
[237] Li N, Zheng M, Lu H, Hu Z, Shen C, Chang X, Ji G, Cao J, Shi Y. High-rate lithiumsulfur batteries promoted by reduced graphene oxide coating. Chem Commun 2012;48:4106-8.

[238] Liu S, Xie K, Li Y, Chen Z, Hong X, Zhou L, Yuan J, Zheng C. Graphene oxide wrapped hierarchical porous carbon-sulfur composite cathode with enhanced cycling and rate performance for lithium sulfur batteries. RSC Adv 2015;5:5516-22.

[239] Liu Y, Guo J, Zhang J, Su Q, Du G. Graphene-wrapped sulfur nanospheres with ultra-high sulfur loading for high energy density lithium-sulfur batteries. Appl Surf Sci 2015;324:399-404.

[240] Tang C, Zhang Q, Zhao MQ, Huang JQ, Cheng XB, Tian GL, Peng HJ, Wei F. Nitrogendoped aligned carbon nanotube/graphene sandwiches: Facile catalytic growth on bifunctional natural catalysts and their applications as scaffolds for high-rate lithiumsulfur batteries. Adv Mater 2014;26:6100-5.

[241] He G, Hart CJ, Liang X, Garsuch A, Nazar LF. Stable cycling of a scalable grapheneencapsulated nanocomposite for lithium-sulfur batteries. ACS Appl Mater Interfaces 2014;6:10917-23.

[242] Xu J, Shui J, Wang J, Wang M, Liu HK, Dou SX, Jeon IY, Seo JM, Baek JB, Dai L. Sulfur-graphene nanostructured cathodes via ball-milling for high-performance lithium sulfur batteries. ACS Nano 2014;8:10920-30.

[243] Evers S, Nazar LF. Graphene-enveloped sulfur in a one pot reaction: a cathode with good coulombic efficiency and high practical sulfur content. Chem Commun 2012;48:1233-5.

[244] Zu C, Manthiram A. Hydroxylated graphene-sulfur nanocomposites for high-rate lithiumsulfur batteries. Adv Energy Mater 2013;3:1008-12.

[245] Sun H, Xu GL, Xu YF, Sun SG, Zhang X, Qiu Y, Yang S. A composite material of uniformly dispersed sulfur on reduced graphene oxide: Aqueous one-pot synthesis, characterization and excellent performance as the cathode in rechargeable lithium-sulfur batteries. Nano Res 2012;5:726-38.

[246] Xu H, Deng Y, Shi Z, Qian Y, Meng Y, Chen G. Graphene-encapsulated sulfur (GES) composites with a core-shell structure as superior cathode materials for lithium-sulfur batteries. J Mater Chem A 2013;1:15142-9. 
[247] Lu S, Cheng Y, Wu X, Liu J. Significantly improved long-cycle stability in high-rate Li-S batteries enabled by coaxial graphene wrapping over sulfur-coated carbon nanofibers. Nano Lett 2013;13:2485-9.

[248] Wang H, Yang Y, Liang Y, Robinson JT, Li Y, Jackson A, Cui Y, Dai H. Graphenewrapped sulfur particles as a rechargeable lithium-sulfur battery cathode material with high capacity and cycling stability. Nano Lett 2011;11:2644-7.

[249] Qiu Y, Li W, Li G, Hou Y, Zhou L, Li H, Liu M, Ye F, Yang X, Zhang Y. Polyanilinemodified cetyltrimethylammonium bromide-graphene oxide-sulfur nanocomposites with enhanced performance for lithium-sulfur batteries. Nano Res 2014;7:1355-63.

[250] Zhou W, Chen H, Yu Y, Wang D, Cui Z, DiSalvo FJ, Abruna HD. Amylopectin wrapped graphene oxide/sulfur for improved cyclability of lithium-sulfur battery. ACS Nano 2013;7:8801-8.

[251] Song MK, Zhang Y, Cairns EJ. A long-life, high-rate lithium/sulfur cell: A multifaceted approach to enhancing cell performance. Nano Lett 2013;13:5891-9.

[252] Huang X, Sun B, Li K, Chen S, Wang G. Mesoporous graphene paper immobilised sulfur as a flexible electrode for lithium-sulfur batteries. J Mater Chem A 2013;1:13484-9.

[253] Jin J, Wen Z, Ma G, Lu Y, Cui Y, Wu M, Liang X, Wu X. Flexible self-supporting graphene-sulfur paper for lithium sulfur batteries. RSC Adv 2013;3:2558-60.

[254] Liu ML, Visco SJ, Dejonghe LC. Novel solid redox polymerization electrodes - All-solidstate, thin-film, rechargeable lithium batteries. J Electrochem Soc 1991;138:1891-5.

[255] Liu ML, Visco SJ, Dejonghe LC. Novel solid redox polymerization electrodes Electrochemical properties. J Electrochem Soc 1991;138:1896-901.

[256] Visco SJ, Mailhe CC, Dejonghe LC, Armand MB. A novel class of organosulfur electrodes for energy storage J Electrochem Soc 1989;136:661-4.

[257] Doeff MM, Lerner MM, Visco SJ, Dejonghe LC. The use of polysulfides and copolymer disulfides in the Li/PEO/SPRE battery system J Electrochem Soc 1992;139:2077-81.

[258] Doeff MM, Visco SJ, Dejonghe LC. Thin-film rechargeable room-temperature batteries using solid redox polymerization electrodes J Electrochem Soc 1992;139:1808-12.

[259] Doeff MM, Visco SJ, Dejonghe LC. The use of redox polymerization electrodes in lithium batteries with liquid electrolytes J Appl Electrochem 1992;22:307-9. 
[260] Kaminaga A, Tatsuma T, Sotomura T, Oyama N. Reactivation and reduction of electrochemically inactivated polyaniline by 2,5-dimercapto-1,3,4-thiadiazole J Electrochem Soc 1995;142:L47-L9.

[261] Oyama N. Development of polymer-based lithium secondary battery. Macromol Symp 2000;159:221-7.

[262] Oyama N, Hatozaki O. Lithium polymer battery with high energy density. Macromol Symp 2000;156:171-8.

[263] Oyama N, Naoi K, Sotomura T, Uemachi H, Sato Y, Kanbara T, Takeyama K. Reversible disulfide group-containing electrode material, its preparation, and use as cathode in secondary lithium batteries. EP 497308-A, Matsushita Electric Industrial Co Ltd Japan, 1992.

[264] Oyama N, Tatsuma T, Sato T, Sotomura T. Dimercaptan-polyaniline composite electrodes for lithium batteries with high-energy density. Nature 1995;373:598-600.

[265] Oyama N, Tatsuma T, Sotomura T. Disulfide-polyaniline composite cathodes for rechargeable batteries with high energy density. Macromol Symp 1996;105:85-90.

[266] Sotomura T, Tatsuma T, Oyama N. An organosulfur polymer cathode with a high current capability for rechargeable batteries. J Electrochem Soc 1996;143:3152-7.

[267] Sotomura T, Uemachi H, Miyamoto Y, Kaminaga A, Oyama N. Lithium polymer secondary cell using disulfide-polyaniline composite cathode and gel electrolyte. Denki Kagaku 1993;61:1366-72.

[268] Sotomura T, Uemachi H, Takeyama K, Naoi K, Oyama N. New organodisulfide polyaniline composite cathode for secondary lithium battery. Electrochim Acta 1992;37:1851-4.

[269] Tatsuma T, Sotomura T, Sato T, Buttry DA, Oyama N. Dimercaptan-polyaniline cathodes for lithium batteries: Addition of a polypyrrole derivative for rapid charging. $\mathrm{J}$ Electrochem Soc 1995;142:L182-L4.

[270] Nishide H, Iwasa S, Pu YJ, Suga T, Nakahara K, Satoh M. Organic radical battery: nitroxide polymers as a cathode-active material. Electrochim Acta 2004;50:827-31.

[271] Nishide H, Suga T, Tada K. Active mass layers for secondary batteries, and method and coating solution for forming the layers. JP 2007184227-A, Waseda University Japan; Toyo Gosei Co Ltd, 2007. 
[272] Nishide H, Suga T, Tada K. Crosslinked norbornene copolymers and their manufacture. JP 2007070384-A, Waseda University Japan; Toyo Gosei Co Ltd, 2007.

[273] Oyaizu K, Suga T, Yoshimura K, Nishide H. Synthesis and characterization of radicalbearing polyethers as an electrode-active material for organic secondary batteries. Macromolecules 2008;41:6646-52.

[274] Suga T, Konishi H, Nishide H. Photocrosslinked nitroxide polymer cathode-active materials for application in an organic-based paper battery. Chem Commun 2007;1730-2.

[275] Suga T, Ohshiro H, Sugita S, Oyaizu K, Nishide H. Emerging N-type redox-active radical polymer for a totally organic polymer-based rechargeable battery. Adv Mater 2009;21:1627-30.

[276] Suga T, Pu YJ, Kasatori S, Nishide H. Cathode and anode active poly(nitroxylstyrene)s for rechargeable batteries: $p$ - and n-type redox switching via substituent effects. Macromolecules 2007;40:3167-73.

[277] Jaehnert T, Haeupler B, Janoschka T, Hager MD, Schubert US. Polymers based on stable phenoxyl radicals for the use in organic radical batteries. Macromol Rapid Commun 2014;35:882-7.

[278] Gracia R, Mecerreyes D. Polymers with redox properties: materials for batteries, biosensors and more. Polym Chem 2013;4:2206-14.

[279] Jeon JW, O'Neal J, Shao L, Lutkenhaus JL. Charge storage in polymer acid-doped polyaniline-based layer-by-layer electrodes. ACS Appl Mater Interfaces 2013;5:10127-36.

[280] Mike JF, Shao L, Jeon JW, Lutkenhaus JL. Charge storage in decyl- and 3,6,9trioxadecyl-substituted poly(dithieno 3,2-b:2,3-d pyrrole) electrodes. Macromolecules 2014;47:79-88.

[281] Shao L, Jeon JW, Lutkenhaus JL. Polyaniline/vanadium pentoxide layer-by-Layer electrodes for energy storage. Chem Mater 2012;24:181-9.

[282] Shao L, Jeon JW, Lutkenhaus JL. Porous polyaniline nanofiber/vanadium pentoxide layerby-layer electrodes for energy storage. J Mater Chem A 2013;1:7648-56.

[283] Liu K, Zheng J, Zhong G, Yang Y. Poly(2,5-dihydroxy-1,4-benzoquinonyl sulfide) (PDBS) as a cathode material for lithium ion batteries. J Mater Chem 2011;21:4125-31. 
[284] Jeon JW, Ma Y, Mike JF, Shao L, Balbuena PB, Lutkenhaus JL. Oxidatively stable polyaniline:polyacid electrodes for electrochemical energy storage. Phys Chem Chem Phys 2013;15:9654-62.

[285] Trofimov BA, Parshina L, Gusarova N, Ivanova N, Myachina G, Kovalev I, Skotheim T. Sulfur-rich copolymers of sulfur with 5-vinylbicyclo[2.2.1] hept-2-ene and tricyclo[5.2.1.0.2.6]deca-3,8-diene as prospective cathode materials for lithium cells. Sulfur Lett 2002;25:219-27.

[286] Trofal'kina AG, Dorofeev IA, Myachina GF, Rodionova IV, Vakul'skaya TI, Sinegovskaya LM, Skotheim TA. Ethynedithiol oligomers as cathode components of lithium-sulfur batteries. Dokl Chem 2007;414:125-7.

[287] Trofimov BA, Myachina GF, Rodionova IV, Mal'kina AG, Dorofeev IA, Vakul'skaya TI, Sinegovskaya LM, Skotheim TA. Ethynedithiol-based polyeneoligosulfides as active cathode materials for lithium-sulfur batteries. J Appl Polym Sci 2008;107:784-7.

[288] Griebel JJ, Li G, Glass RS, Char K, Pyun J. Kilogram scale inverse vulcanization of elemental sulfur to prepare high capacity polymer electrodes for Li-S batteries. J Polym Sci Part A Polym Chem 2015;53:173-7.

[289] Sun Z, Xiao M, Wang S, Han D, Song S, Chen G, Meng Y. Sulfur-rich polymeric materials with semi-interpenetrating network structure as a novel lithium-sulfur cathode. J Mater Chem A 2014;2:9280-6.

[290] Wei Y, Li X, Xu Z, Sun H, Zheng Y, Peng L, Liu Z, Gao C, Gao M. Solution processible hyperbranched inverse-vulcanized polymers as new cathode materials in Li-S batteries. Polym Chem 2015;6:973-82.

[291] Liu JG, Ueda M. High refractive index polymers: Fundamental research and practical applications. J Mater Chem 2009;19:8907-19.

[292] Higashihara T, Ueda M. Recent progress in high refractive Index Polymers. Macromolecules 2015;48:1915-29.

[293] Lorenz L. Ueber die refractionsconstante. Ann Phys 1880;247:70-103.

[294] Lorentz HA. Ueber die beziehung zwischen der fortpflanzungsgeschwindigkeit des lichtes und der körperdichte. Annalen der Physik 1880;245:641-65. 
[295] Liu JG, Nakamura Y, Shibasaki Y, Ando S, Ueda M. Synthesis and characterization of highly refractive polyimides from 4,4 '-thiobis [(p-phenylenesulfanyl)aniline] and various aromatic tetracarboxylic dianhydrides. J Polym Sci Part A Polym Chem 2007;45:5606-17.

[296] Liu JG, Nakamura Y, Shibasaki Y, Ando S, Ueda M. High refractive index polyimides derived from 2,7-bis(4-aminophenylenesulfanyl)thianthrene and aromatic dianhydrides. Macromolecules 2007;40:4614-20.

[297] Liu JG, Nakamura Y, Suzuki Y, Shibasaki Y, Ando S, Ueda M. Highly refractive and transparent polyimides derived from 4,4'- m-sulfonylbis(phenylenesulfanyl) diphthalic anhydride and various sulfur-containing aromatic diamines. Macromolecules 2007;40:7902-9.

[298] Liu JG, Nakamura Y, Shibasaki Y, Ando S, Ueda M. Synthesis and characterization of high refractive index polyimides derived from 4,4'-(p-phenylenedisulfanyl)dianiline and various aromatic tetracarboxylic dianhydrides. Polym J 2007;39:543-50.

[299] Suzuki Y, Liu JG, Nakamura Y, Shibasaki Y, Ando S, Ueda M. Synthesis of highly refractive and transparent polyimides derived from 4,4 '- p-sulfonylbis(phenylenesulfanyl) diphthalic anhydride and various sulfur-containing aromatic diamines. Polym J 2008;40:414-20.

[300] Terraza CA, Liu JG, Nakamura Y, Shibasaki Y, Ando S, Ueda M. Synthesis and properties of highly refractive polyimides derived from fluorene-bridged sulfur-containing dianhydrides and diamines. J Polym Sci Part A Polym Chem 2008;46:1510-20.

[301] Liu JG, Nakamura Y, Terraza CA, Shibasaki Y, Ando S, Ueda M. Highly refractive polyimides derived from 2,8-bis(p-aminophenylenesulfanyl) dibenzothiophene and aromatic dianhydrides. Macromol Chem Phys 2008;209:195-203.

[302] You NH, Suzuki Y, Yorifuji D, Ando S, Ueda M. Synthesis of high refractive index polyimides derived from 1,6-bis(p-aminophenylsulfanyl)-3,4,8,9-tetrahydro-2,5,7,10tetrathiaanth racene and aromatic dianhydrides. Macromolecules 2008;41:6361-6.

[303] You NH, Suzuki Y, Higashihara T, Ando S, Ueda M. Synthesis and characterization of highly refractive polyimides derived from 2,7-bis(4 '-aminophenylenesulfanyl)thianthrene5,5,10,10-tetraoxide and aromatic dianhydrides. Polymer 2009;50:789-95.

[304] You NH, Nakamura Y, Suzuki Y, Higashihara T, Ando S, Ueda M. Synthesis of highly refractive polyimides derived from 3,6-bis(4-aminophenylenesulfanyl)pyridazine and 4,6- 
bis(4-aminophenylenesulfanyl)pyrimidine. J Polym Sci Part A Polym Chem 2009;47:4886-94.

[305] You NH, Higashihara T, Ando S, Ueda M. Highly refractive polymer resin derived from sulfur-containing aromatic acrylate. J Polym Sci Part A Polym Chem 2010;48:2604-9.

[306] Nakagawa Y, Ogura T, Higashihara T, Ueda M. Optically transparent sulfur-containing semi-alicyclic polyimide with high refractive index. Chem Lett 2010;39:392-3.

[307] Fukuzaki N, Higashihara T, Ando S, Ueda M. Synthesis and characterization of highly refractive polyimides derived from thiophene-containing aromatic diamines and aromatic dianhydrides. Macromolecules 2010;43:1836-43.

[308] Okutsu R, Suzuki Y, Ando S, Ueda M. Poly(thioether sulfone) with high refractive index and high Abbe's number. Macromolecules 2008;41:6165-8.

[309] Suzuki Y, Murakami K, Ando S, Higashihara T, Ueda M. Synthesis and characterization of thianthrene-based poly(phenylene sulfide)s with high refractive index over 1.8. J Mater Chem 2011;21:15727-31.

[310] Nakano K, Tatsumi G, Nozaki K. Synthesis of sulfur-rich polymers: Copolymerization of episulfide with carbon disulfide by using PPN Cl/(salph)Cr(III)Cl system. J Am Chem Soc 2007;129:15116-7.

[311] Li C, Li Z, Liu JG, Zhao XJ, Yang HX, Yang SY. Synthesis and characterization of organo-soluble thioether-bridged polyphenylquinoxalines with ultra-high refractive indices and low birefringences. Polymer 2010;51:3851-8.

[312] Li C, Li Z, Liu JG, Yang HX, Yang SY. Multi-methyl-substituted polyphenylquinoxalines with high solubility and high glass transition temperatures: Synthesis and characterization. J Macromol Sc Part A 2010;47:248-53.

[313] You NH, Higashihara T, Oishi Y, Ando S, Ueda M. Highly refractive-poly(phenylene thioether) containing triazine unit. Macromolecules 2010;43:4613-5.

[314] Nakagawa Y, Suzuki Y, Higashihara T, Ando S, Ueda M. Synthesis of highly refractive poly(phenylene thioether) derived from 2,4-dichloro-6-alkylthio-1,3,5-triazines and aromatic dithiols. Macromolecules 2011;44:9180-6.

[315] Olshavsky MA, Allcock HR. Polyphosphazenes with high refractive indices: Synthesis, characterization, and optical properties. Macromolecules 1995;28:6188-97. 
[316] Olshavsky M, Allcock HR. Polyphosphazenes with high refractive indices: Optical dispersion and molar refractivity. Macromolecules 1997;30:4179-83.

[317] Seesukphronrarak S, Kawasaki S, Kobori K, Takata T. Synthesis of fluorene-based high performance polymers. I. Poly(arylene thioether)s with excellent solubility and high refractive index. J Polym Sci Part A Polym Chem 2007;45:3073-82.

[318] Minns RA, Gaudiana RA. Design and synthesis of high refractive-index polymers. II J Macromol Sci Pure 1992;29:19-30.

[319] Yang CJ, Jenekhe SA. Effects of structure on refractive index of conjugated polyimines. Chem Mater 1994;6:196-203.

[320] Yang CJ, Jenekhe SA. Group contribution to molar refraction and refractive index of conjugated polymers. Chem Mater 1995;7:1276-85.

[321] Griebel JJ, Namnabat S, Kim ET, Himmelhuber R, Moronta DH, Chung WJ, Simmonds AG, Kim KJ, van der Laan J, Nguyen NA, Dereniak EL, Mackay ME, Char K, Glass RS, Norwood RA, Pyun J. New infrared transmitting material via inverse vulcanization of elemental sulfur to prepare high refractive index polymers. Adv Mater 2014;26:3014-8.

[322] Kloxin CJ. Reversible covalent bond formation as a strategy for healable polymer networks. In: Hayes W, Greenland BW, editors. Healable Polymer Systems. Cambridge, United Kingdom: RSC Publishing; 2013. p. 62-87.

[323] Fox JD, Rowan SJ. Supramolecular polymerizations and main-chain supramolecular polymers. Macromolecules 2009;42:6823-35.

[324] Greenland BW, Fiore GL, Rowan SJ, Weder C. Healable supramolecular polymeric materials. In: Hayes W, Greenland BW, editor. Healable Polymer Systems. Cambridge, United Kingdom: RSC Publishing, 2013. p. 92-121.

[325] Rowan SJ, Cantrill SJ, Cousins GRL, Sanders JKM, Stoddart JF. Dynamic covalent chemistry. Angew Chem Int Ed 2002;41:898-952.

[326] Burnworth M, Tang L, Kumpfer JR, Duncan AJ, Beyer FL, Fiore GL, Rowan SJ, Weder C. Optically healable supramolecular polymers. Nature 2011;472:334-8.

[327] Wojtecki RJ, Meador MA, Rowan SJ. Using the dynamic bond to access macroscopically responsive structurally dynamic polymers. Nat Mater 2011;10:14-27.

[328] Fiore GL, Rowan SJ, Weder C. Optically healable polymers. Chem Soc Rev 2013;42:7278-88. 
[329] Kloxin CJ, Scott TF, Adzima BJ, Bowman CN. Covalent adaptable networks (CANS): A Unique paradigm in cross-linked polymers. Macromolecules 2010;43:2643-53.

[330] Maeda T, Otsuka H, Takahara A. Dynamic covalent polymers: Reorganizable polymers with dynamic covalent bonds. Prog Polym Sci 2009;34:581-604.

[331] Bowman CN, Kloxin CJ. Covalent adaptable networks: Reversible bond structures incorporated in polymer networks. Angew Chem Int Ed 2012;51:4272-4.

[332] Buerkle LE, Rowan SJ. Supramolecular gels formed from multi-component low molecular weight species. Chem Soc Rev 2012;41:6089-102.

[333] Roy D, Cambre JN, Sumerlin BS. Future perspectives and recent advances in stimuliresponsive materials. Prog Polym Sci 2010;35:278-301.

[334] Otsuka H, Nagano S, Kobashi Y, Maeda T, Takahara A. A dynamic covalent polymer driven by disulfide metathesis under photoirradiation. Chem Commun 2010;46:1150-2.

[335] Yoon JA, Kamada J, Koynov K, Mohin J, Nicolay R, Zhang Y, Balazs AC, Kowalewski T, Matyjaszewski K. Self-healing polymer films based on thiol-disulfide exchange reactions and self-healing kinetics measured using atomic force microscopy. Macromolecules 2012;45:142-9.

[336] Michal BT, Jaye CA, Spencer EJ, Rowan SJ. Inherently photohealable and thermal shapememory polydisulfide networks. ACS Macro Lett 2013;2:694-9.

[337] Scott TF, Schneider AD, Cook WD, Bowman CN. Photoinduced plasticity in cross-linked polymers. Science 2005;308:1615-7.

[338] Park HY, Kloxin CJ, Scott TF, Bowman CN. Stress relaxation by addition-fragmentation chain transfer in highly cross-linked thiol-ynenetworks. Macromolecules 2010;43:1018890.

[339] Amamoto Y, Kamada J, Otsuka H, Takahara A, Matyjaszewski K. Polymers through reshuffling of trithiocarbonate units. Angew Chem Int Ed 2011;50:1660-3.

[340] Amamoto Y, Otsuka H, Takahara A, Matyjaszewski K. Self-healing of covalently crosslinked polymers by reshuffling thiuram disulfide moieties in air under visible light. Adv Mater 2012;24:3975-80.

[341] Nicolay R, Kamada J, Van Wassen A, Matyjaszewski K. Responsive gels based on a dynamic covalent trithiocarbonate cross-linker. Macromolecules 2010;43:4355-61. 
[342] Scott TF, Draughon RB, Bowman CN. Actuation in crosslinked polymers via photoinduced stress relaxation. Adv Mater 2006;18:2128-32.

[343] Park HY, Kloxin CJ, Fordney MF, Bowman CN. Stress reduction and $\mathrm{T}_{\mathrm{g}}$ enhancement in ternary thiol-yne-methacrylate systems via addition-fragmentation chain transfer. Macromolecules 2012;45:5647-52.

[344] Park HY, Kloxin CJ, Abuelyaman AS, Oxman JD, Bowman CN. Stress relaxation via addition-fragmentation chain transfer in high $\mathrm{T}_{\mathrm{g}}$, high conversion methacrylate-based systems. Macromolecules 2012;45:5640-6.

[345] Kloxin CJ, Scott TF, Bowman CN. Stress relaxation via addition-fragmentation chain transfer in a thiol-ene photopolymerization. Macromolecules 2009;42:2551-6.

[346] Amamoto Y, Kikuchi M, Masunaga H, Sasaki S, Otsuka H, Takahara A. Reorganizable chemical polymer gels based on dynamic covalent exchange and controlled monomer insertion. Macromolecules 2009;42:8733-8.

[347] Su J, Amamoto Y, Nishihara M, Takahara A, Otsuka H. Reversible cross-linking of hydrophilic dynamic covalent polymers with radically exchangeable alkoxyamines in aqueous media. Polym Chem 2011;2:2021-6.

[348] Otsuka H, Aotani K, Higaki Y, Takahara A. Polymer scrambling: Macromolecular radical crossover reaction between the main chains of alkoxyamine-based dynamic covalent polymers. J Am Chem Soc 2003;125:4064-5.

[349] Telitel S, Amamoto Y, Poly J, Morlet-Savary F, Soppera O, Lalevee J, Matyjaszewski K. Introduction of self-healing properties into covalent polymer networks via the photodissociation of alkoxyamine junctions. Polym Chem 2014;5:921-30.

[350] Chen XX, Dam MA, Ono K, Mal A, Shen HB, Nutt SR, Sheran K, Wudl F. A thermally re-mendable cross-linked polymeric material. Science 2002;295:1698-702.

[351] Chen XX, Wudl F, Mal AK, Shen HB, Nutt SR. New thermally remendable highly crosslinked polymeric materials. Macromolecules 2003;36:1802-7.

[352] Amato DN, Strange GA, Swanson JP, Chavez AD, Roy SE, Varney KL, Machado CA, Amato DV, Costanzo PJ. Synthesis and evaluation of thermally-responsive coatings based upon Diels-Alder chemistry and renewable materials. Polym Chem 2014;5:69-76. 
[353] Thongsomboon W, Sherwood M, Arellano N, Nelson A. Thermally induced nanoimprinting of biodegradable polycarbonates using dynamic covalent cross-links. ACS Macro Lett 2013;2:19-22.

[354] Cordier P, Tournilhac F, Soulie-Ziakovic C, Leibler L. Self-healing and thermoreversible rubber from supramolecular assembly. Nature 2008;451:977-80.

[355] Montarnal D, Capelot M, Tournilhac F, Leibler L. Silica-like malleable materials from permanent organic networks. Science 2011;334:965-8.

[356] Capelot M, Montarnal D, Tournilhac F, Leibler L. Metal-catalyzed transesterification for healing and assembling of thermosets. J Am Chem Soc 2012;134:7664-7.

[357] Bapat AP, Roy D, Ray JG, Savin DA, Sumerlin BS. Dynamic-covalent macromolecular stars with boronic ester linkages. J Am Chem Soc 2011;133:19832-8.

[358] Kautz H, van Beek DJM, Sijbesma RP, Meijer EW. Cooperative end-to-end and lateral hydrogen-bonding motifs in supramolecular thermoplastic elastomers. Macromolecules 2006;39:4265-7.

[359] Sivakova S, Bohnsack DA, Mackay ME, Suwanmala P, Rowan SJ. Utilization of a combination of weak hydrogen-bonding interactions and phase segregation to yield highly thermosensitive supramolecular polymers. J Am Chem Soc 2005;127:18202-11.

[360] Li G, Wie JJ, Nguyen NA, Chung WJ, Kim ET, Char K, Mackay ME, Pyun J. Synthesis, self-assembly and reversible healing of supramolecular perfluoropolyethers. J Polym Sci Part A Polym Chem 2013;51:3598-606.

[361] Burattini S, Colquhoun HM, Fox JD, Friedmann D, Greenland BW, Harris PJF, Hayes W, Mackay ME, Rowan SJ. A self-repairing, supramolecular polymer system: healability as a consequence of donor-acceptor pi-pi stacking interactions. Chem Commun 2009;6717-9.

[362] Fox J, Wie JJ, Greenland BW, Burattini S, Hayes W, Colquhoun HM, Mackay ME, Rowan SJ. High-strength, healable, supramolecular polymer nanocomposites. J Am Chem Soc 2012;134:5362-8.

[363] Burattini S, Greenland BW, Merino DH, Weng W, Seppala J, Colquhoun HM, Hayes W, Mackay ME, Hamley IW, Rowan SJ. A healable supramolecular polymer blend based on aromatic pi-pi stacking and hydrogen-bonding Interactions. J Am Chem Soc 2010;132:12051-8. 
[364] Burattini S, Greenland BW, Hayes W, Mackay ME, Rowan SJ, Colquhoun HM. A supramolecular polymer based on tweezer-type pi-pi Stacking interactions: Molecular design for healability and enhanced toughness. Chem Mater 2011;23:6-8.

[365] Beck JB, Rowan SJ. Multistimuli, multiresponsive metallo-supramolecular polymers. J Am Chem Soc 2003;125:13922-3.

[366] Zhao YQ, Beck JB, Rowan SJ, Jamieson AM. Rheological behavior of shear-responsive metallo-supramolecular gels. Macromolecules 2004;37:3529-31.

[367] Beck JB, Ineman JM, Rowan SJ. Metal/ligand-induced formation of metallosupramolecular polymers. Macromolecules 2005;38:5060-8.

[368] Iyer PK, Beck JB, Weder C, Rowan SJ. Synthesis and optical properties of metallosupramolecular polymers. Chem Commun 2005;319-21.

[369] Rowan SJ, Beck JB. Metal-ligand induced supramolecular polymerization: A route to responsive materials. Faraday Discuss 2005;128:43-53.

[370] Weng W, Beck JB, Jamieson AM, Rowan SJ. Understanding the mechanism of gelation and stimuli-responsive nature of a class of metallo-supramolecular gels. J Am Chem Soc 2006;128:11663-72.

[371] Knapton D, Iyer PK, Rowan SJ, Weder C. Synthesis and properties of metallosupramolecular poly(p-xylylene)s. Macromolecules 2006;39:4069-75.

[372] Knapton D, Rowan SJ, Weder C. Synthesis and properties of metallo-supramolecular poly(p-phenylene ethynylene)s. Macromolecules 2006;39:651-7.

[373] Weng W, Li Z, Jamieson AM, Rowan SJ. Control of gel morphology and properties of a class of metallo-supramolecular polymers by good/poor solvent environments. Macromolecules 2009;42:236-46.

[374] Weng W, Li Z, Jamieson AM, Rowan SJ. Effect of monomer structure on the gelation of a class of metallo-supramolecular polymers. Soft Matter 2009;5:4647-57.

[375] Kumpfer JR, Jin J, Rowan SJ. Stimuli-responsive europium-containing metallosupramolecular polymers. J Mater Chem 2010;20:145-51.

[376] McKenzie BM, Wojtecki RJ, Burke KA, Zhang C, Jakli A, Mather PT, Rowan SJ. Metallo-responsive liquid crystalline monomers and polymers. Chem Mater $2011 ; 23: 3525-33$. 
[377] Fiore GL, Rowan SJ, Weder C. Light-activated healing of metallosupramolecular polymers. Chimia 2011;65:745.

[378] Miller AK, Li Z, Streletzky KA, Jamieson AM, Rowan SJ. Redox-induced polymerisation/depolymerisation of metallo-supramolecular polymers. Polym Chem 2012;3:3132-8.

[379] Kumpfer JR, Wie JJ, Swanson JP, Beyer FL, Mackay ME, Rowan SJ. Influence of metal Ion and polymer core on the melt rheology of metallosupramolecular films. Macromolecules 2012;45:473-80.

[380] Kumpfer JR, Rowan SJ. Directed self-assembly of metallosupramolecular polymers at the polymer-polymer interface. ACS Macro Lett 2012;1:882-7.

[381] Burnworth M, Rowan SJ, Weder C. Structure-property relationships in metallosupramolecular poly(p-xylylene)s. Macromolecules 2012;45:126-32.

[382] Tobolsky AV, Beevers RB, Owen GDT. Vicsoelastic properties of crosslinked poly(ethylene tetrasulfide). J Colloid Sci 1963;18:353-8.

[383] Tobolsky AV, Owen GDT, Beevers RB. Vicsoelastic properties of crosslinked poly(ethylene tetrasulfide). J Colloid Sci 1963;18:359-69.

[384] Owen GDT, Macknight WJ, Tobolsky AV. Urethane elastomers containing disulfide and tetrasulfide linkages. J Phys Chem 1964;68:784-6.

[385] Tobolsky AV, Takahashi M, Macknight WJ. Relaxation of disulfide and tetrasulfide polymers. J Phys Chem 1964;68:787-90.

[386] Kende I, Pickerin Tl, Tobolsky AV. Dissociation energy of tetrasulfide linkage. J Am Chem Soc 1965;87:5582-6.

[387] Gust D, Moore TA, Moore AL. Molecular mimicry of photosynthetic energy and electrontransfer. Acc Chem Res 1993;26:198-205.

[388] Meyer TJ. Catalysis - The art of splitting water. Nature 2008;451:778-9.

[389] McKone JR, Lewis NS, Gray HB. Will solar-driven water-splitting devices see the light of day? Chem Mater 2014;26:407-14.

[390] Zhuo S, Huang Y, Liu C, Wang H, Zhang B. Sulfur copolymer nanowires with enhanced visible-light photoresponse. Chem Commun 2014;50:11208-10.

[391] Zou Y, Su X, Jiang J. Phase-controlled synthesis of $\mathrm{Cu}_{2} \mathrm{ZnSnS}_{4}$ nanocrystals: The Role of reactivity between Zn and S. J Am Chem Soc 2013;135:18377-84. 
[392] Bear JC, Peveler WJ, McNaughter PD, Parkin IP, O'Brien P, Dunnill CW. Nanoparticlesulphur "inverse vulcanization" polymer composites. Chem Commun 2015;51:10467-70.

[393] Ding B, Chang Z, Xu G, Nie P, Wang J, Pan J, Dou H, Zhang X. Nanospace-Confinement Copolymerization Strategy for Encapsulating Polymeric Sulfur into Porous Carbon for Lithium-Sulfur Batteries. ACS Appl Mater Interfaces 2015;7:11165-71.

[394] Griebel JJ, Nguyen NA, Namnabat S, Anderson LE, Glass RS, Norwood RA, MacKay ME, Char K, Pyun J. Dynamic Covalent Polymers via Inverse Vulcanization of Elemental Sulfur for Healable Infrared Optical Materials. ACS Macro Lett 2015;4:862-6.

[395] Kim H, Lee J, Ahn H, Kim O, Park MJ. Synthesis of three-dimensionally interconnected sulfur-rich polymers for cathode materials of high-rate lithium-sulfur batteries. Nat Commun 2015;6:7278.

[396] Kim JH, Kim T, Jeong YC, Lee K, Park KT, Yang SJ, Park CR. Stabilization of Insoluble Discharge Products by Facile Aniline Modification for High Performance Li-S Batteries. Adv Energy Mater 2015;DOI: 10.1002/aenm.201500268.

[397] Li W, Wu X, Zhao Z, Qin A, Hu R, Tang BZ. Catalyst-Free, Atom-Economic, Multicomponent Polymerizations of Aromatic Diynes, Elemental Sulfur, and Aliphatic Diamines toward Luminescent Polythioamides. Macromolecules 2015;48:7747-54.

[398] Lim J, Jung U, Joe WT, Kim ET, Pyun J, Char K. High Sulfur Content Polymer Nanoparticles Obtained from Interfacial Polymerization of Sodium Polysulfide and 1,2,3Trichloropropane in Water. Macromol Rapid Commun 2015;36:1103-7.

[399] Liu P, Gardner JM, Kloo L. Solution processable, cross-linked sulfur polymers as solid electrolytes in dye-sensitized solar cells. Chem Commun 2015;51:14660-2.

[400] Martin TR, Mazzio KA, Hillhouse HW, Luscombe CK. Sulfur copolymer for the direct synthesis of ligand-free CdS nanoparticles. Chem Commun 2015;51:11244-7.

[401] Oleshko VP, Kim J, Schaefer JL, Hudson SD, Soles CL, Simmonds AG, Griebel JJ, Glass RS, Char K, Pyun J. Structural origins of enhanced capacity retention in novel copolymerized sulfur-based composite cathodes for high-energy density Li-S batteries. MRS Commun 2015;5:353-64.

[402] Oschmann B, Park J, Kim C, Char K, Sung YE, Zentel R. Copolymerization of Polythiophene and Sulfur To Improve the Electrochemical Performance in Lithium-Sulfur Batteries. Chem Mater 2015;27:7011-7. 
[403] Yu S, Kwon H, Noh HR, Park BI, Park NK, Choi HJ, Choi SC, Kim GD. Preparation and characterization of a new cement-based composite with sulfur polymer. RSC Adv 2015;5:36030-5.

[404] Crockett MP, Evans AM, Worthington MJH, Albuquerque IS, Slattery AD, Gibson CT, Campbell JA, Lewis DA, Bernardes GJL, Chalker JM. Sulfur-Limonene Polysulfide: A Material Synthesized Entirely from Industrial By-Products and Its Use in Removing Toxic Metals from Water and Soil. Angew Chem Int Ed 2016;55:1714-8.

[405] Li G, Sun J, Hou W, Jiang S, Huang Y, Geng J. Three-dimensional porous carbon composites containing high sulfur nanoparticle content for high-performance lithiumsulfur batteries. Nat Commun 2016;7:10601.

[406] Lim J, Cho Y, Kang EH, Yang S, Pyun J, Choi TL, Char K. A one-pot synthesis of polysulfane-bearing block copolymer nanoparticles with tunable size and refractive index. Chem Commun 2016;52:2485-8.

[407] Arslan M, Kiskan B, Yagci Y. Combining Elemental Sulfur with Polybenzoxazines via Inverse Vulcanization. Macromolecules 2016;49:767-73. 


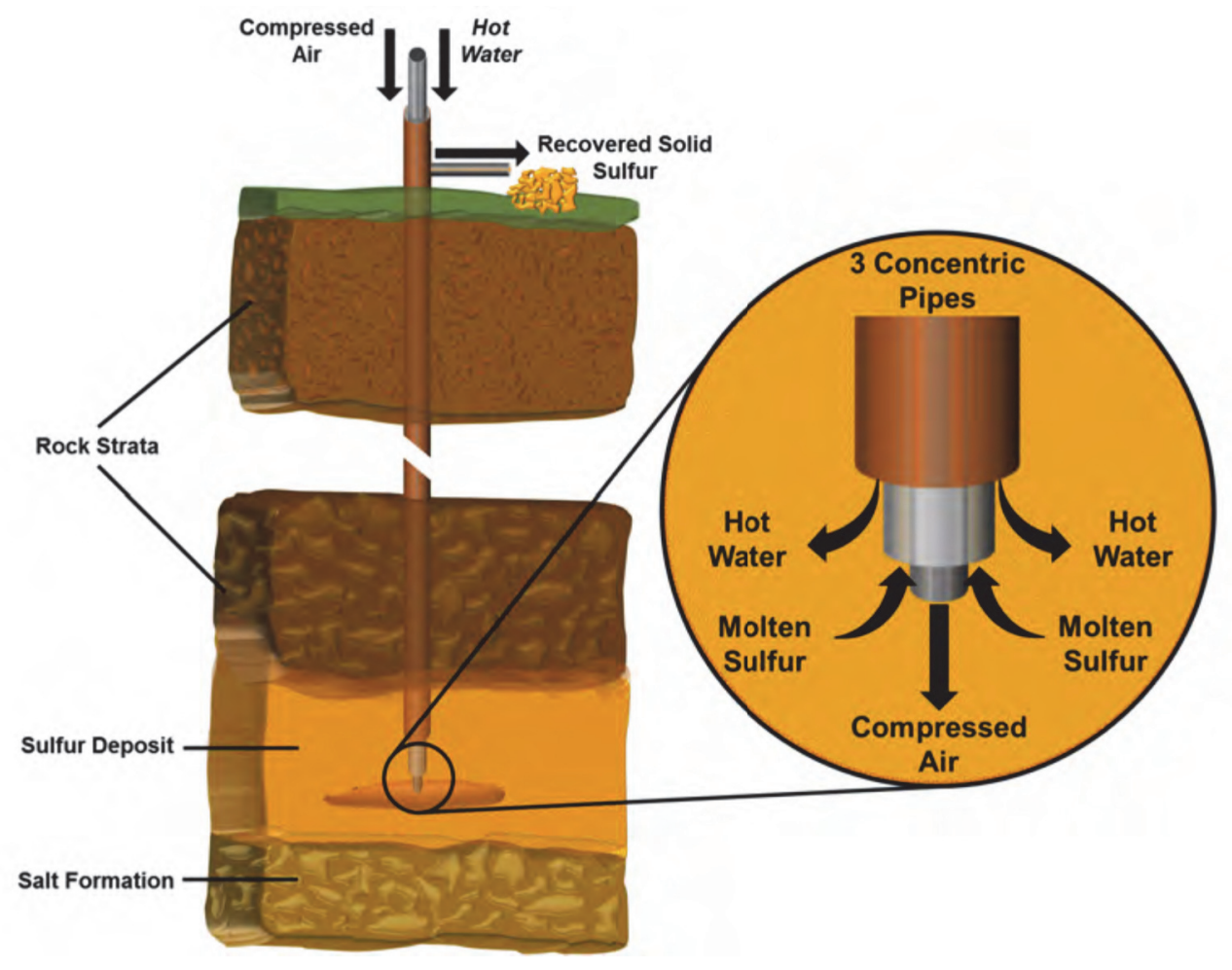

1. Schematic cartoon depicting the Frasch process for extraction of elemental sulfur from subterranean deposits through steam liquefaction and compressed air propulsion to the surface. 


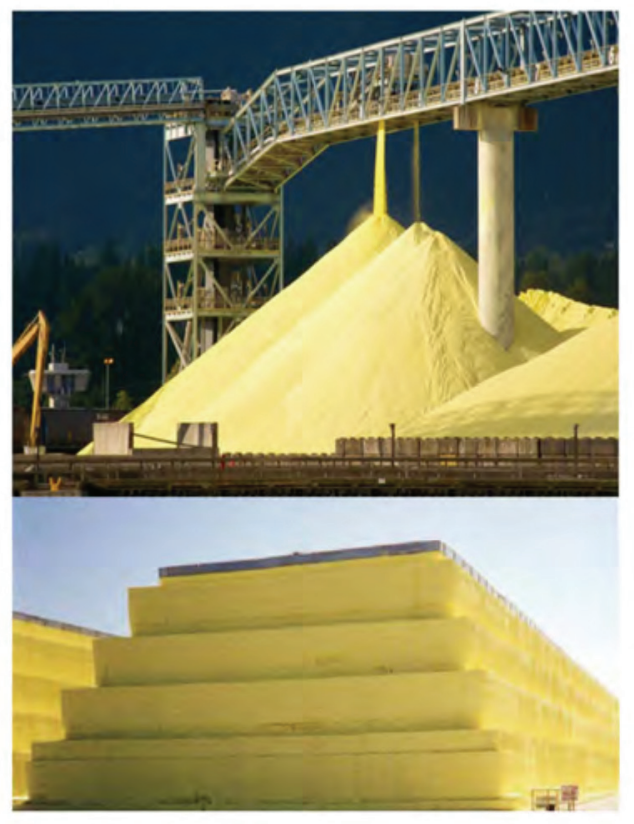

2. Examples of megaton above ground sulfur storage sites resulting from refining of petroleum via the Claus process. Adapted with permissions from [131], Copyright 2011, John Wiley \& Sons Inc; [134], Copyright 2013, Nature Publishing Group. 
a)

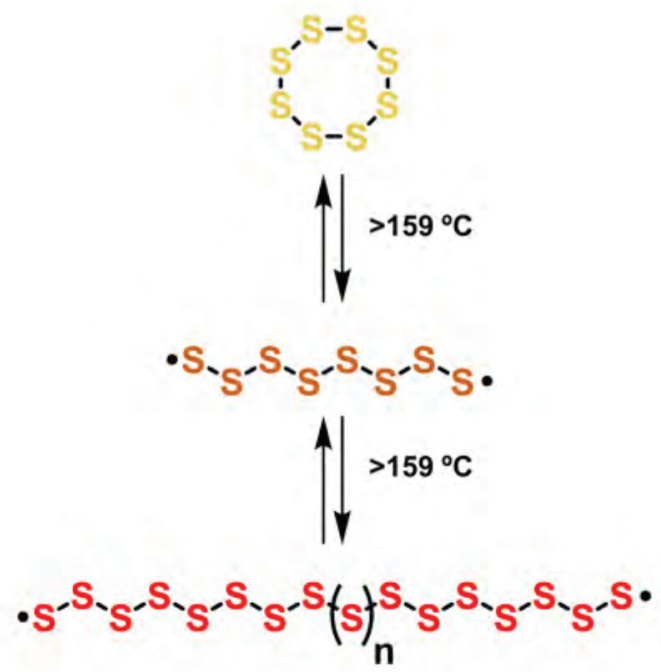

b)

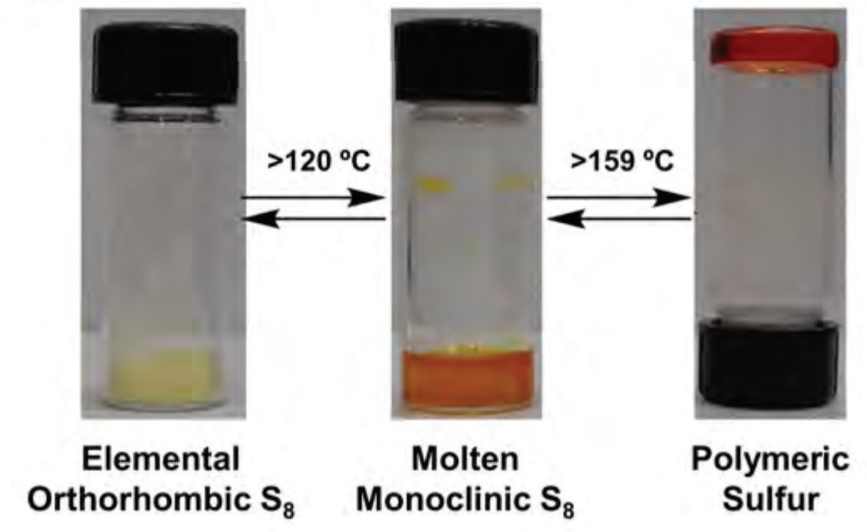

3. a) Thermally induced ring opening polymerization of elemental sulfur to yield high molecular weight polymeric sulfur. b) Photographs of sulfur in different states during the thermal ring opening polymerization. Adapted with permission from [134], Copyright 2013, Nature Publishing Group. 
a)

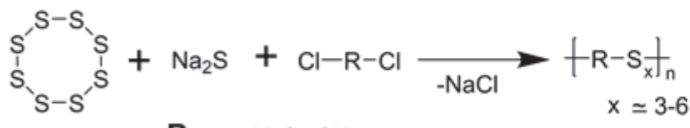

$$
\begin{aligned}
& \text { R: } \mathrm{H}_{2} \mathrm{C}-\mathrm{CH}_{2} \\
& \mathrm{H}_{2} \mathrm{C} \smile \mathrm{O} \vee \mathrm{CH}_{2} \\
& \mathrm{H}_{2} \mathrm{C} \smile \mathrm{O} \smile \mathrm{O} \sim \mathrm{CH}_{2} \\
& \mathrm{H}_{2} \mathrm{C}_{\mathrm{Cl}} \mathrm{CH}_{2}
\end{aligned}
$$

b)

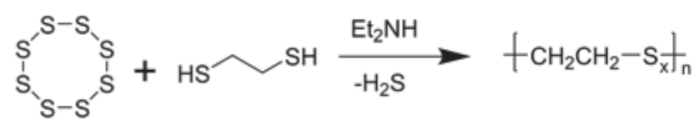

c)

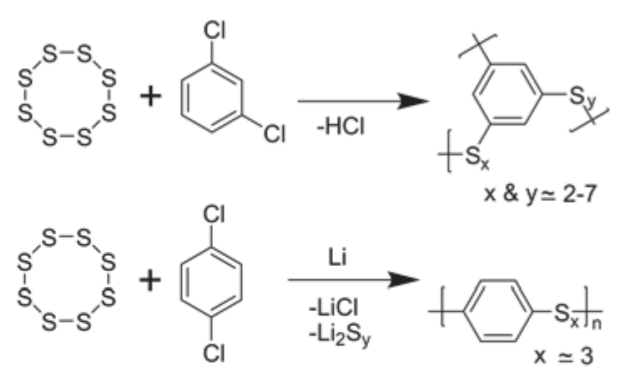

d)

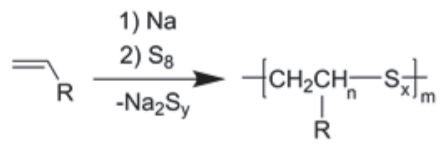

$$
\begin{aligned}
& \text { R: } \mathrm{H}_{2} \mathrm{C}=\mathrm{C}^{\prime} \mathrm{CH}_{3} \quad \mathrm{HC}=\mathrm{CH}_{2}
\end{aligned}
$$

4. Condensation copolymerization of elemental sulfur to generate high sulfur content polysulfides. a) reaction of $\alpha, \omega$-alkyl dihalides with sodium polysulfides; b) base catalyzed reaction of alkyl dithiols and sulfur; c) thermally or lithium metal initiated reaction of dichlorobenzene and sulfur; d) anionic generation of dicarbanionic oligomers followed by condensation with sulfur. 


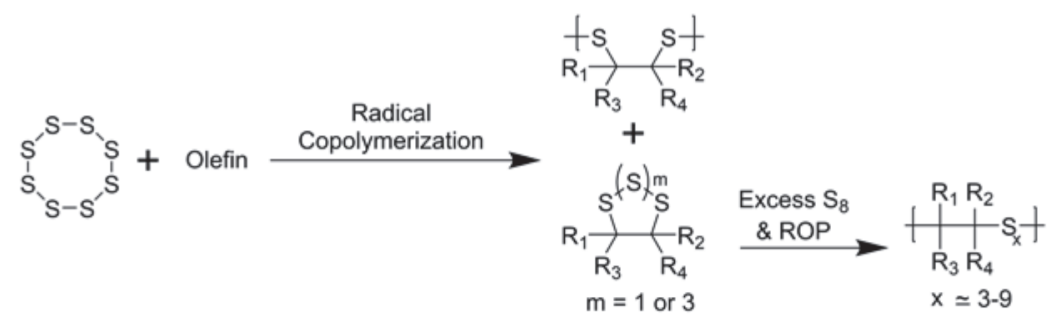

Vinylics:

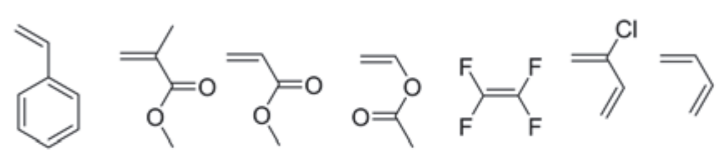

Cyclic olefins:

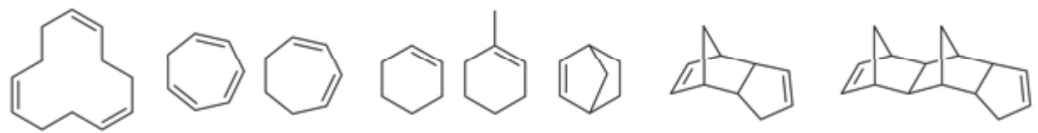

Terpenoids:

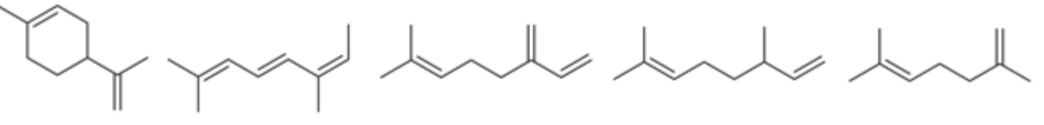

5. Scheme demonstrating free-radical copolymerization of sulfur with various olefin comonomers to generate polysulfide copolymers. 
a)

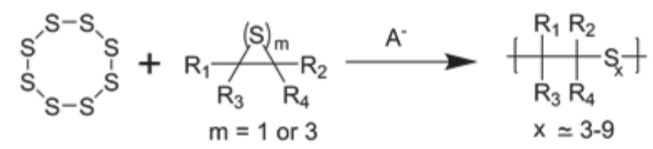

Thiiranes and Trithioles
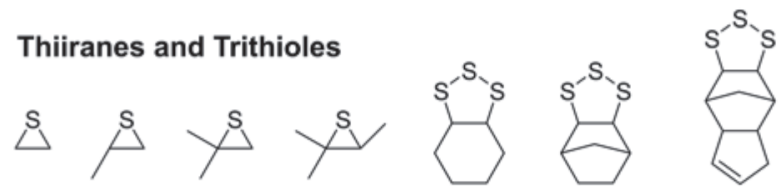

b)

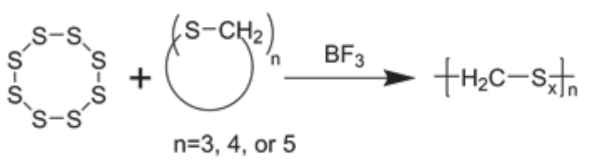

6. Ionic copolymerization of elemental sulfur with cyclic sulfur containing monomers. a) Anionic copolymerization of elemental sulfur with thiiranes and trithioles. b) Cationic copolymerization of elemental sulfur with cyclic thianes. 


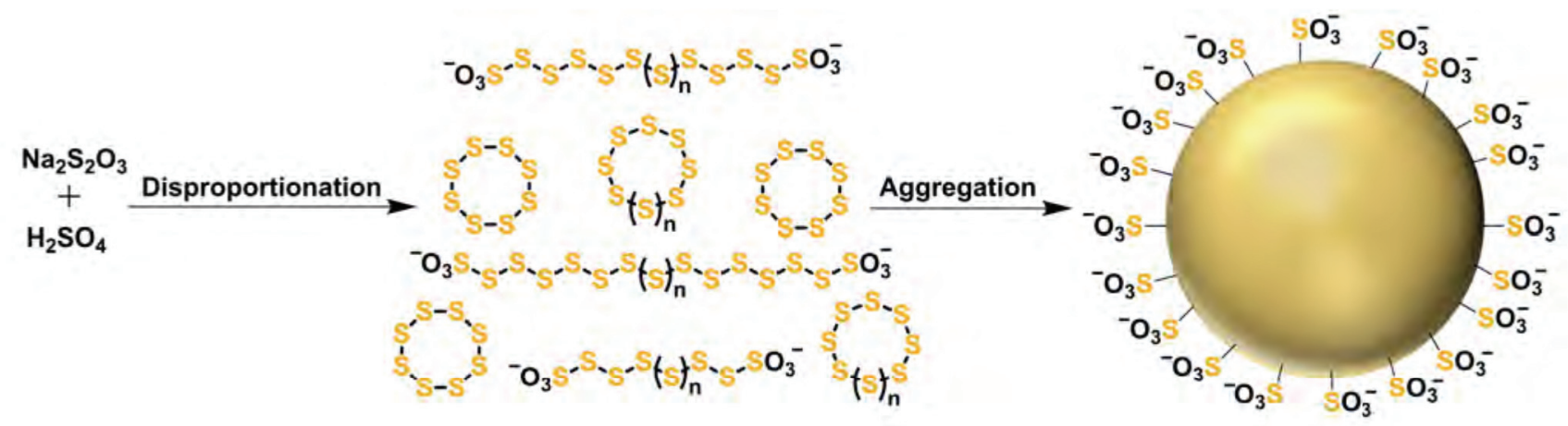

7. Acid catalyzed generation of sulfur colloids (Raffo sols) stabilized by amphiphilic polythionates possessing hydrophilic end groups and a core composed of crystalline cyclic sulfur species $\left(\mathrm{S}_{\mathrm{n}}\right.$, $\mathrm{n}>5$ ). Adapted with permission from [92], Copyright 2003, Springer. 

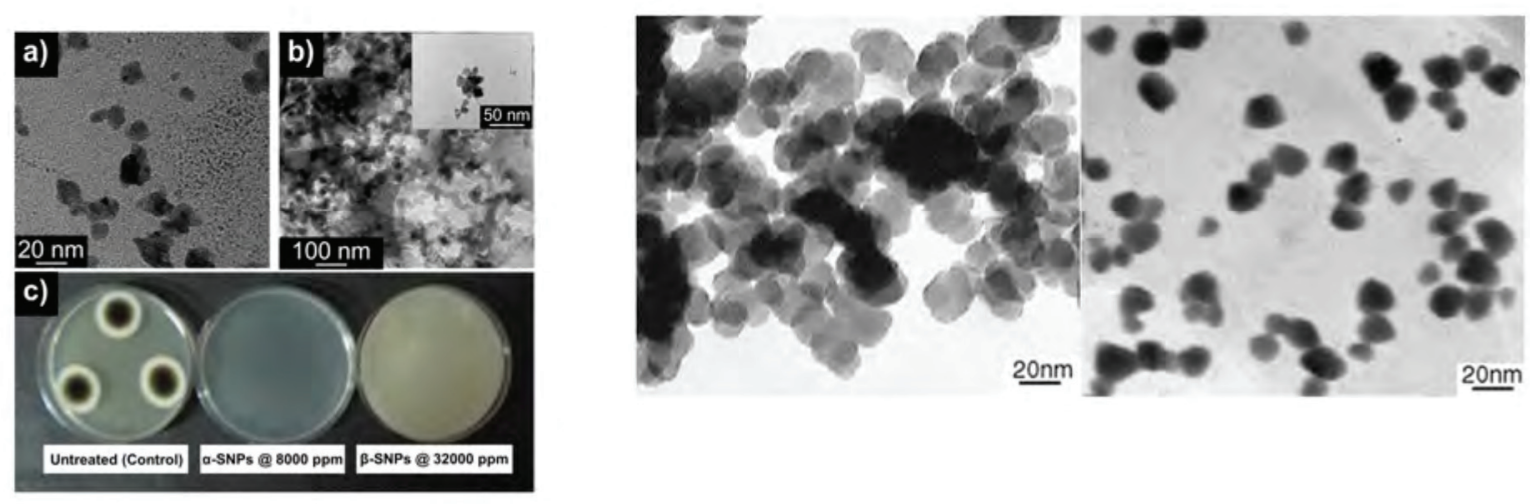

8. Preparation of sulfur nanoparticles (SNPs) by a) liquid phase precipitation to generate $\alpha$-sulfur nanoparticles and b) water-in-oil emulsion generation of $\beta$-sulfur nanoparticles for antimicrobial capabilities. Inset of (b) reveals the conglomeration of monoclinic SNPs into tetrapod-like structures. c) Antifungal assay determining minimum concentration of sulfur necessary to inhibit growth of Aspergillus niger (black mold). Adapted with permission from [103], Copyright 2013, John Wiley \& Sons Inc. 

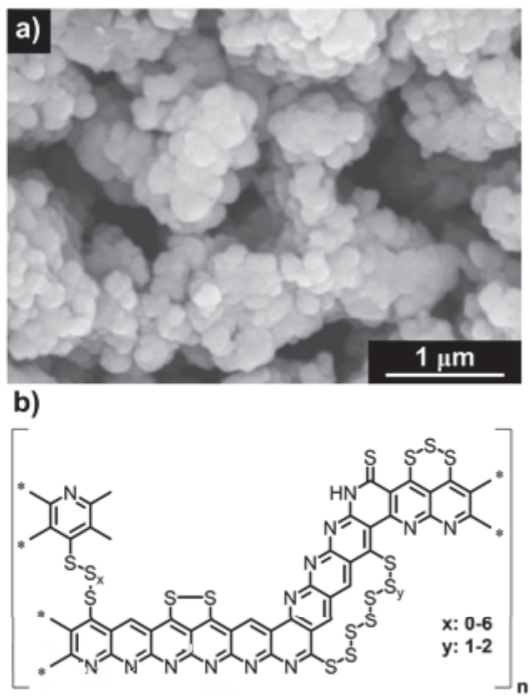

9. a) Sulfur composite colloids generated from pyrolysis of sulfur and poly(acrylonitrile) (PAN) at high temperatures. b) Proposed chemical structure of composite as a result of sulfur reacting with the PAN during pyrolysis. Adapted with permissions from (a) [107], Copyright 2002, John Wiley \& Sons Inc; (b) [109], Copyright 2011, the American Chemical Society. 


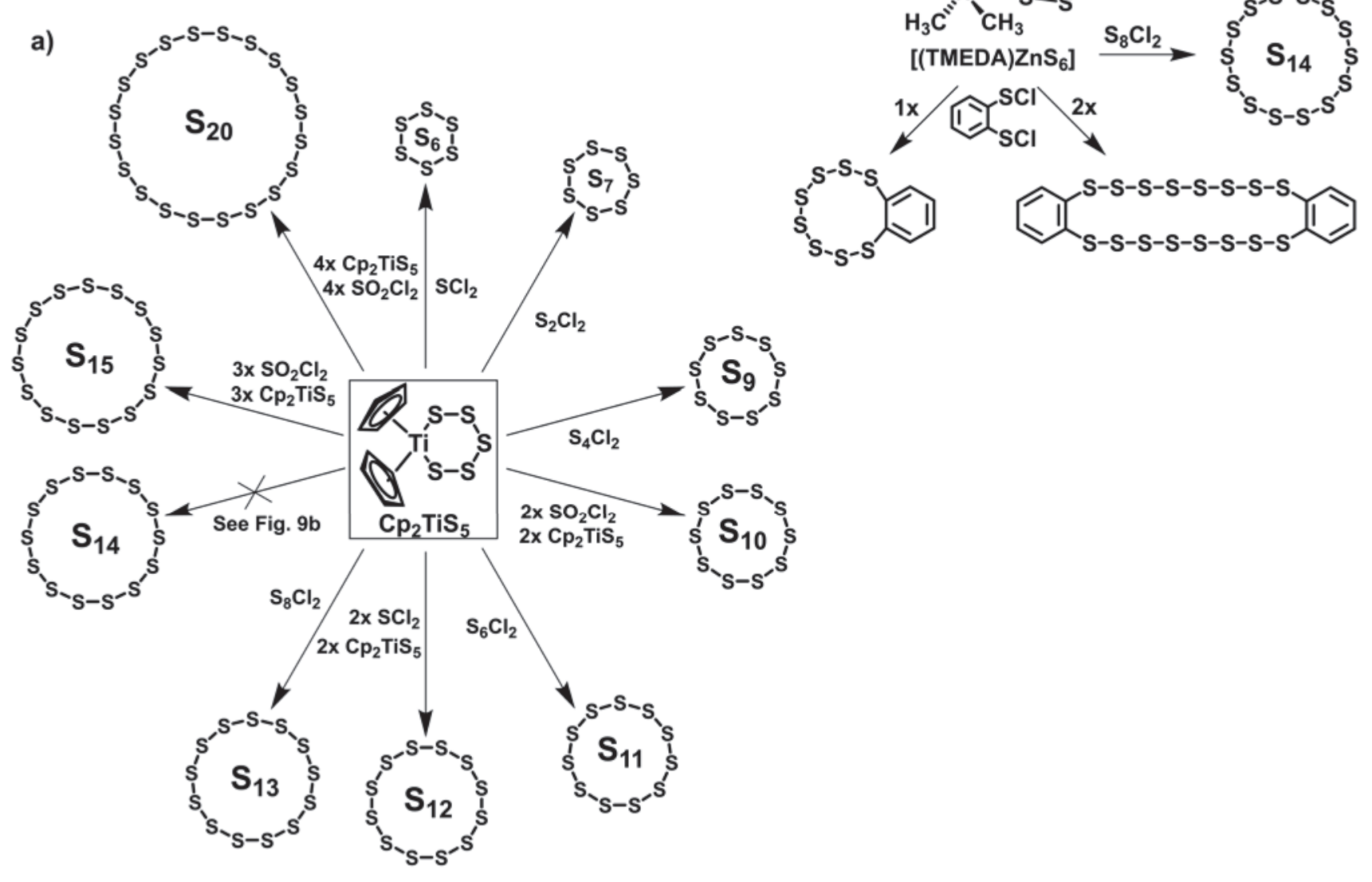

10. Synthesis of high sulfur-content molecules through activated sulfur-precursors. a) Utilization of $\operatorname{bis}\left(\eta^{5}\right.$-cyclopentadienyl)titanium pentasulfide $\left(\mathrm{Cp}_{2} \mathrm{TiS}_{5}\right)$ as the starting material to generate several homocyclic sulfur allotropes. b) Utilization of the tetramethylethylenediamine zinc hexasulfido complex as the starting material to generate $c y c l o$-tertadecasulfur $\left(\mathrm{S}_{14}\right)$ as well as other cyclic polysulfide molecules. 


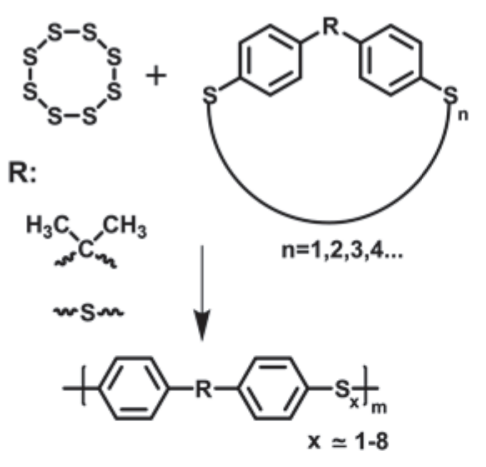

11. Thermally initiated ring-opening copolymerization of cyclic bis(benzene di and higher sulfide) oligomers with elemental sulfur to generate high sulfur-content copolymers. 


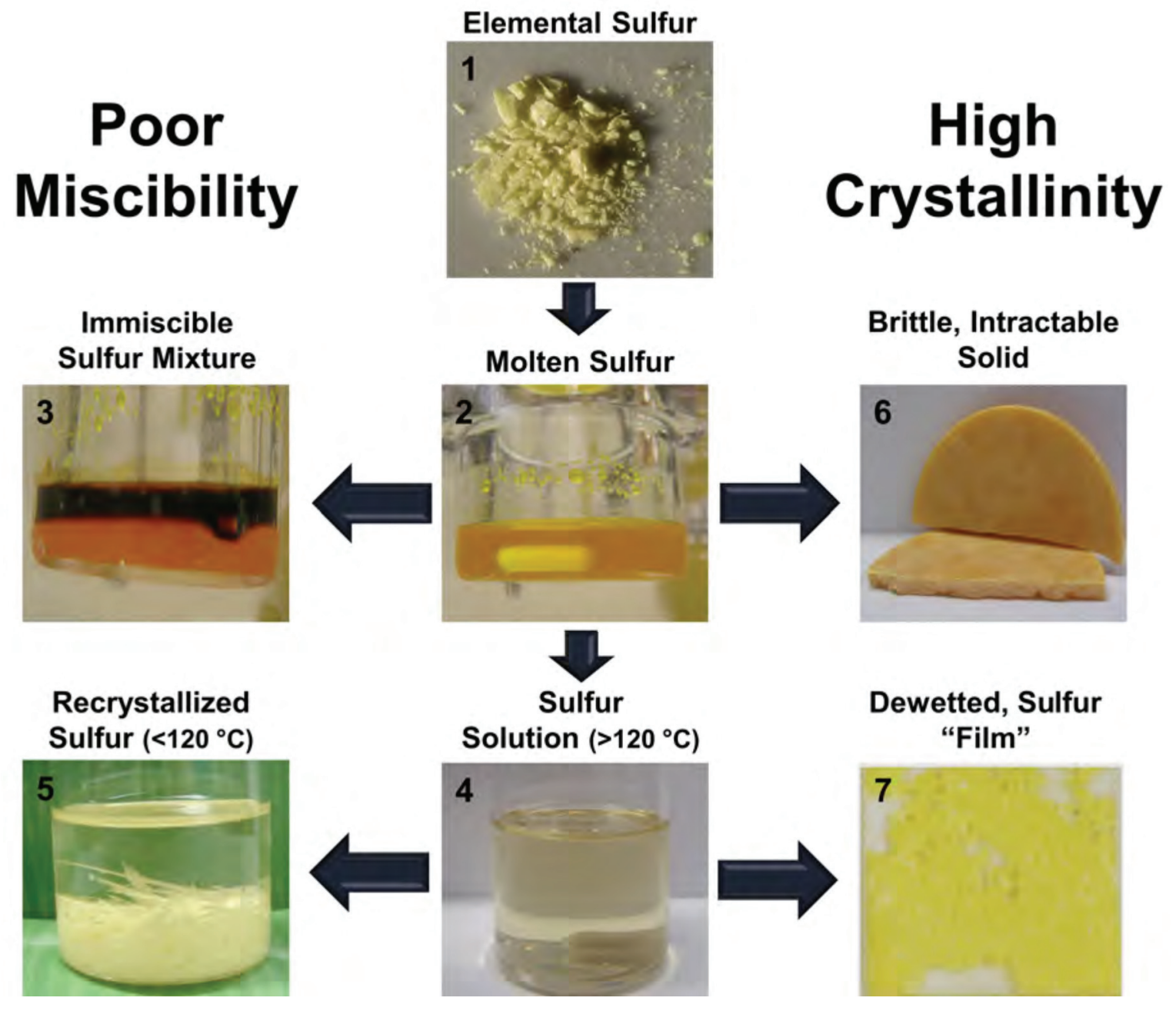

12. Scheme depicting challenges associated with attempting chemistry and processing of elemental sulfur in molten or solution based instances. (1) powdered elemental sulfur; (2) molten elemental sulfur; (3) immiscible solution of molten sulfur and bisaminopropyl terminated poly(ethylene glycol) ( $\mathrm{Mn} \approx 1500 \mathrm{~g} / \mathrm{mol}, 150^{\circ} \mathrm{C}$ ); (6) molded elemental sulfur disk; (4) solution of elemental sulfur in 1,2 dichlorobenzene $\left(150^{\circ} \mathrm{C}\right)$; (5) precipitated elemental sulfur in 1,2 dichlorobenzene $\left(25^{\circ} \mathrm{C}\right)$; (7) film spun from elemental sulfur solution on glass. 


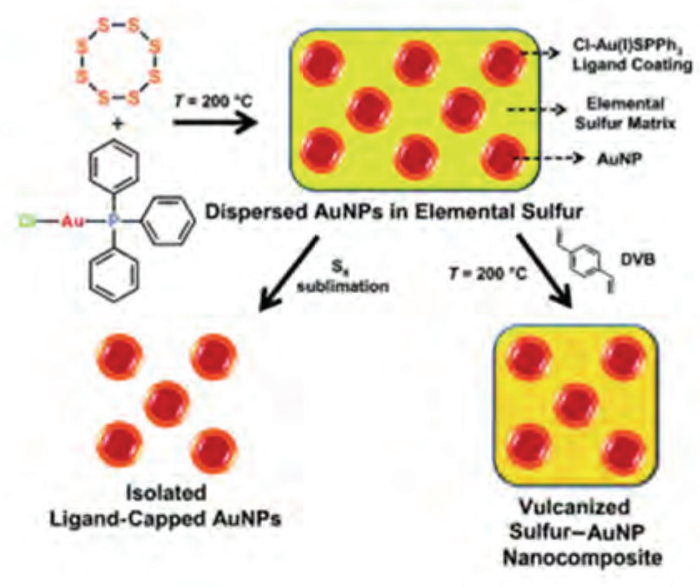

13. Schematic representation of gold nanoparticle synthesis directly in molten elemental sulfur followed by isolation through sulfur sublimation or matrix crosslinking through introduction of divinylbenzene (DVB, a mixture of 1,3 or 1,4 isomers). Adapted with permission from [131], Copyright 2011, John Wiley \& Sons Inc. 
a)
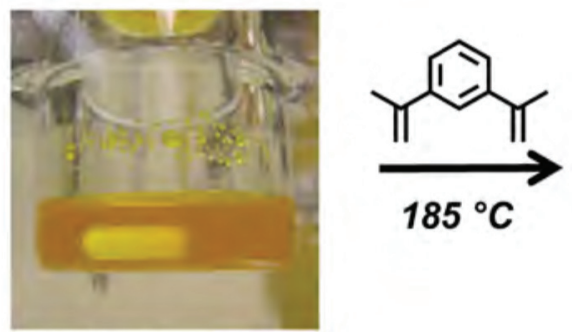

Molten Elemental

Sulfur<smiles>SSSSSSSSS</smiles>

Oligomeric Sulfur (95-35 wt\%)

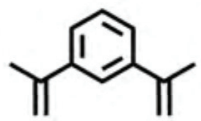

1,3 Diisopropenylbenzene

(DIB) (5-65 wt\%)
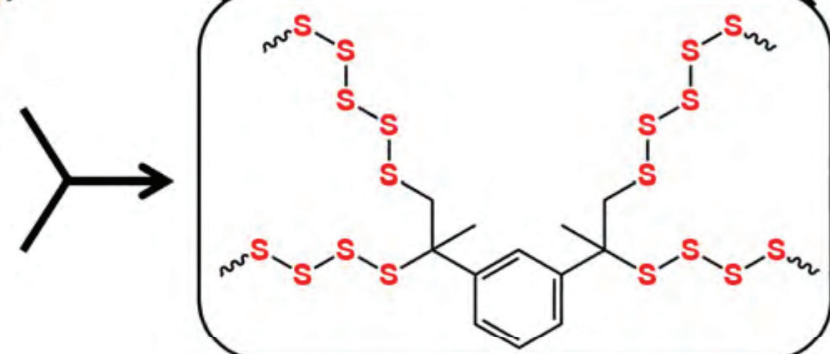

Poly(S-r-DIB) Copolymer

b)

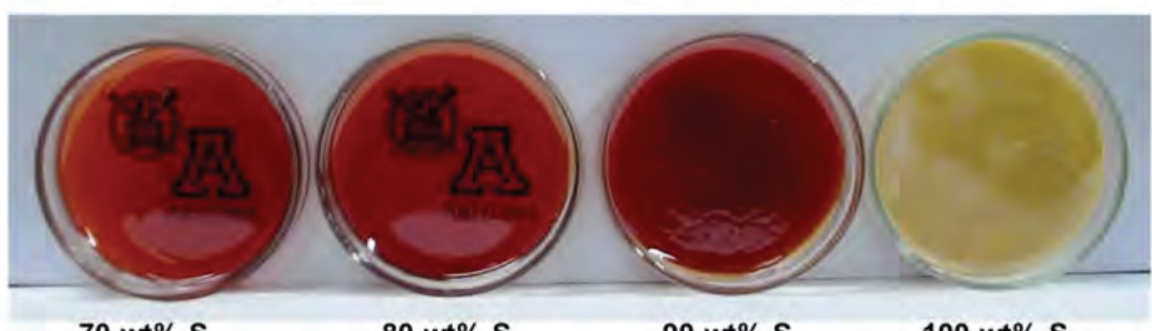

$70-w t \% S_{8}$

$80-w t \% S_{8}$

$90-w t \% S_{8}$

$100-w t \% S_{8}$

14. a) Bulk copolymerization of sulfur and 1,3-diisopropenylbenzene (DIB) at $185^{\circ} \mathrm{C}$ to generate high sulfur content poly(sulfur-random-1,3-diisopropenylbenzene) (poly(S-r-DIB)) copolymers.

b) Digital images illustrating control over properties of copolymers as a function of DIB content. Adapted with permission from [134], Copyright 2013, Nature Publishing Group. 
More $\mathrm{S}_{8}$

More DIB
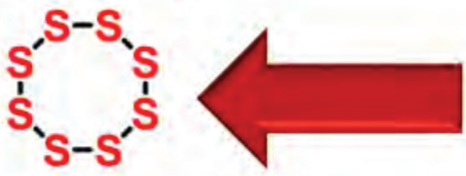

\section{Sulfur polymer microstructure}<smiles>C=C(C)c1cccc(C(=C)C)c1</smiles>

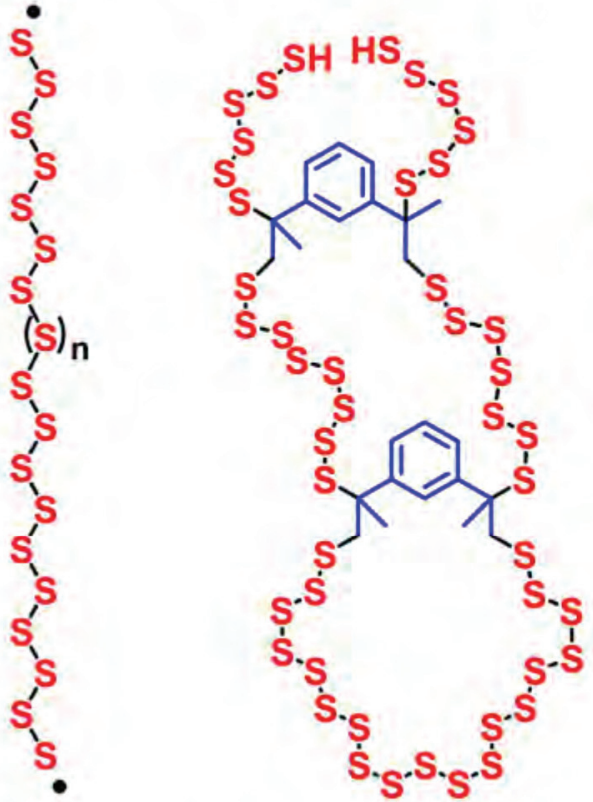

$100 \%$ Sulfur $\quad 90 \%$ Sulfur, $10 \%$ DIB Linear Chains Macromolecular Loops $S$ rank: $\sim 0^{6} \quad S$ rank: 20 per vinyl

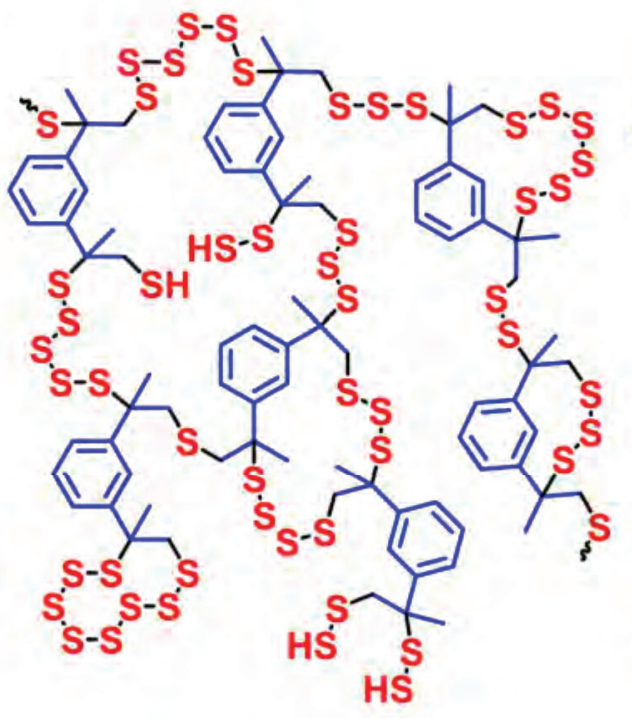

$\mathbf{8 0 - 5 0 \% ~ S u l f u r , ~} \mathbf{2 0 - 5 0 \%}$ DIB Hyperbranched S rank: 2-10 per vinyl

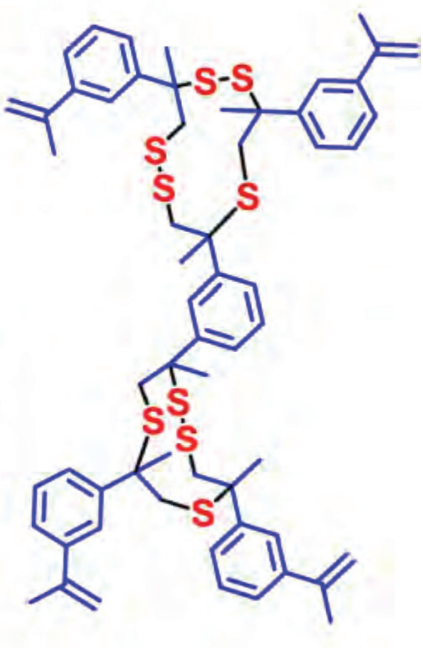

$35 \%$ Sulfur, $65 \%$ DIB Vinyl Terminated $S$ rank: 1 per vinyl

15. Schematic representation of proposed sulfur polymer microstructure as a function of 1,3diisopropenylbenzene (DIB) content. 


\section{a)}

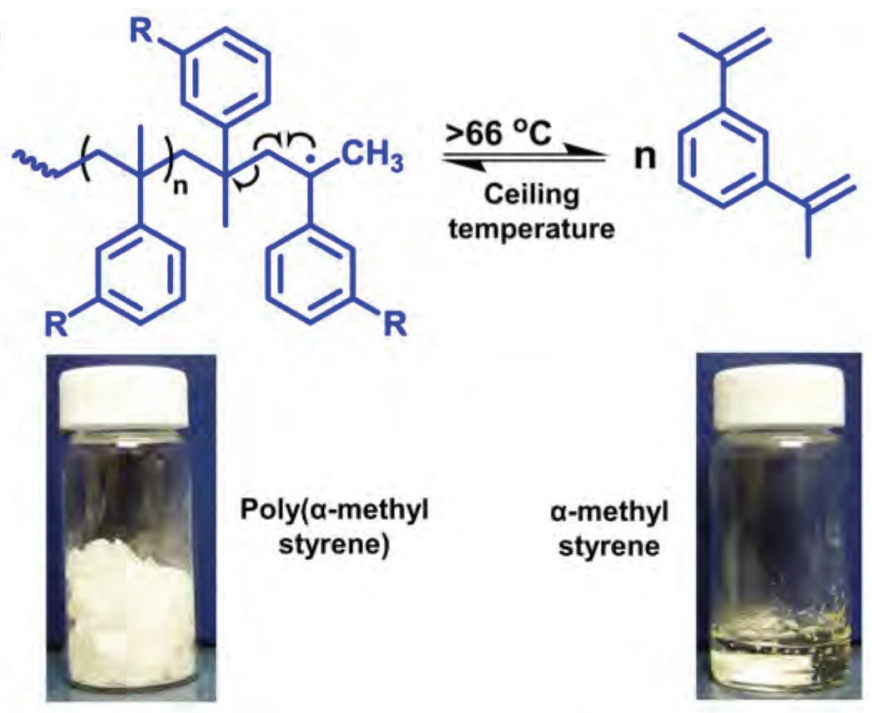

b)
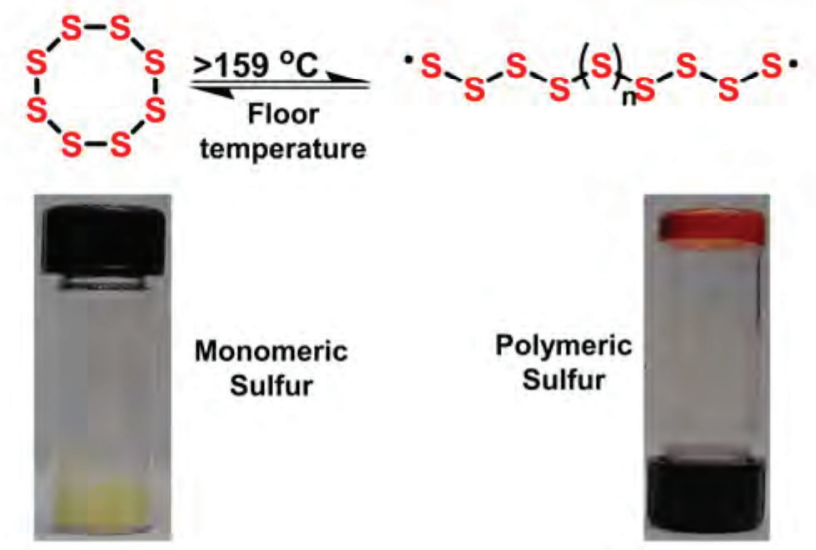

16. a) Schematic representation and digital images of poly( $\alpha$-methylstyrene) undergoing depolymerization at temperatures exceeding the ceiling temperature $\left(T_{c}=66^{\circ} \mathrm{C}\right)$. b) Schematic representation and digital images of elemental sulfur undergoing ring-opening polymerization at temperatures exceeding the floor temperature $\left(\mathrm{T}_{\mathrm{f}}=159^{\circ} \mathrm{C}\right)$. 
a)

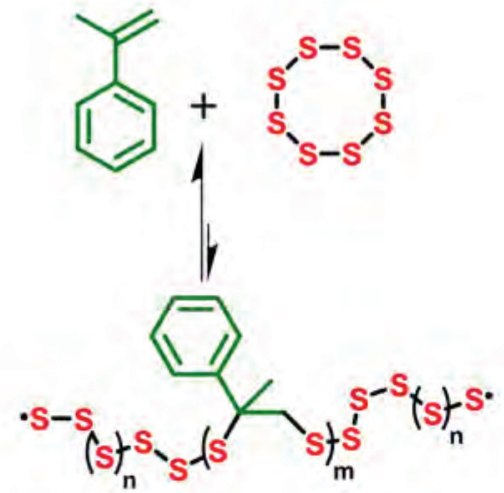

c)
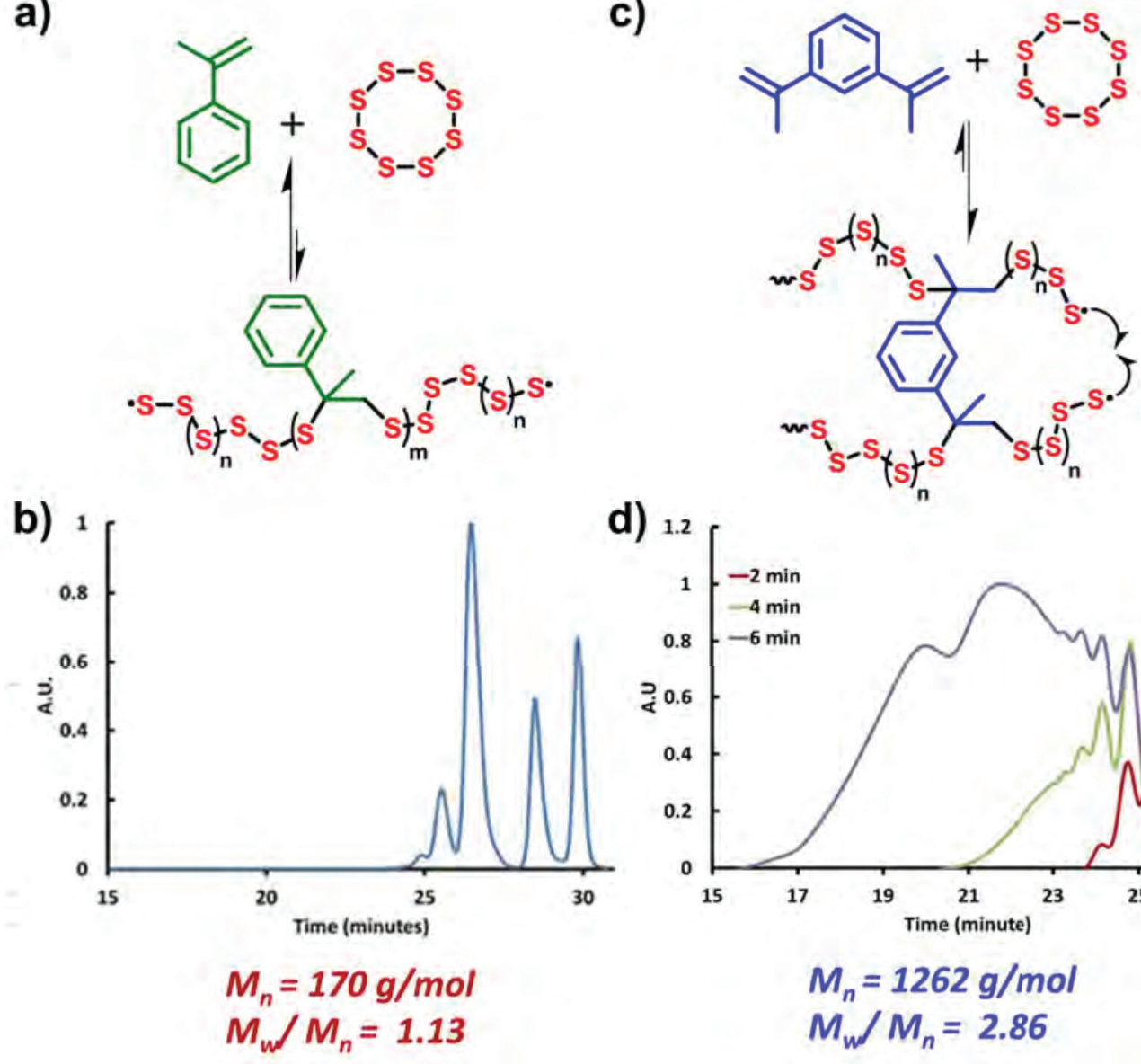

d)

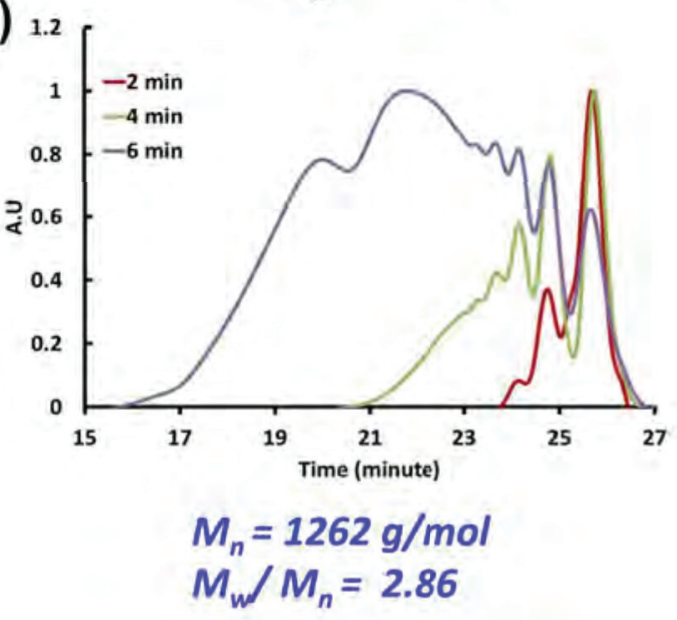

17. Inverse vulcanization of sulfur with monofunctional ( $\alpha$-methylstyrene) and difunctional $(1,3-$ diisopropenylbenzene) comonomers. a) Copolymerization of sulfur and $\alpha$-methylstyrene leading to an unstable oligomeric product that reverts back to monomers. b) Gel permeation chromatography plot with molecular weight data showing only oligomeric products. c) Copolymerization of sulfur and 1,3-diisopropenylbenzene leading to a stable polymeric product. d) Gel permeation chromatography plot with molecular weight data showing polymeric products increasing in molecular weight with reaction time. Adapted with permission from [129], Copyright 2013, Nature Publishing Group. 
a)

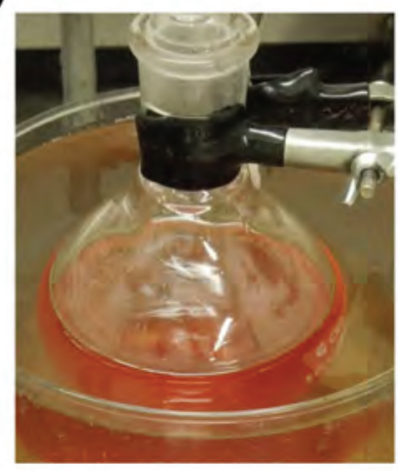

Inverse Vulcanization Reaction

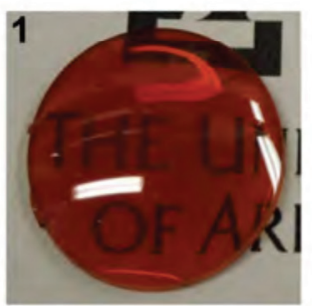

b)

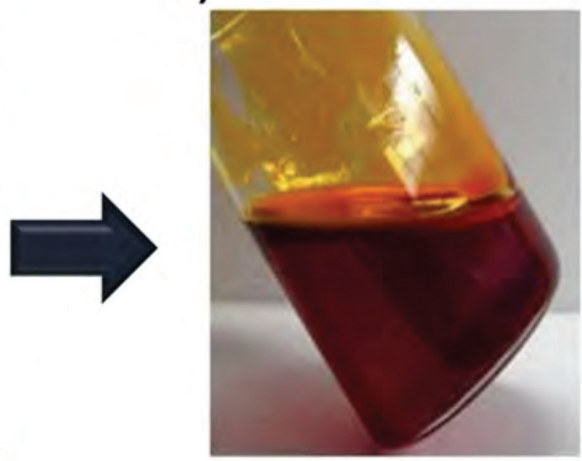

Low Viscosity Sulfur Pre-polymer c)

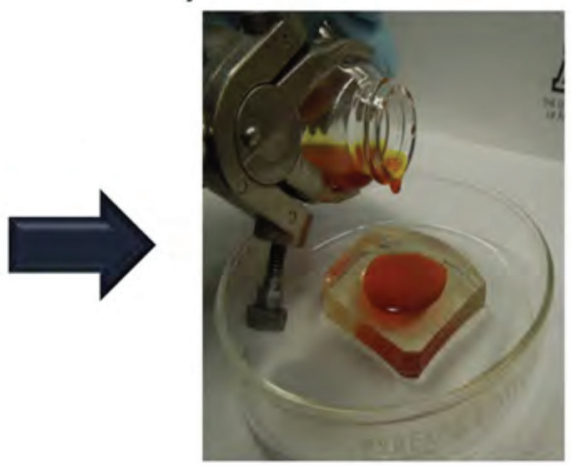

Molding of

Sulfur Pre-polymer
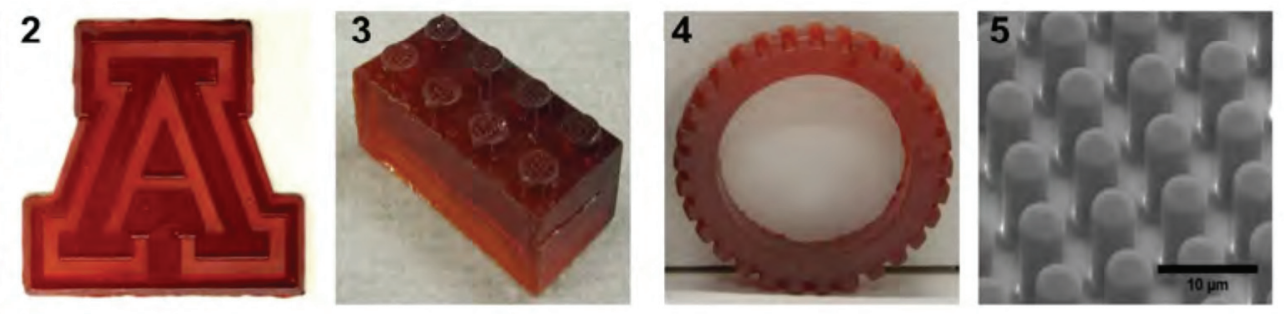

18. Generation of high precision replica objects by molding of poly(S-r-DIB) pre-polymer. a) Bulk inverse vulcanization reaction kept to low monomer conversion. b) Small volume of low-viscosity pre-polymer ready to pour into prepared PDMS mold. c) Pouring of low-viscosity pre-polymer into PDMS mold before thermally curing at $185^{\circ} \mathrm{C}$. A variety of molded poly(S-r-DIB) copolymer objects: (1) plano-convex lens; (2) logo; (3) connectable block; (4) tire; and (5) micropatterned pillars. 


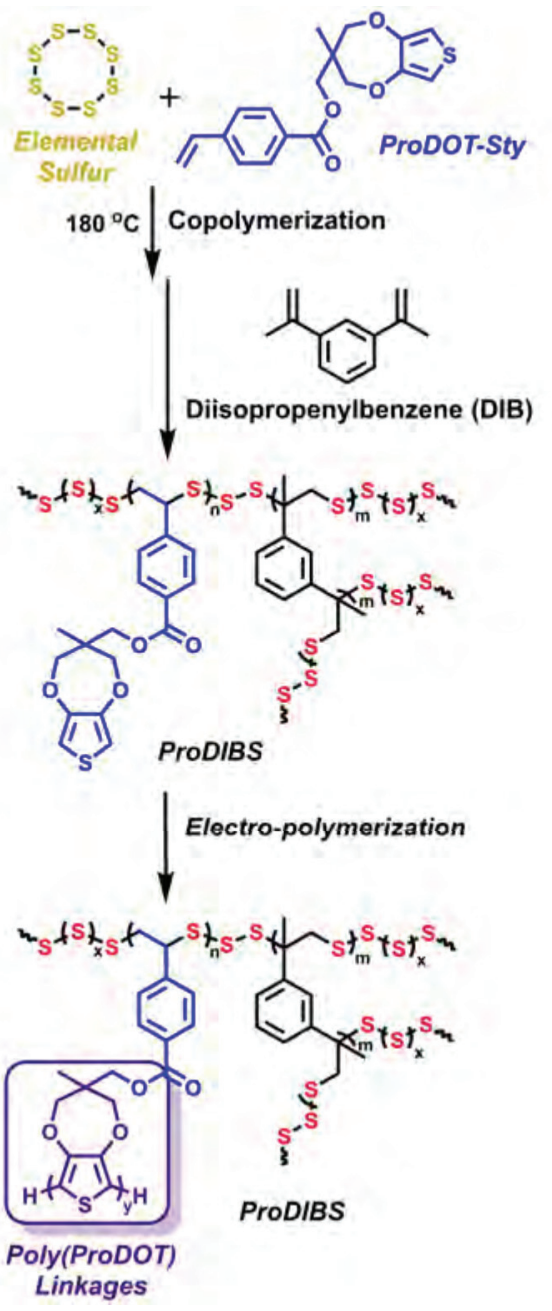

19. Synthesis of sulfur copolymer containing a thiophene based functional side group using tandem inverse vulcanization followed by electropolymerization of the thiophene moieties to generate conductive pathways within the high sulfur-content copolymer. Adapted with permission from [138], Copyright 2015, the American Chemical Society. 


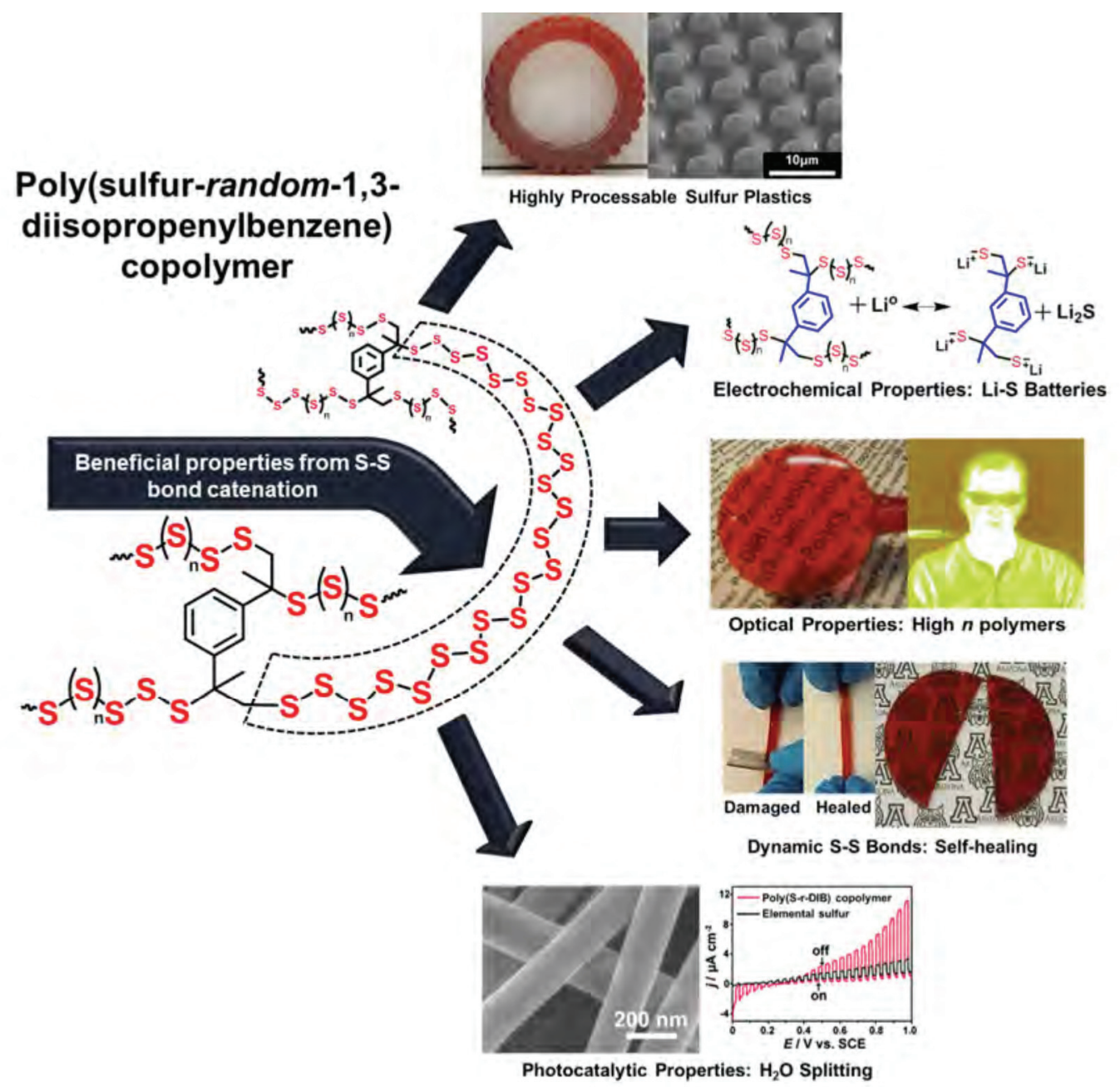

20. Poly(sulfur-random-1,3-diisopropenylbenzene) copolymers possess a high sulfur-content and beneficial properties resulting from the large population of S-S bonds can ultimately be exploited in a variety of novel applications. 
a)

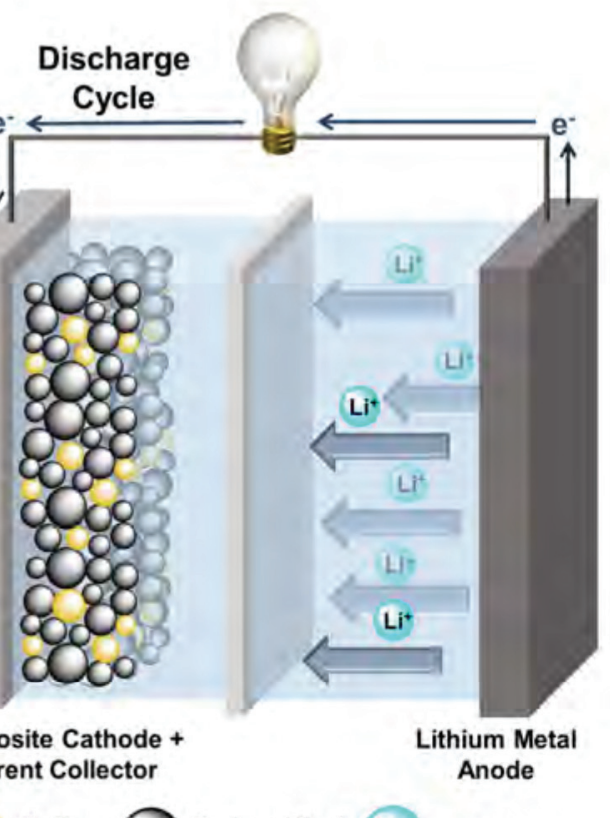

Sulfur Carbon Black Particle Particle

Lithium Ion

c)

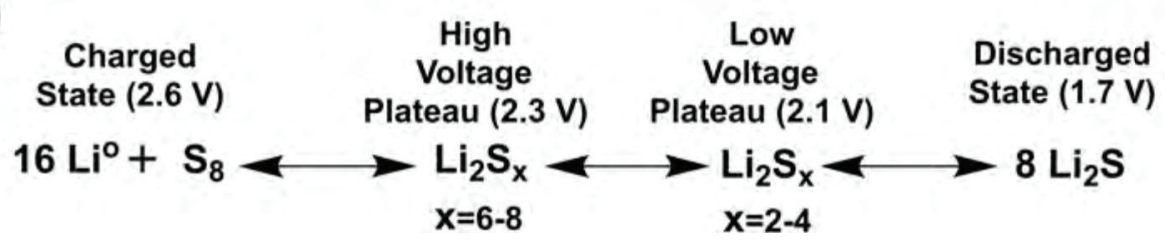

b)

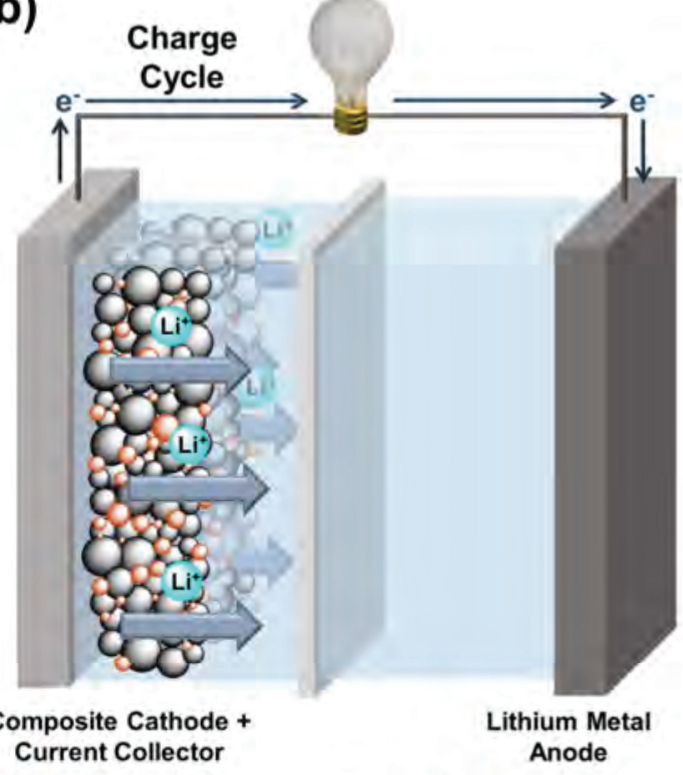

$\mathrm{Li}_{2} \mathrm{~S}_{\mathrm{x}} \bigcirc$ Carbon Black Particle Particle

Lithium lon

21. Schematic representation of Lithium-Sulfur battery in discharging and charging state. a) Discharging cycle with movement of lithium ions and electrons to the cathode to reduce elemental sulfur and form lithium sulfides $\left(\mathrm{Li}_{2} \mathrm{~S}_{\mathrm{x}}\right)$. b) Charging cycle with oxidation of lithium sulfides back to sulfur and movement of lithium ions and electrons back to anode to reform lithium metal. c) Chemical species present within the Li-S cell at various voltages throughout the cycling of the cell. 
a)
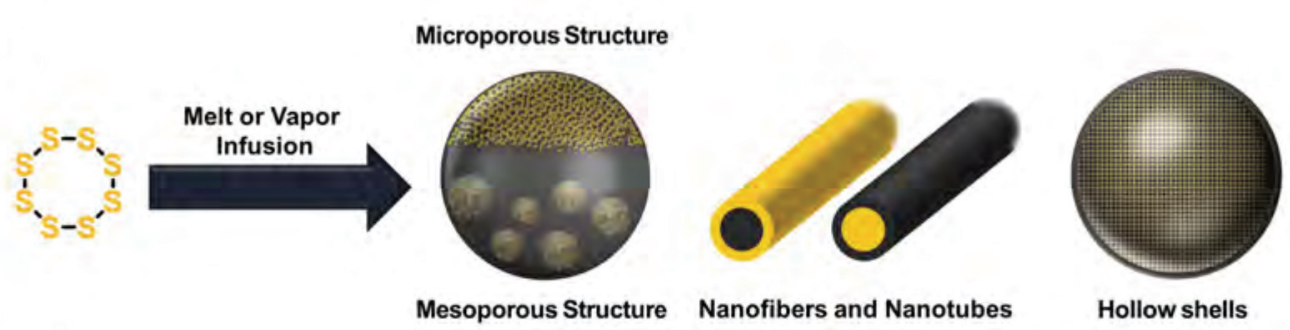

b)
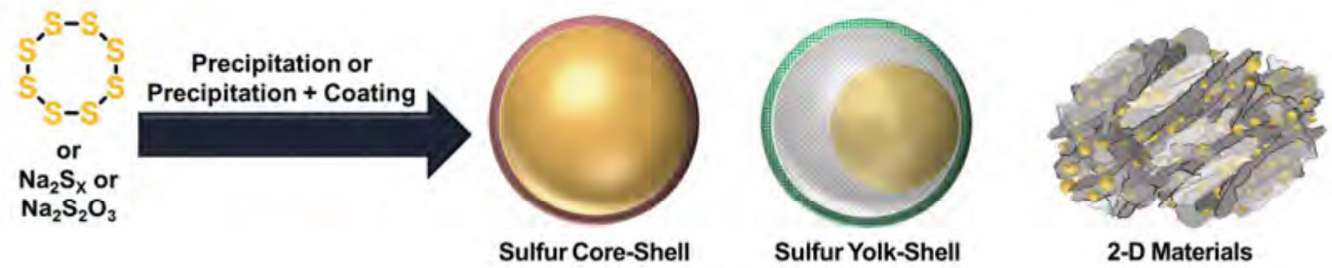

22. Schematic representation of commonly generated sulfur nanocomposite active materials for Li-S batteries formed by a) diffusion of sulfur into the nanomaterial; or b) precipitative methods to generate sulfur nanoparticles followed by enwrapping. 


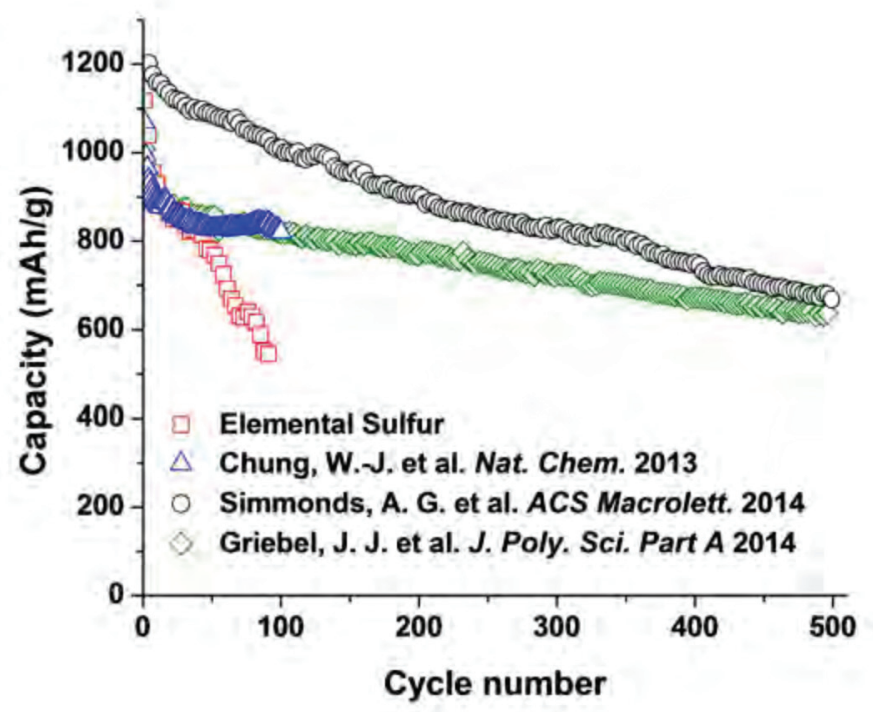

23. Comparison of capacity as function of cycle number for elemental sulfur ( $\square$ ) and poly(sulfurrandom-1,3-diisopropenylbenzene) copolymers: first example of poly(S-r-DIB 10$)$ copolymer battery, Nature Chemistry work $(\Delta)$; optimized poly $\left(\right.$ S- $_{\text {-DIB }}$ ) copolymer battery, ACS Macro Letters work $(\circ)$; and 1-kg scale poly $(\mathrm{S}-r$-DIB 10$)$ copolymer battery, Journal of Polymer Science Part A work $(\diamond)$. Cycling rate of $0.1 \mathrm{C}, 167.2 \mathrm{~mA} \cdot \mathrm{g}^{-1}$. Adapted with permissions from [134], Copyright 2013, Nature Publishing Group; [145], Copyright 2014, the American Chemical Society; [289], Copyright 2015, John Wiley \& Sons Inc. 


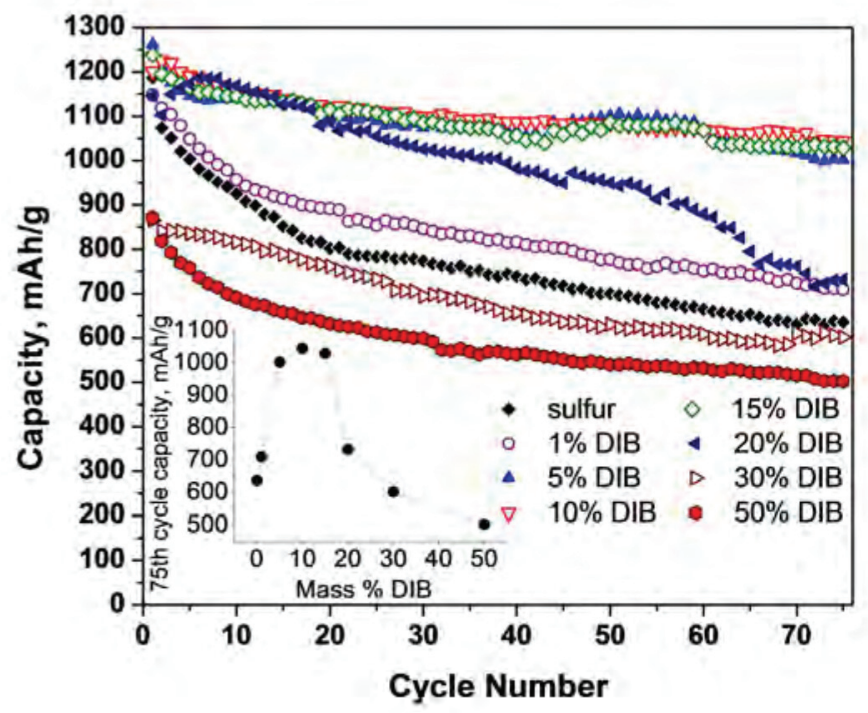

24. Cycling performance of $\mathrm{Li}-\mathrm{S}$ batteries from poly(S-r-DIB) copolymers of varying composition (0-50\% by mass DIB) up to 75 cycles at $0.1 \mathrm{C}, 167.2 \mathrm{~mA} \cdot \mathrm{g}^{-1}$. Inset figure shows a plot of the specific capacity measured at the $75^{\text {th }}$ cycle against DIB content in the copolymer. Adapted with permission from [145], Copyright 2014, the American Chemical Society. 


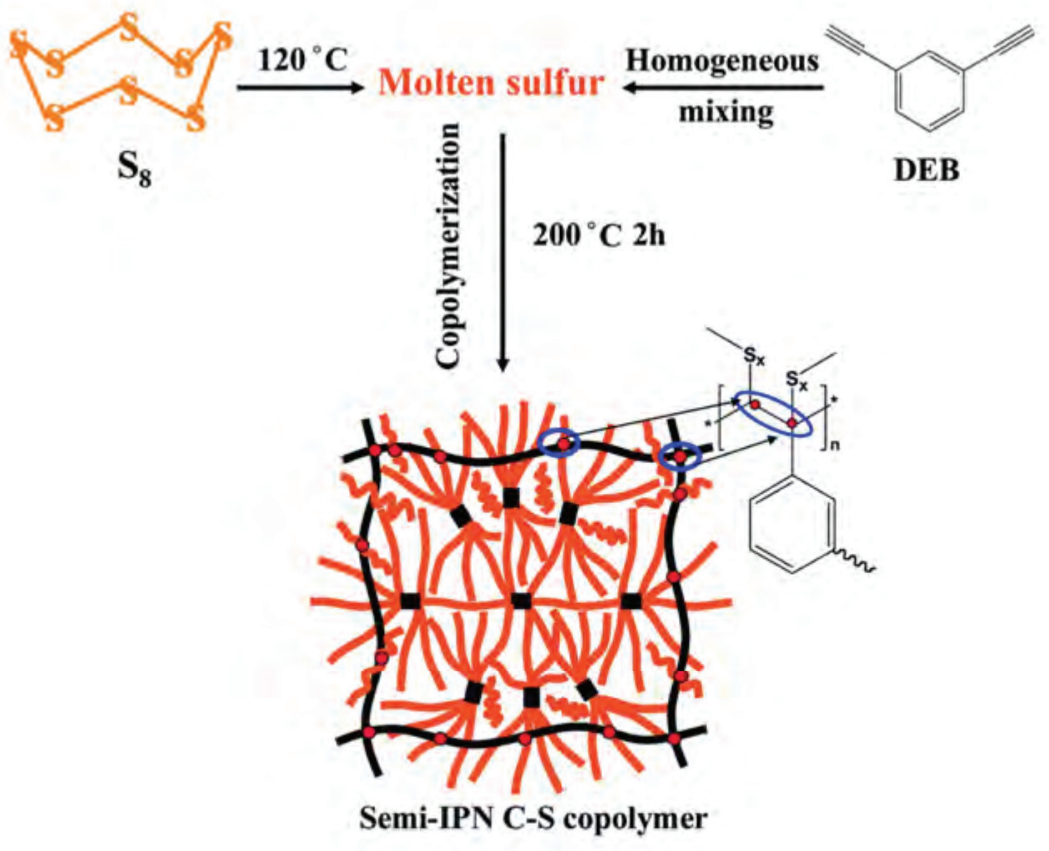

25. Schematic representation of the bulk copolymerization between elemental sulfur and 1,3 diethynylbenzene (DEB) at high temperatures to generate a semi-interpenetrating network copolymer. Adapted with permission from [290], Copyright 2014, the Royal Society of Chemistry. 


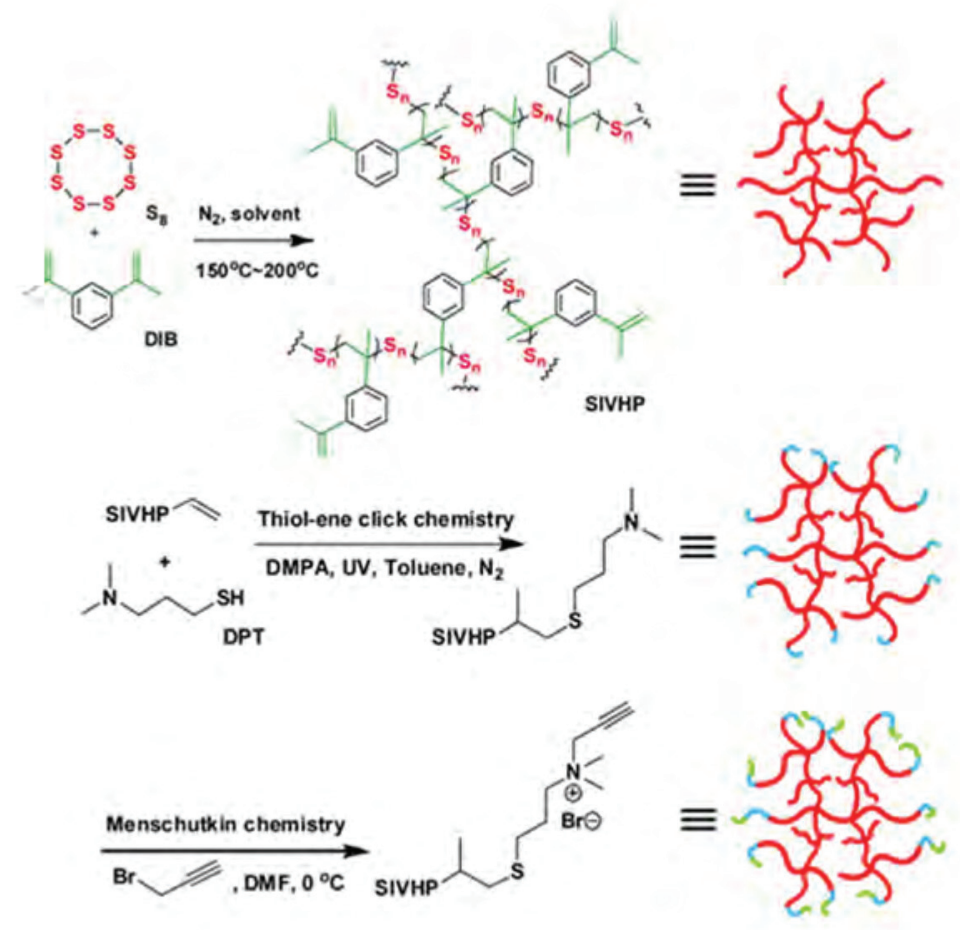

26. Synthesis of soluble inverse-vulcanized hyper branched (SIVHP) copolymer by a modified inverse vulcanization reaction. Formation of a water-soluble SIVHP copolymer by postpolymerization modification by thiol-ene reaction on dangling double bonds followed by a Menschutkin click reaction. Adapted with permission from [291], Copyright 2015, the Royal Society of Chemistry. 
a)

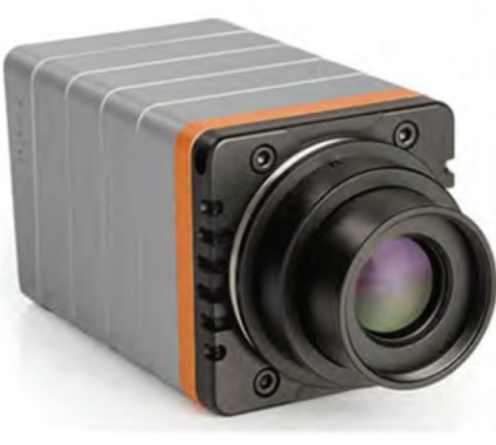

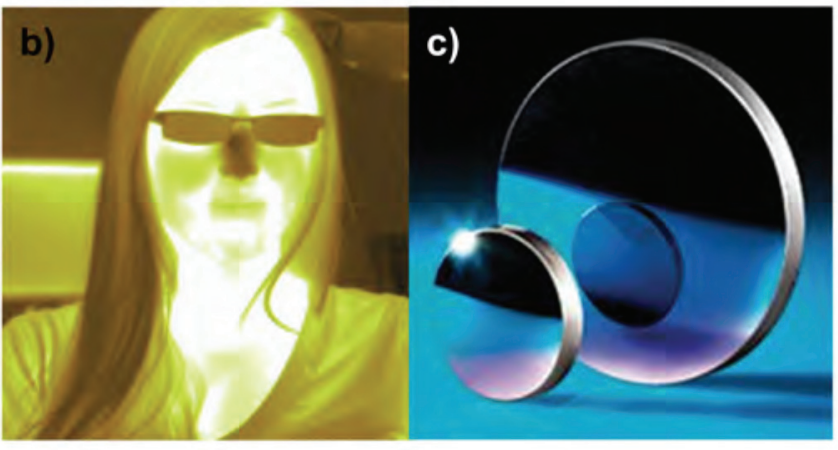

27. a) Thermal imaging digital camera capable of capturing mid and far-infrared wavelength images (Xenics Gobi Camera, Stemmer Imaging Ltd.). b) Thermal image of female subject captured with a digital thermal imaging camera in the mid-IR wavelengths. c) Germanium windows capable of transmitting mid and far-infrared light $(2-16 \mu \mathrm{m})$ (Edmund Optics Inc.). 
a)

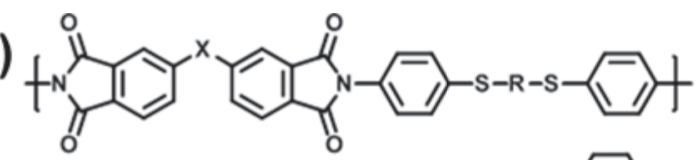<smiles>[X]c1ccc(Sc2ccc(S)cc2)cc1</smiles>

$\mathrm{n}_{\text {avg, } 633 \mathrm{~nm}}=1.7692$

b)

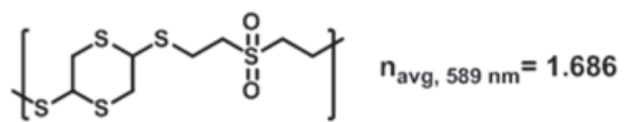

c)

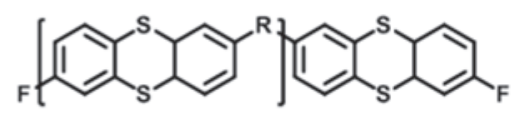

$R:-S-n_{\text {avg, } 633 \mathrm{~nm}}=1.8020$

d)

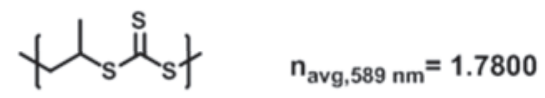

e)

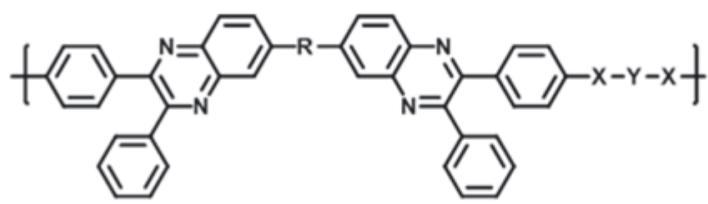

R: absent

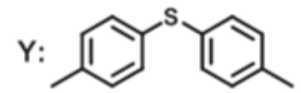

$\mathrm{x}:-\mathrm{s}-$ f)

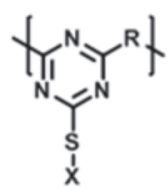

X: $\mathrm{CH}_{3}: \mathrm{C}_{4} \mathrm{H}_{9}=1: 1$

R: $s$

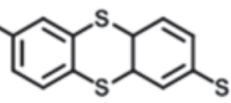

$n_{\text {avg, } 633 \mathrm{~nm}}=1.760$

g)

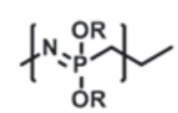

R:

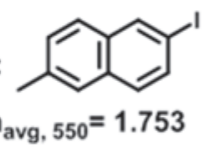

h)
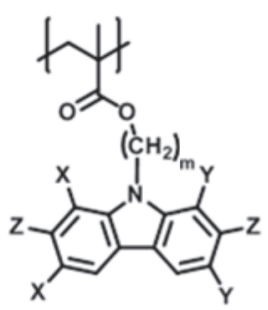

$\begin{array}{llllll}X & Y & Z & m & n_{\text {avg, }} 889 \mathrm{~nm}\end{array}$

$\begin{array}{lllll}\mathrm{I} & \mathrm{I} & \mathrm{H} & 4 & 1.77\end{array}$

28. High refractive index (high- $n$ ) polymers detailing the structures and highest indices reported for several classes of polymers. a) poly(imides); b) poly(thioether sulfone); c) poly (thianthrene phenylene sulfides); d) poly(trithiocarbonate); e) poly(phenylquinoxalines); f) triazine-containing poly(phenylene sulfides); g) poly(phosphazenes); and h) functionalized carbazole rings on poly(methyl methacrylates). 
a)

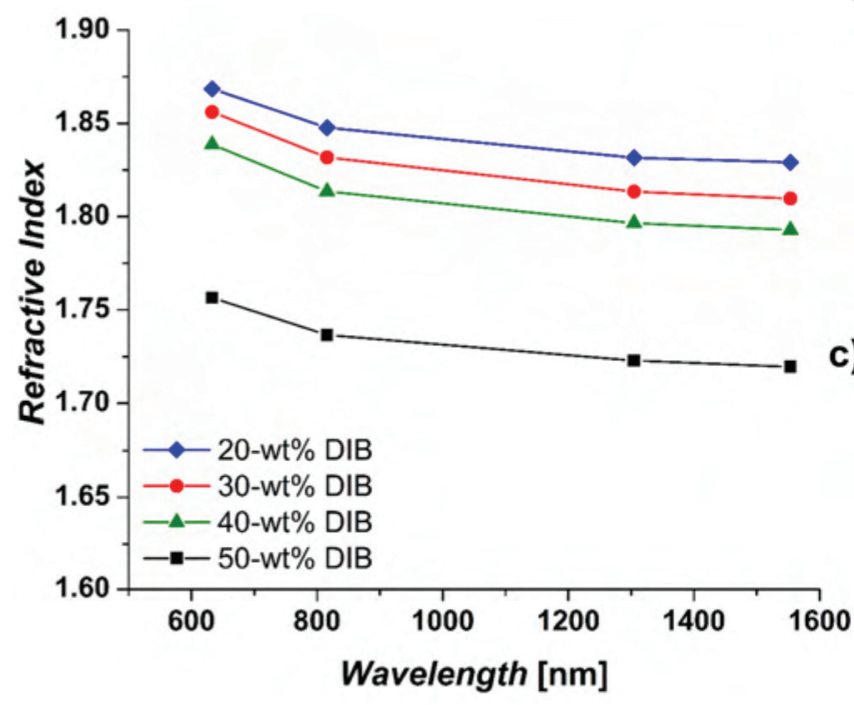

b)

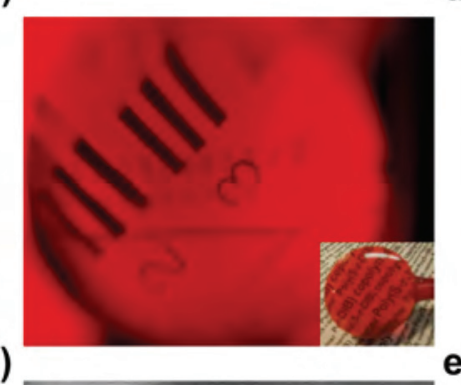

e)

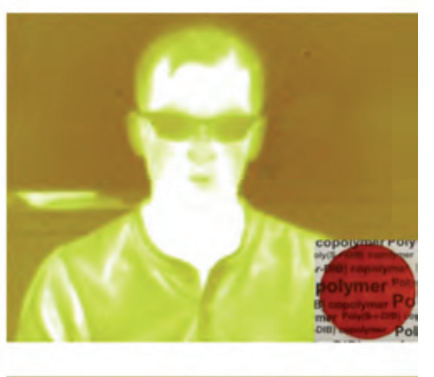

d)

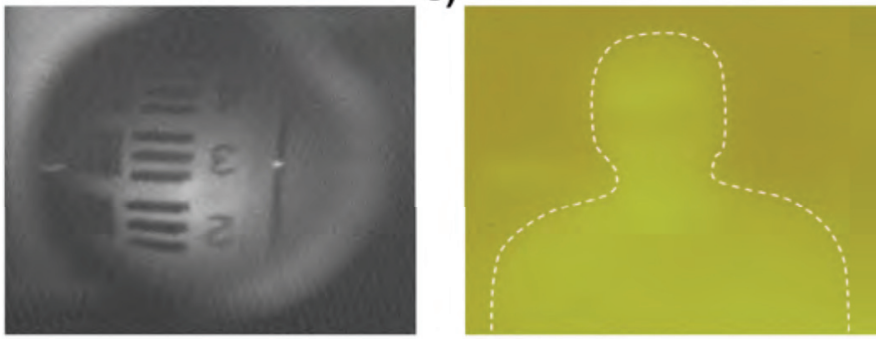

29. High refractive index poly(sulfur-random-1,3-diisopropenylbenzene) copolymers. a)

Ellipsometrically measured refractive indices as a function of wavelength for copolymers with $50-80-w t \%$ elemental sulfur. b) Visible light (500-700 nm) transparency of poly(S-r-DIB $\left.{ }_{20}\right)$ copolymer lens. Inset: digital image of poly(S-r-DIB $\left.{ }_{20}\right)$ copolymer lens. c) Near-IR $(1.55 \mu \mathrm{m})$ transparency of poly(S-r-DIB $\left.{ }_{20}\right)$ copolymer lens. d) Mid-IR (3-5 $\left.\mu \mathrm{m}\right)$ transparency of poly(S- $r$ $\left.\mathrm{DIB}_{20}\right)$ copolymer window. Inset: digital image of poly $(\mathrm{S}-r$-DIB 20$)$ copolymer window. e) Mid-IR (3-5 $\mu \mathrm{m})$ transparency of poly(methyl methacrylate) film. Adapted with permission from [322], Copyright 2014, John Wiley \& Sons Inc. 
a)

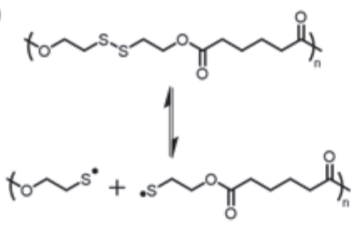

c)

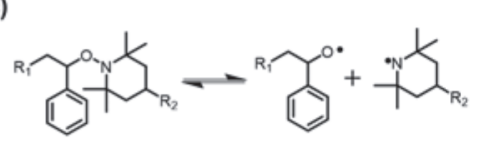

d)

f)

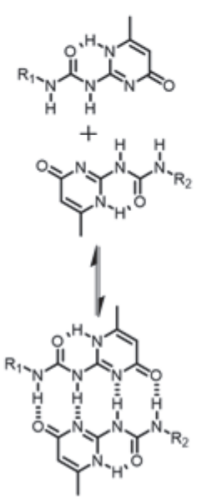

b)

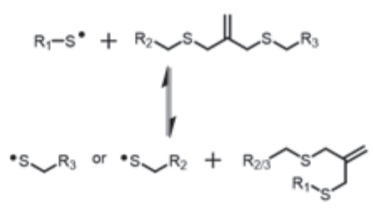

e)

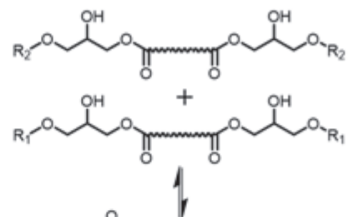

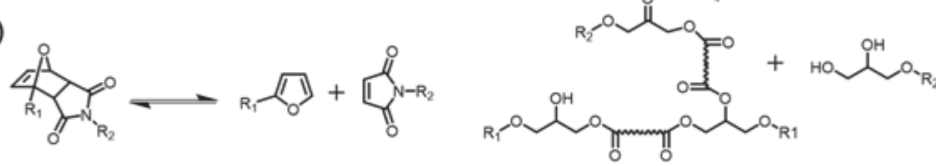

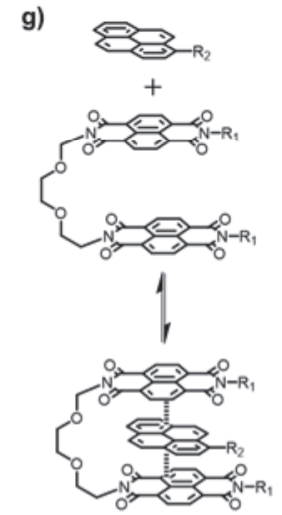

h)

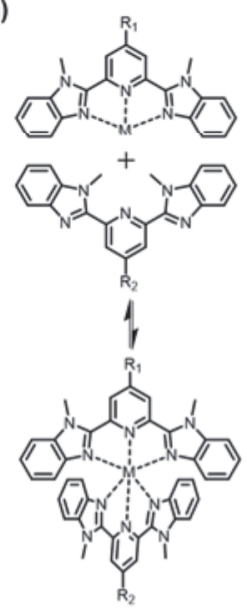

30. Stimuli-responsive functionality incorporated into polymer architecture to enable dynamic behavior. a) disulfide exchange; b) radical mediated addition-fragmentation chain transfer; c) alkoxyamine exchange; d) thermoreversible Diels-Alder adducts; e) transesterification; f) hydrogen bonding; g) $\pi-\pi$ stacking; and h) metal-ion ligand interactions. 
a)

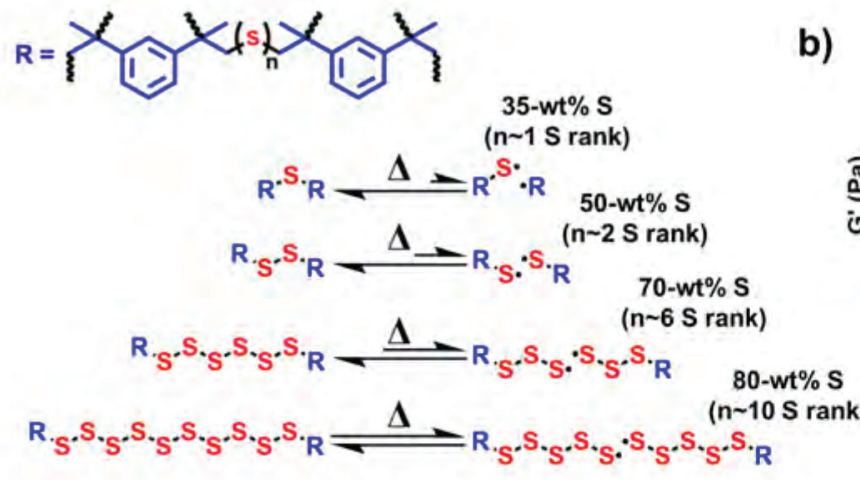

c)

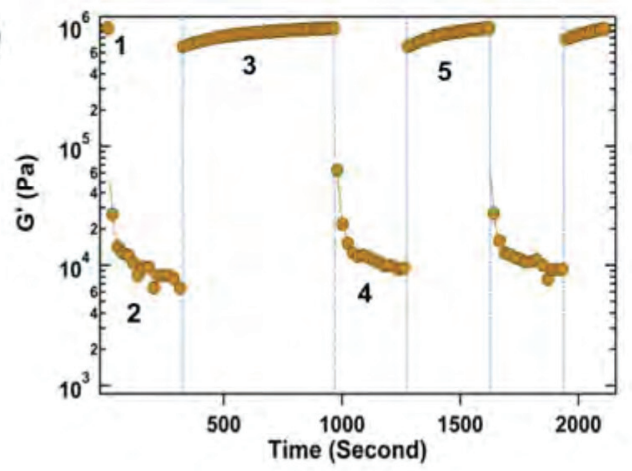

b)

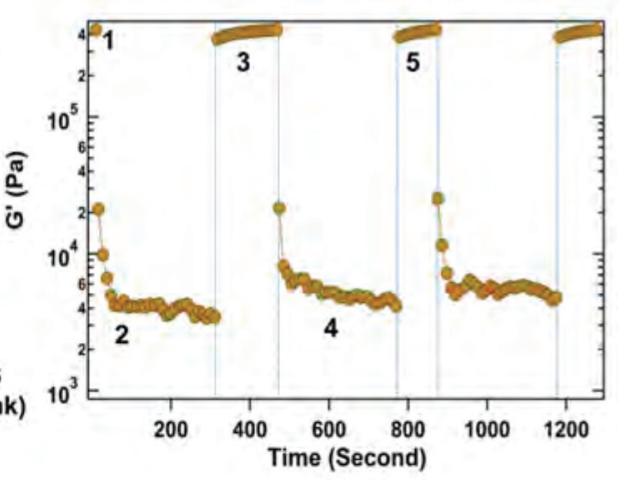

d)

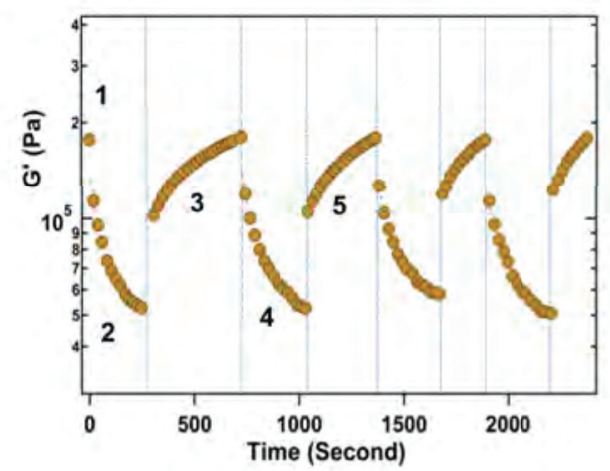

31. a) Schematic representation of dynamic behavior under stimulus $\left(\mathrm{T}=100^{\circ} \mathrm{C}\right)$ in poly(S-r-DIB) copolymers as a function of dynamic S-S bond content. In situ rheological characterization of dynamic behavior in poly $\left(\mathrm{S}-r-\mathrm{DIB}_{20}\right)$ copolymers at $\mathrm{T}=130{ }^{\circ} \mathrm{C}$ and $100 \mathrm{rad} / \mathrm{s}$. Regions within the plots represent: (1) initial modulus; (2) 100\% strain, 1st damaging cycle; (3) 8\% strain, 1 st recovery cycle; (4) 100\% strain, 2nd damaging cycle; (5) 8\% strain, 2nd recovery cycle. Adapted with permission from [135], Copyright 2014, the American Chemical Society. 


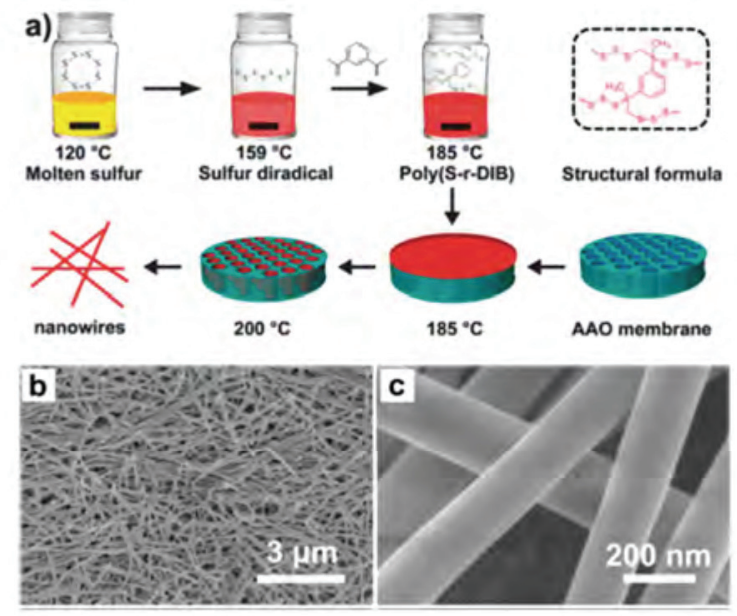

32. a) Schematic representation of poly(S-r-DIB) pre-polymer synthesis and templating of nanowires in anodic aluminum oxide scaffolds. Low resolution (b) and high resolution (c) scanning electron microscopy (SEM) images of copolymer nanowires. Adapted with permission from [391], Copyright 2014, the Royal Society of Chemistry. 

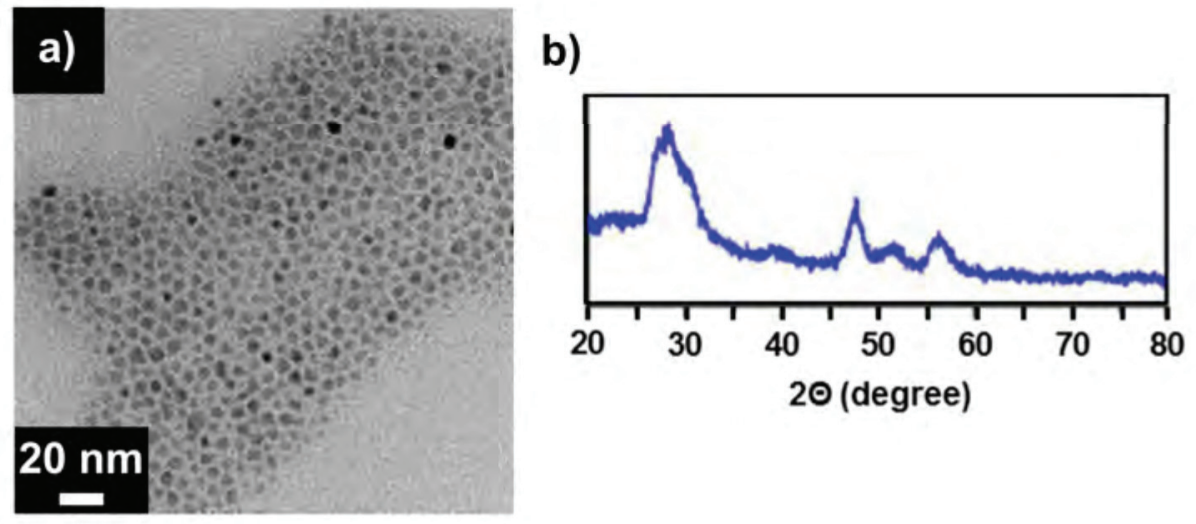

33. a) Transmission electron microscopy (TEM) images of $\mathrm{Cu}_{2} \mathrm{ZnSnS}_{4}$ (CZTS) nanoparticles generated with poly(S-r-DIB 30$)$ copolymer as the sulfur source. b) Corresponding X-ray diffraction pattern of nanoparticles. Adapted with permission from [392], Copyright 2013, the American Chemical Society. 